Portland State University

PDXScholar

$1-1-1983$

\title{
A Comparison of the Effects of Ordinary Prose and Left-hand Right-hand Practice Upon the Development of Keystroking Skills
}

Bonnie Sue Smith

Portland State University

Follow this and additional works at: https://pdxscholar.library.pdx.edu/open_access_etds Let us know how access to this document benefits you.

Recommended Citation

Smith, Bonnie Sue, "A Comparison of the Effects of Ordinary Prose and Left-hand Right-hand Practice Upon the Development of Keystroking Skills" (1983). Dissertations and Theses. Paper 780.

https://doi.org/10.15760/etd.780

This Dissertation is brought to you for free and open access. It has been accepted for inclusion in Dissertations and Theses by an authorized administrator of PDXScholar. Please contact us if we can make this document more accessible: pdxscholar@pdx.edu. 
A COMPARISON OF THE EFFECTS OF ORDINARY PROSE

AND LEFT-HAND/RIGHT-HAND PRACTICE UPON

THE DEVELOPMENT OF KEYSTROKING SKILLS

\author{
by
}

BONNIE SUE SMITH

A dissertation submitted in partial fulfillment of the requirements for the degree of

DOCTOR OF EDUCATION

in

COMMUNITY COLLEGE EDUCATION

Portland State University

The University of Oregon

Oregon State University

1983 
TO THE OFFICE OF GRADUATE STUDIES AND RESEARCH:

The members of the Committee approve the dissertation of Bonnie Sue Smith presented July 22, 1983.
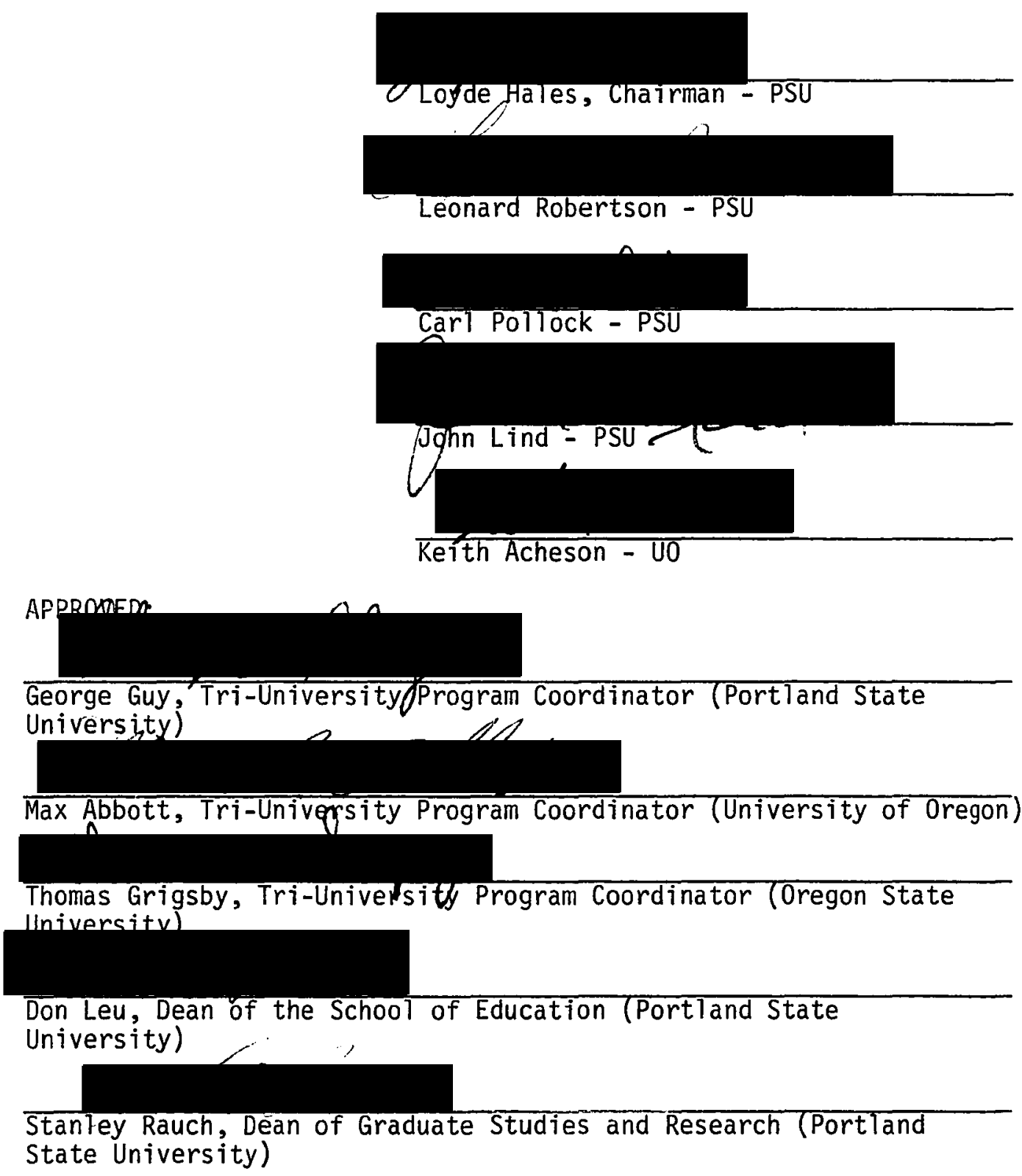
AN ABSTRACT OF THE DISSERTATION OF Bonnie Sue Smith for the Doctor of Education in Community College Education presented July 22, 1983.

Title: A Comparison of the Effects of Ordinary Prose and Left-hand/Right-hand Practice Upon the Development of Keystroking Skills.

APPROVED BY MEMBERS OF THE DISSERTATION COMMITTEE:
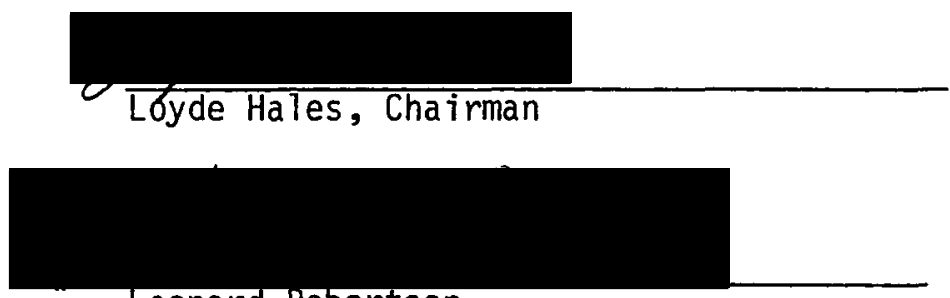

Leonard Robertson

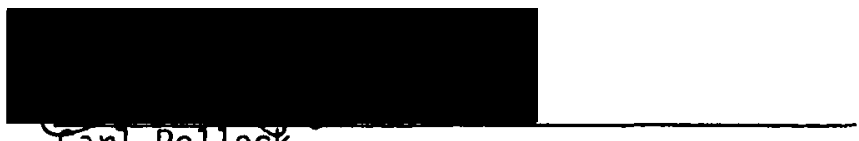

Tarl POHOCK

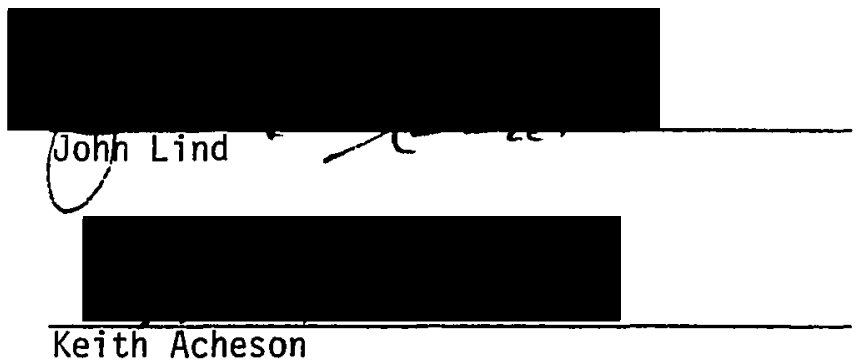

The problem of this study was to compare the effects of Prose practice, Left-hand/right-hand Equal practice, and Left-hand/ right-hand Prescribed practice on the development of stroking skills of students enrolled in beginning typewriting classes. In addition, 
the effects of the practices were examined for subjects with high and low initial straight-copy abilities.

The 260 subjects in the study represented 12 classes from three high schools in rural, southeastern Minnesota during first semester, 1982-1983.

Pretest and posttest measures of straight-copy, left-hand, and right-hand stroking skills were obtained by the administration of two different three-minute straight-copy, three different one-minute left-hand, and three different one-minute right-hand timed writings on each occasion.

Following the pretest, subjects within each class were randomly assigned to the three treatments. The practice sessions involved five minutes of practice per day for fifteen days. Subjects received individualized practice packets corresponding to their assigned treatments and were advised to type the materials at a rate that was slightly faster than comfortable.

Subjects in the Prose group practiced ordinary prose copy containing no special features or contrived words. Subjects in the Left-hand/right-hand Equal group practiced equal amounts of left-hand and right-hand 1ines. Subjects in the Presisibed group practiced a proportional number of left-hand and right-hand lines, depending on hand-weaknesses exhibited on the pretest.

The statistical hypothesis that on each of the six dependent variables of interest the means of the populations for the three treatment levels are equal was tested for the total sample and for the high and low group separately, using analysis of covariance. 
Respective pretest measures of the dependent variable criteria were used as covariates.

In testing the six statistical hypotheses for the total sample, four were rejected at the .05 level of confidence: straight-copy speed, left-hand speed, right-hand speed, and right-hand accuracy. Four statistical hypotheses were rejected for the high speed level group: straight-copy speed, left-hand speed, right-hand speed, and right-hand accuracy. Three statistical hypotheses were rejected for the low speed level group: left-hand speed, right-hand speed, and right-hand accuracy. Following rejection for the main effects of practice, the statistical hypothesis for each pair-wise mean comparison was tested at the .05 level of confidence, using the Tukey test.

The findings of the study support the following conclusions: 1) practice using prose copy is more effective than practice using equal amounts of left-hand/right-hand copy in the development of straight-copy speed for students with initial straight-copy ability of 21.0 gwpm or higher, 2) left-hand/right-hand practice in equal or prescribed amounts is more effective than prose practice in the development of left-hand speed, 3) left-hand/right-hand practice in equal or prescribed amounts is more effective than prose practice in the development of right-hand speed, 4) left-hand/right-hand practice in prescribed amounts results in more errors per minute on right-hand copy than does practice using prose copy, and 5) significantly improving one-handed keystroking skill does not improve straight-copy stroking skill. 
ACKNOWLEDGEMENTS

I express my sincere gratitude to my doctoral advisor, Dr. Loyde Hales, for his assistance and guidance in the preparation of my dissertation and for his continued support throughout my doctoral program.

I thank my colleagues at Winona State University for the assistance I received in completing the dissertation: Mr. Bob Collins and Mr. Dave Forsythe, Computer Services; Dr. Dennis Tanner, Dean of Business and Industry; and the work-study students in the Business Education and Office Administration Department. A special thank you to department secretary, Mrs. Shirley Flikki, for her invaluable assistance in conducting the study and for typing the dissertation.

I am deeply grateful to the five teachers and their students who participated in the research.

My appreciation goes to my children for their support and in particular to my daughter Montrew for her countless hours of help and for her patience.

A very special thank you to Dr. Leonard Robertson, Portland State University Business Education Department, for his direction and encouragement throughout my educational career. 
TABLE OF CONTENTS

PAGE

ACKNOWLEDGEMENTS ......................... $i$...

LIST OF TABLES ............................. vii

CHAPTER

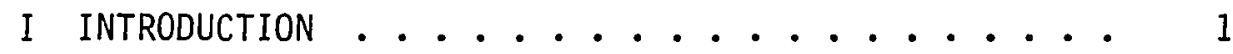

Need for the Study ............ 2

Purpose of the Study ........... 2

Statement of the Problem ......... 3

Detimitations .................. 3

Limitations .................. 4

Definition of Terms ........... 4

Straight-copy Typewriting

Speed (gwpm)

Accuracy (epm)

Ordinary Prose Copy (PROSE)

Right-hand Copy

Left-hand Copy

Prescribed Practice

Summary ................. 5

Organization of study .......... 6

II LITERATURE REVIEW . . . . . . . . . . 7

Implications of Right-hand/Left-hand

Differences ............ 7

Differences in Workload of Left Hand and Right Hand 
Effects of Hand Weakness on Speed and Accuracy Instructional Methodology

Experimental Studies ........... 13

Summary . . . . . . . . . . . . 16

II METHODS AND PROCEDURES . . . . . . . . . . 17

Selection of the Sample......... . 17

Research Design .......... 20

Description of the Treatments . . . . . . 22

Leve1 1--Prose

Level 2--Left-hand/Right-hand Equal

Leve 7 3--Left-hand/Right-hand Prescribed

Duration of Treatments . . . . . . 28

Conducting the Practice ......... 29

Testing........................ 31

Treatment of the Data ......... 32

IV FINDINGS . . . . . . . . . . 35

Description of the Groups ......... . 35

Straight-copy Pretest and Posttest Results . . 37

Straight-copy Speed

Straight-copy Accuracy

Left-hand Pretest and Posttest Results . . . 40

Left-hand Speed

Left-hand Accuracy

Right-hand Pretest and Posttest Results .....

Right-hand Speed

Right-hand Accuracy 
Tests of Statistical Significance . . . . . . 46 Statistical Mode1 Hypothesis Testing--Total Sample Hypothesis Testing--High Speed Level Hypothes is Testing--Low Speed Leve?

$\checkmark$ SUMMARY, CONCLUSIONS, IMPLICATIONS,

AND RECOMMENDATIONS FOR FURTHER STUDY . . . . 83

Overview of the Study ........... 83

Methods and Procedures

Findings

Conctusions . . . . . . . . . . . 87

Implications ............... 88

Recommendations for Further Study ...... 9 90

REFERENCE NOTES ............................... 91

BIBLIOGRAPHY . . . . . . . . . . . . . . . 92

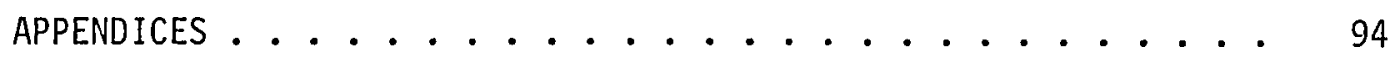

A Prose Practice ............... 95

B Left-hand/right-hand Practice--E . . . . . . . 101

C Left-hand/right-hand Practice--P

For Three Right to One Left . . . . . . . 107

D Practice Guidelines ............. 113

E Test Timings..................... 115

F Testing Procedures .............. 119 


\section{LIST OF TABLES}

TABLE

PAGE

I Distribution of Subjects by School, Teacher

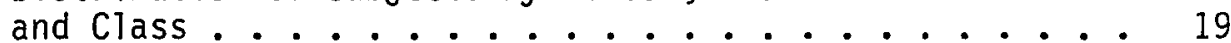

II Scale for Prescription Based on Left-hand/Right-hand Pretest Speed Differences . . . . . . . . . 25

III Scale for Modification of Prescription Based on Speed Due to Pretest Accuracy Differences . . . . . . 26

IV Frequencies of Prescriptions in the Prescribed Group . . 27

V Timetable for the Study . . . . . . . . . . . 29

VI Retention Percentages by Practice Group and High School ................ 36

VII Distribution of Subjects by Practice Group and Speed Level Group .. . . . . . . . . . . 37

VIII Measures of Central Tendency and Dispersion of Pretest and Posttest Straight-copy Speed Raw Scores (Gwpm) ... 38

IX Measures of Central Tendency and Dispersion of Pretest and Posttest Straight-copy Accuracy Raw Scores (Epm) . . 40

$X$ Measures of Central Tendency and Dispersion of Pretest and Posttest Left-hand Speed Raw Scores (Gwpm) ..... 41

XI Measures of Central Tendency and Dispersion of Pretest and Posttest Left-hand Accuracy Raw Scores (Epm) . . . 4.3

XII Measures of Central Tendency and Dispersion of Pretest and Posttest Right-hand Speed Raw Scores (Gwpm) . . . . 44

XIII Measures of Central Tendency and Dispersion of Pretest and Posttest Right-hand Accuracy Raw Scores (Epm) . . . 46

XIV Straight-copy Speed: Analysis of Covariance and Adjusted Group Means for the Total Sample . . . . . . 48 
viii

TABLE

PAGE

XV Straight-copy Accuracy: Analysis of Covariance and Adjusted Group Means for the Total Sample . . . . . . . 50

XVI Left-hand Speed: Analys is of Covariance and Adjusted Group Means for the Total Sample . . . . . . 51

XVII Left-hand Accuracy: Analysis of Covariance and Adjusted Group Means for the Total Sample . . . . . . 53

XVIII Right-hand Speed: Analys is of Covariance and Adjusted Group Means for the Total Sample . . . . . . 54

XIX Right-hand Accuracy: Analysis of Covariance and Adjusted Group Means for the Total Sample . . . . . . 56

XX Summary of Hypothesis Testing--Total Sample . . . . . 59

XXI Straight-copy Speed: Analysis of Covariance and Adjusted Group Means for the High Initial Speed Level Classification ............ 60

XXII Straight-copy Accuracy: Analysis of Covariance and Adjusted Group Means for the High Initial Speed Level Classification ............. . . 62

XXIII Left-hand Speed: Analys is of Covariance and Adjusted Group Means for the High Initial Speed Level Classification ............ . . 63

XXIV Left-hand Accuracy: Analysis of Covariance and Adjusted Group Means for the High Initial Speed Level Classification .............. 65

XXV Right-hand Speed: Analysis of Covariance and Adjusted Group Means for the High Initial Speed Level Classification ............. 66

XXVI Right-hand Accuracy: Analys is of Covariance and Adjusted Group Means for the High Initial Speed Level Classification ............ 68

XXVII Summary of Hypothesis Testing--High Speed Level . . . . 71

XXVIII Straight-copy Speed: Analysis of Covariance and Adjusted Group Means for the Low Initial Speed Level Classification .............. 
TABLE

PAGE

XXIX Straight-copy Accuracy: Analysis of Covariance and Adjusted Group Means for the Low Initial Speed Level Classification ........... . . 73

XXX Left-hand Speed: Analys is of Covariance and Adjusted Group means for the Low Initial Speed Level Classification ............ 74

XXXI Left-hand Accuracy: Analysis of Covariance and Adjusted Group Means for the Low Initial Speed Level Classification ............. 76

XXXII Right-hand Speed: Analysis of Covariance and Adjusted Group Means for the Low Initial Speed Level Classification ............ . . 77

XXXIII Right-hand Accuracy: Analysis of Covariance and Adjusted Group Means for the Low Initial Speed Level Classification . . . . . . . . 79

XXXIV Summary of Hypothesis Testing--Low Speed Leve1 . . . . 82 


\title{
CHAPTER I
}

\author{
INTRODUCTION
}

Considerable disagreement exists among typewriting teachers as

to the benefit of specialized typewriting drills in the development of

keystroking skilis. One such specialized drill, the left-hand/right-

hand drill, has been the subject of controversy among classroom

teachers and typewriting "experts" alike.

Nothing by way of specialized content, vocabulary, letter sequences or anything else has ever been found to have the slightest positive effects on stroking skills--in contrast to ordinary prose. . . . Transfer of gains to "all copy" requires practice at "all copy" (i.e., at the largest possible variety of letter sequences--the chances of variety being maximized in ordinary prose over a wide vocabulary). (West, 1974, p. 12)

Analysis of the words used in the practice materials. . . shows that it is possible to give realistic emphasis to high-frequency words, the "handedness" factor of words, and the finger facility or variable stroking patterns required to type words with different components. This can be done and still accommodate the need to encounter in meaningful context the various word components that are considered essential to the development of optimum skill for all students in the limited time available for practice. . . . At least three years would be required for typewriting students on typical practice schedules to encounter a11 keystroking combinations even once if nonrepetitive, unstructured materials were used to develop typewriting skill. . . . The random or accidental occurrence of these essential. learning components, left to chance by practice on "normal" prose, can result at best in only minimal initial exposure and cyclical reinforcement and at worst in uneconomical use of the student's time--the greatest waste in all of education. (Robinson \& Lessenberry, 1977, pp. 40-41)

The value of special drills was of particular interest to the researcher since specialized, one-hand drills are included in various 
community college typewriting programs, as well as typewriting programs at other educational levels. There was a need to provide data related to the question, "Are such drills superior to practice on ordinary prose?"

Need for the Study

As an indication of the importance of typewriting instruction in postsecondary education, it is estimated that the annual enrollment in typing classes is between 600,000 and 700,000 students. (West, 1983, pp. 5-6) For community colleges, typing instruction is particularly important since a preponderance of these institutions have secretarial programs which provide typing instruction to majors and nonmajors, the latter taking such courses for vocational and/or personal reasons. Therefore, the identification of appropriate methods of typewriting instruction is important to curricular developmert and effective instruction.

Information regarding the effectiveness of typewriting drills, a major component of typing instruction, is necessary in order to provide an efficient skillbuilding program. Optimum utilization of classroom time demands that drills be selected on the basis of proven benefit to the development of stroking skills. This information is best provided through experimental research.

\section{Purpose of the Study}

The purpose of this study was to provide experimentally obtained evidence regarding the effects on keystroking skills of practicing 
one-hand drills as compared to practicing ordinary prose. The results of the study provide information which may be used by community college educators, methods instructors, textbook authors, and typewriting instructors at other educational levels to evaluate the typewriting practice drills included in their programs and materials.

\section{Statement of the Problem}

The problem of this study was to compare the effects of skillbuilding practice using ordinary prose copy and skillbuilding practice using left-hand/right-hand copy on the development of keystroking skills of students enrolled in beginning typewriting.

The effects of the practice materials were compared on the bases of the dependent variable criteria: 1) straight-copy stroking speed, 2) straight-copy stroking accuracy, 3) left-hand stroking speed, 4) left-hand stroking accuracy, 5) right-hand stroking speed, and 6) right-hand stroking accuracy.

Although six dependent variable criteria were included, the primury focus of this study was on straight-copy stroking speed and accuracy. Left-hand and right-hand speed and accuracy were of secondary consideration and were included in order to explore the total impact of the practice methods.

\section{Delimitations}

There was no attempt to relate the effects of the practice to anything other than straight-copy, left-hand, and right-hand speed and 
accuracy. Consequentiy, the following factors were excluded: 1) effects of the practice upon production typewriting proficiency, and 2) effects of the practice on the frequency of various types of errors.

In addition, no other type of practice material was studied. The prose and left-hand/right-hand practice was not conducted under rate-forcing conditions. The data were not analyzed by such factors as sex, age, nationality, or year in school. No attempt was made to assess differences in attitudes toward the two types of practice.

\section{Limitations}

Subjects in the study were enrolled in regular typewriting courses requiring various typewriting activities using ordinary prose. Therefore, it was not possible to limit the left-hand/right-hand groups to left-hand/right-hand practice only. However, this situation is consistent with the recommended and actual utilization of this drill in typewriting instruction.

Although an attempt was made to ensure purposeful practice and adherence to the rules of practice, it is possible that this was not accomplished for every subject at each practice session.

\section{Definition of Terms}

\section{Straight-copy Typewriting}

Word-for-word copying of printed or typed prose material without erasing and without requiring format decisions by the typist. 
Speed (gwpm)

Average gross words per minute of the timed writings. Gross words per minute is obtained by dividing the total number of typing strokes by five and dividing this number by the number of minutes the student typed.

Accuracy (epm)

Errors per minute represents the sum of the errors made on the timed writings divided by the number of minutes the student typed.

Ordinary Prose Copy (Prose)

Copy with no special features or contrived combination of words.

Right-hand Copy

Copy containing only right-hand words.

Left-hand Copy

Copy containing only left-hand words.

Prescribed Practice

Left-hand/right-hand practice in which the student types a proportionate number of left-hand and right-hand lines depending on diagnosis of left-hand and right-hand abilities.

\section{Summary}

Skillbuilding drills are a major component of many typewriting courses. A considerable amount of student time is devoted to practicing various specialized drills in an effort to improve straight-copy speed and accuracy. 
There are many specialized drills available, some of which are highly recommended by typewriting textbook authors and classroom teachers. However, some authors and teachers believe specialized drills are useless and that the best way to improve straight-copy skill is to practice using ordinary prose copy. Experimental study is necessary to provide information concerning the effectiveness of various dri11s.

This study examined one such specialized drill, the left-hand/ right-hand drill, and compared it with practice on ordinary prose.

\section{Organization of the Study}

Chapter I presented an introduction to the study, including the need for the study, purpose of the study, statement of the problem, delimitations and limitations, and a definition of terms. Chapter II presents a review of related literature. Chapter III presents the methods and procedures used in the study. Chapter IV details the findings provided by the study. Chapter $V$ presents a summary of the study, conclusions, implications, and recommendations for further study. 
CHAPTER II

\section{LITERATURE REVIEW}

The literature regarding left-hand/right-hand practice and

ordinary prose practice is lacking in experimental studies which compare the two types of practice. However, there are various articles which discuss the weakness of the right hand and those which support or deny the necessity of including left-hand/right-hand practice in the skillbuilding program.

\section{Implications of Right-hand/Left-hand Differences}

The differences between the workload of the right hand and left hand in typewriting, the relation of hand used and typewriting speed and accuracy, and the implications of these differences to instruction are considered in this section.

Differences in Workload of Left Hand and Right Hand

"The standard typewriter keyboard is a haphazard imposition, wretchedly unbalanced, and absurdly awkward in vital reaches," according to Dvorak, Merrick, Dealey, and Ford (1936, p. xii). The disproportionate loads of the fingers in typing were recognized by Dvorak et al. in arriving at the conclusion: "Here is a left-handed typewriter in a right-handed world!" (p. 212).

In 1922, Hoke (cited in Dvorak et a1., 1936) counted the number 
of keystrokes for each letter in the copy, determined the loads carried by each typing finger, and compared the typing loads of the left-hand and right-hand fingers. He found that the left little finger does nearly three times the work of the right little finger, the left second finger has a 53 percent excessive overload, and the left first finger has a 49 percent excessive overload. Hoke determined that the weaker left hand makes 131 strokes to every 100 by the right hand and concluded that there is a 47 percent typing overload upon the left hand on the conventional typewriting keyboard. Reimer's (cited in Dvorak et al., 1936) estimate was somewhat higher: the left hand makes 144 strokes to every 100 by the right hand. While listening to a fast typist, Dvorak et al. (1936) detected a break in pace whenever the copy contained words typed with one hand. Consequently, they did a study of letter frequency in the 1,000 most common English words and found that words typed with one hand were heavily loaded in the left hand.

\section{Effects of Hand Weakness on Speed and Accuracy}

Beaumont (1969) used a sample of 600 high school students at three levels of skill development and discovered that typing speeds decreased significantly as the percent of one-hand and near one-hand words in the copy was increased beyond 33 percent. Such information as this has probabiy supported the opinion that specialized practice on one-hand words is necessary. Javed (1975) found predominantly left- and right-hand materials to be a significant factor in the achievement of speed and accuracy. 
He concluded that left-hand material is easier to type than right-hand material, which may be because of the greater incidence of left-hand words in the language. This has led to the conclusion by some that the right hand needs remedial practice. (Winger, 1965)

Instructional Methodology

The classroom use of specialized drills to improve typewriting skill developed from the typewriting contests of the early 1900's. Winners of these contests developed various books of drills stressing repeated practice of specific skill components. These structured materials were adapted to classroorn textbooks. (Robinson, Erickson, Crawford, Beaumont, \& Ownby, 1979)

According to Robinson et al. (1979):

It is not surprising, then, that from such a beginning there developed a debate among teachers as to which kinds of materials would develop the best speed: paragraph material incorporating a wide open vocabulary? or specialized drills made up of a judicious selection of words that incorporated keystroking sequences thought to encourage high speed and those comprised of a different selection of words containing speed type combinations thought to require special intensive practice to be executed fluently? These questions have not been satisfactorily answered even today. (p. 64)

Winger (1965) acknowledged the situation of a left-handed typewriter in a right-handed world. He stated:

Dvorak, in particular, and others too, have made good points to the effect that our present keyboard is responsible for many of the error patterns that develop. It behooves the typing teacher, then, to make an honest effort to do the best job possible in detecting and correcting these keyboard deficiencies. As an example, we know that the left hand and its individual fingers carry far more of the typing load than the right hand and we need to be sure that a good remedial program is developed (through warmups and drills) to correct deficiencies. (p. 84)

Winger (1974) reported on a one-hand proficiency program that 
had been in effect at Oregon State University for many years. Oneminute pretests were administered on alternate-hand words, left-hand words, and right-hand words. The one-hand timings were then repeated to permit selection of the more accurate of the two. A goal for each student was set for each hand by adding eight to ten words to the slowest hand. Students were required to practice more words with the weaker hand (right hand) in order to bring the speed of the weaker hand up to the level of the stronger hand. "This is where the present keyboard points up the right-hand weaknesses, because the left hand is usualiy much faster" (p. 7), Winger stated. After a practice time of two and one-half to three weeks, students repeated the pretest as a posttest. Two or three weeks after the posttest, the same timings were given again.

Winger (1974) indicated the success of the drill by showing the percent of increase in speed and percent of error reduction for the weaker hand. However, his "action" research did not indicate any transfer effects to prose copy and did not include a control group.

Winger (Note 1) stressed the need for right-hand remedial practice, "Although classes are different, right-hand speeds will normally be 5-10 words per minute slower." He pointed to the need for students to practice more right-hand words in order to build right-hand speed to the level of left-hand speed, which would therefore improve straight-copy ski11. Winger (Note 1) stated, "If you don't do something about left-hand/right-hand, you will deprive students of the most critical area of typewriting--bar none."

Ha11 (1981) recommended the use of Winger's pretest/practice/ 
posttest in the classroom and included left-hand/right-hand materiais as a valuable component. Hall stated, "The typewriter keyboard favors the left hand. To overcome the left-handed typewriter, a three-week systematic skillbuilding program is suggested" (p. 4).

In discussing opening activities for the typing class, Hall (1982.) again recommended the use of the left-hand/right-hand drill. Hall described the left-hand/right-hand practice as follows:

Since the 'qwerty' keyboard is not the most efficient keyboard that could have been developed, some time can be spent helping students compensate for this difficulty. The project takes two weeks. Students take a pretest on the first day to determine which hand is faster, and they chart their starting points. The next eight days are spent practicing a combination of right-hand/left-hand drills in proportion to the need indicated in the pretest. The tenth day is spent administering the posttest. (p. 10)

The importance of selective practice to correct difficulties arising from the typewriter keyboard was discussed by Holmes and Eide (1981). They stated:

Every student will benefit from practice time devoted to these additional activities: service key-drills, figure drills, left-hand/right-hand drills (which overcome the imbalance of the existing keyboard by strengthening the typist's weaker hand). ( $p$. 14)

Based on a computer analysis of keystroking components of words used in written general and business communication, Robinson and Lessenberry (1977) maintain that structured, specialized drills assure systematic student practice on the keystroking components that make up the typewritten language. They stated that practice on ordinary prose copy leaves to chance the practice needed on essential components and therefore may result in a waste of student practice time. This rationale suggests that specialized one-hand drills would have benefit 
in a typewriting skillbuilding program.

By analyzing errors to find what types of words had the highest overall error incidence, Robinson (1972a) determined that no copy of a single character can be identified as the best type of copy for improving keystroking accuracy. The study specifically sought to answer the question of whether differences in accuracy result from typing copy selections loaded with specific types of letter combinations including one-hand words.

Even though one of Robinson's (1972a) conclusions was that "no copy of a single character. . . can be identified as the 'best' kind of copy for inducing accurate keystroking," he still recommended the use of a variety of kinds of copy in developing basic skill competency, including contrived sentence copy.

West (1969) summarized his opposition to the use of contrived copy in the development of straight-copy stroking skills by stating:

The reason for the failure of contrived materials. . to be beneficial lies in the concept that is fundamental to all of learning, one with which the reader should by now be familiar, transfer. (p. 239)

West (1969) explained the essence of transfer as follows:

Practice at some thing makes one better at that thing, not at other things. In the despost sense, there is no such thing as speed in general, facility in general, rhythm in general. Instead, one develops those things on whatever particular words have been practiced. One might suspect such materials to be mere window dressing, perhaps created out of a need to feel that there is something complicated or recondite about the materials of practice. (p. 240)

In order to facilitate transfer, West (1969) insisted that materials for building straight-copy stroking speed must be ordinary prose. He stated: 
If you want speed in general, you must practice on materials in general. So ignore the window dressing of drills using particular words, that is, words calling for particular kinds of movement sequences. Instead, apply speed practice to the broadest possible vocabulary of ordinary, unselected prose. (p. 251)

Regarding accuracy development, West (1969) listed as valueless materials such as "right-hand words, left-hand words, balancedmovement words, and the like" (p. 267). West (1974) stated that letter sequence drills "may be dismissed out of hand because such drills were found totally useless in dozens of earlier studies" ( $p$. 14).

Accourding to West (1983), stroking accuracy depends on typing at the right speed, that is, one a little below the rate at which too many errors are made. In a list of totally ineffective accuracy procedures, he included "all concoctions of specialized materials based on various kinds of motion sequences" (p. 131).

Erickson (1967) found that students improved their accuracy as they discovered their error threshholds (the rate at which they began to lose control and make an excessive number of errors--four or more per minute). Erickson's findings supported West's (1983) contention that accuracy depends upon typing at the right speed.

\section{Experimental Studies}

West (1969, pp. 266-267) made reference to early studies which demonstrated the uselessness of corrective procedures and materials. Griggs (cited in West, 1969) used drills of various kinds together with technique check sheets and error-analysis charts and did not find 
this combination beneficial. Van Ordstrand (cited in West, 1969) obtained "no difference" results from the use of location drill sequences and lines of words emphasizing the use of a particular fingers. Sleeter (cited in West, 1969) was unable to demonstrate superior results when using error-analys is charts, teacher discussion of errors and their sources, and corrective drills based on individual errors.

West (1969) referred to the Holmes (cited in West, 1969) study as the "study to end all such studies" (p. 267). West reported that in the Holmes study, 98 causes of errors were specified and 76 corrective procedures and materials were employed, each supposedly relevant to some cause of error. The battery of corrective procedures and materials included every technique and type of material used in the history of typewriting. The techniques were applied during two, four-week periods toward the middle of the school year to beginners as well as those with one and two semesters of prior typing experience. Her findings were that there was no reduction in total errors nor in the frequencies for various types of errors. Although Holmes did not use a control group, West (1969) stated that the "flat failure to reduce errors or to change particular error frequencies is impressive enough" (p. 267).

Long (1977) compared th_ effectiveness of ordinary prose copy and contrived copy upon the development of copying skill. She pretested 141 beginning typewriting students after alphabetic keyboard presentation and divided the students into ability groups. From the preselected skill group, students were randomly assigned to prose or 
contrived copy for skillbuilding under timed conditions. Long's findings indicated that either ordinary prose or contrived copy can be used efficiently for skillbuilding.

Prater (1976) compared the effects of "selective" skills, textbook drills, magazine typing, and no drills on straight-copy speed and accuracy using a sample of low-ability intermediate typewriting students in three different colleges. The "selective" drills, were selected from Selective Practice Typing Drills (Lloyd, Poland, Rowe, Winger \& Griffith, 1974). On straight-copy speed gain, Prater (1976) found a statistically significant difference between no drills and "selective drills" in favor of the no drills group. No significant differences were found among the groups on straight-copy accuracy gain.

Shannon and Robertson (Note 2) compared the effects of prose practice and left-hand/right-hand practice and found no significant differences in regard to posttest straight-copy speed or accuracy. However, students practicing left-hand/right-hand materials exhibited higher right-hand speeds than did students who practiced prose materials.

In the Shannon and Robertson study (Note 2), the sample consisted of 173 students enrolled in postsecondary typewriting courses. Students practiced either prose materials or left-hand/ right-hand materials for 10 minutes per day, two days per week, for five consecutive weeks during the middle of the academic quarter. The left-hand/right-hand 1 ines were practiced in equal amounts with no prescriptive element. Shannon and Robertson (Note 2) concluded 
that "significantly improving one-handed keystroking skill does not significantly improve straight-copy skili" (p. 29).

Summary

As far back as 1922, when Hoke studied the typing loads of the fingers, typewriting researchers and theorists have been searching for the "solution" to developing speed and accuracy on the keyboard.

Present research data do not support either the group which advocates the use of ordinary prose or the group which advocates the use of contrived copy for the development of straight-copy keystroking ability. So far, the best evidence is that it does not make any difference, and to that extent, support may go to the ordinary prose group. Why spend innumerable hours contriving copy that does not "work" any better than newspaper copy? Interestingly, even though researchers have been unable to identify value in using different kinds of specialized copy, some continue to advocate the use of contrived drill materials. 


\section{CHAPTER III}

\section{METHODS AND PROCEDURES}

The study was designed to compare three levels of the independent variable, type of practice (Prose, Left-hand/righthand Equal, Left-hand/right-hand Prescribed ) on straight-copy, left-hand, and right-hand speed and accuracy. Subjects in each classroom were randomly assigned to the three treatment levels and the sampie was divided on the basis of initial straight-copy speed into two speed levels (high--upper one-half of the subjects; low--lower one-half of the subjects). The dependent variable criteria were ana?yzed, using analysis of covariance.

The specific components of the study which are detailed in this section include the selection of the sample, research design, description of the treatments, duration of the treatments, practice conditions, testing procedures, and treatment of the data.

\section{Selection of the Sample}

It was important to the execution of this study that the subjects be beginning typing students in structured classes which require regular attendance. Since many beginning community college typewriting students have had previous typewriting instruction and are enrolled in community college courses which are not structured and do not require regular attendance, a high school sample was chosen. In 
addition, the use of the high school sample permitted the comparison of these results to a previous study at the university level, thereby expanding the research base for generalization to introductory typewriting at various educational levels. The legitimacy of such a generalization is provided by West (1983) who, in discussing typewriting instruction, said that "there are no consequential differences in instructional practices at different school levels ( $p$. 15)."

The sample consisted of 260 high school typewriting students from selected rural, southeastern Minnesota high schools. Twelve classes were involved in the study, representing three high schools and five teachers. High School A provided seven classes and three teachers. The total enrollment of High School A was 1,440 students (grades 10-12). High School $A$ is found in a university town of 26,000 people; the economic base of the area served by the high school is agriculture, business, and employment related to the university. High School B provided two classes and one teacher; the school had an enroliment of 549 students (grades 9-12). It is located in a community of 1,400 people; the economic base is agriculture and agriculture-related business. High School C provided three classes and one teacher; it had an enroliment of 498 students (grades 7-12). High School C is located in a community of 2,200 people; the economic base of the area served by this school is agriculture and agriculturerelated business.

Table I details the distribution of subjects by high school, teacher, and class. 


\section{TABLE I}

DISTRIBUTION OF SUBJECTS BY SCHOOL, TEACHER, AND CLASS

\begin{tabular}{|c|c|c|c|}
\hline Teacher/Class & School $A$ & School B & School C \\
\hline $\begin{array}{l}\text { Teacher 1: } \\
\text { Subjects in class } 1 \\
\text { Subjects in class } 2 \\
\text { Subjects in class } 3 \\
\text { Subjects in class } 4\end{array}$ & $\begin{array}{l}23 \\
25 \\
27 \\
29\end{array}$ & & \\
\hline $\begin{array}{l}\text { Teacher 2: } \\
\text { Subjects in class } 1 \\
\text { Subjects in class } 2\end{array}$ & $\begin{array}{l}23 \\
25\end{array}$ & & \\
\hline $\begin{array}{l}\text { Teacher 3: } \\
\text { Subjects in class } 1\end{array}$ & 20 & & \\
\hline $\begin{array}{l}\text { Teacher 4: } \\
\text { Subjects in class } 1 \\
\text { Subjects in class } 2\end{array}$ & & $\begin{array}{l}14 \\
20\end{array}$ & \\
\hline $\begin{array}{l}\text { Teacher 5: } \\
\text { Subjects in class } 1 \\
\text { Subjects in class } 2 \\
\text { Subjects in class } 3\end{array}$ & & & $\begin{array}{l}15 \\
19 \\
20\end{array}$ \\
\hline Total Classes & 7 & 2 & 3 \\
\hline Total Subjects & 172 & 34 & 54 \\
\hline
\end{tabular}

Subjects were enrolled in beginning typewriting courses during the first semester of the 1982-83 school year. The sample consisted of 79 males and 181 females; there were 44 freshmen, 121 sophomores, 65 juniors, and 30 seniors.

Instruction for the beginning classes at High School $A$ and High School B began August 30, 1982; classes began at High School C on 
August 26, 1982. Students in all schools had progressed through alphabetic keyboard presentation.

During the course of the study, students were involved in numeric keyboard presentation and pre-production instruction.

\section{Research Design}

An experimental design was used to assess the effects of the treatment variable on six dependent variables, using analysis of covariance. The treatment variable consisted of three levels (types of practice): 1) Prose, 2) Left-hand/right-hand Equal, and 3) Left-hand/right-hand Prescribed. Six dependent variable criteria were included in the study: 1) straight-copy speed, 2) straight-copy accuracy, 3) left-hand speed, 4) left-hand accuracy, 5) right-hand speed, and 6) right-hand accuracy.

Within each classroom, subjects were randomly assigned to the three treatment levels. A list of subjects pretested was compiled for each class and subjects were assigned to groups within each class by the use of a table of random numbers. Treatment levels were then randomly assigned to groups.

Respective initial measures of the dependent variable criteria were used as covariates to control for initial chance differences remaining after random selection, i.e., straight-copy pretest speed was utilized as the covariate in the analysis of the dependent variable, straight-copy speed, and right-hand pretest speed was used as the covariate in the analysis of the dependent variable, right-hand speed. 
On the basis of the straight-copy pretest, subjects' speed scores were placed in rank order and the sample divided into high (upper one-half) and low (lower one-half) straight-copy speed classifications in order to compare differences in the effects of the practice resulting from differences in initial straight-copy ability. This procedure resulted in a high group with pretest straight-copy scores of 21.0 gross words per minute (gwpm) and above and a low group with pretest straight-copy scores below $21.0 \mathrm{gwpm}$.

The use of pretest measures as covariates to control for initial chance differences precluded the use of the high/low classification as a second factor in a two-way factorial design. However, the effect of the practice on high and low speed groups was of secondary interest so the analysis of covariance was replicated for each initial straight-copy speed level.

A fixed-factor analysis of covariance was performed on each of six dependent variables in the overall model and for the model replicated for high and low initial speed level classifications. The Statistical Package for the Social Sciences (Nie, Hul1, Jenkins, Steinbrenner, \& Bent, 1975) was used in the analyses.

For each dependent variable, the following statistical hypothesis was tested: On the dependent variable of interest, the means of the populations for the Prose group, Left-hand/right-hand Equal group and Left-hand/right-hand Prescribed group are equal. The six hypotheses were tested for the total sample and for the high and low initial speed level classifications separately. Statistical significance at the .05 level of confidence was necessary to reject 
the statistical hypotheses.

If the main effect for treatment was significant at the .05

level of confidence, the statistical hypothesis for each pair-wise mean comparison was tested at the .05 level, using Tukey's HSD (honestly significant difference) test (Wildt \& Ahtola, 1978, pp. 29-41).

\section{Description of the Treatments}

The experiment included three levels of the treatmerit variable, type of practice. Subjects assigned to Level 1 practiced using ordinary prose copy; Level 2 subjects practiced equal amounts of lefthand and right-hand copy; Level 3 subjects practiced a prescribed amount of left-hand and right-hand copy depending on pretest rightand left-hand abilities.

Three types of practice materials corresponding to the three treatment levels were constructed by the researcher. The packets of practice materials included detailed instruction sheets and were duplicated using a different color of paper for each treatment.

\section{Level 1--Prose}

Level 1 of the treatment variable, ordinary prose, consisted of a practice packet of prose lines. Newspaper copy was used as a basis for constructing 7 ines each of which contained 58-62 typewriting strokes. The copy contained no special features or combinations of letters or words. The six-page practice packets included five pages of practice lines (180 lines) and an instruction sheet specifying the 
rules of practice. Material for the prose packet is located in Appendix A.

\section{Level 2--Left-hand/Right-hand Equal}

Level 2, Left-hand/right-hand Equal, consisted of a practice packet of lines composed of left-hand and right-hand words. The copy on each page was arranged with alternating lines of left-hand and right-hand words (a line of left-hand words followed by a line of right-hand words, etc.).

A portion of the words used for this packet were taken from Webster's New Collegiate Dictionary (1973) and others were created by the researcher because of the smaller percentage of right-hand words available in the language. The words were arranged to form 7 ines each of which contained 58-62 typewriting strokes.

The six-page packet included five pages of practice lines (168 lines) and an instruction sheet. Copy for the Left-hand/right-hand Equal packet is located in Appendix B.

\section{Level 3--Left-hand/Right-hand Prescribed}

Leve1 3, Left-hand/right-hand Prescribed, consisted of a packet of lines composed of left-hand and right-hand words. The copy on each page was arranged with a proportionate number of left-hand and righthand lines depending on each subject's prescribed practice.

Prescribed practice. Subjects in the prescribed group practiced a proportionate number of left-hand and right-hand lines. The purpose of the practice was to allow each subject to type more lines using the 
weaker hand. The proportion of left-hand and right-hand lines to be practiced was prescribed by the researcher based on differences in pretest left-hand and right-hand speed and accuracy.

Determining the prescription. Left-hand and right-hand pretest speed and accuracy measures were obtained by the administration of three, one-minute timed writings for each hand. The three timings were averaged for each hand, yielding gross words per minute and errors per minute.

The following steps were followed in arriving at a prescription for each subject in Level 3:

1. Determine which hand was slower (weaker) and to what extent by calculating the difference between the pretest left-hand and right-hand speed scores.

2. Select a practice proportion of lines based on speed, using a scale. The scale used for prescription based on speed is located in Table II. The range of difference between left-hand and right-hand speeds is given in gross words per minute (Column 1). In Column 2, the number of lines to be practiced by the slower hand is the first number. If the left hand is slower by 1.33 to $3.00 \mathrm{gwpm}$, a $2-1$ proportion of lines means practice two lines of left-hand words to one line of right-hand words. 
TABLE I I

SCALE FOR PRESCRIPTION BASED ON LEFT-HAND/

RIGHT-HAND PRETEST SPEED DIFFERENCES

\begin{tabular}{|c|c|c|c|}
\hline \multirow{2}{*}{$\begin{array}{l}\text { Difference in } \\
\text { in speed (gwpm) }\end{array}$} & \multirow{2}{*}{$\begin{array}{l}\text { Proportion } \\
\text { of lines }\end{array}$} & \multicolumn{2}{|c|}{ Prescription } \\
\hline & & STower Hand & Faster Hand \\
\hline $\begin{array}{r}0-1.32 \\
1.33-3.32 \\
3.33-5.32 \\
5.33-7.32 \\
7.33-9.32\end{array}$ & $\begin{array}{l}1-1 \\
2-1 \\
3-1 \\
4-1 \\
5-1\end{array}$ & $\begin{array}{l}1 \text { line } \\
2 \text { lines } \\
3 \text { lines } \\
4 \text { lines } \\
5 \text { 1ines }\end{array}$ & $\begin{array}{l}1 \text { line } \\
1 \text { line } \\
1 \text { line } \\
1 \text { line } \\
1 \text { line }\end{array}$ \\
\hline
\end{tabular}

3. Evaluate/modify the prescription based on speed (Step 2), using an accuracy scale. In this scale, the difference between Teft-hand and right-hand accuracy is given in errors per minute (epm). The proportion of 1 ines based on speed (from Step 2) will be increased or decreased from zero to three categories depending on the degree of differences in accuracy between the hands. Table III shows the number of category increases or decreases based on amount of accuracy difference. 
TABLE III

SCALE FOR MODIFICATION OF PRESCRIPTION BASED

ON SPEED DUE TO PRETEST ACCURACY DIFFERENCES

\begin{tabular}{rcl}
\hline $\begin{array}{l}\text { Differences in } \\
\text { Accuracy (epm) }\end{array}$ & Category Change & Modification \\
\hline $0-2.00$ & 0 & No change in speed prescription \\
$2.01-4.00$ & 1 & Increase/decrease by 1 category \\
$4.01-6.00$ & 2 & Increase/decrease by 2 categories \\
Above 6.01 & 3 & Increase/decrease by 3 categories \\
\hline
\end{tabular}

The following example illustrates the use of the accuracy modification scale in Table III. Due to the unreliable nature of error measures in contrast to speed measures, sufficiently large differences in accuracy were necessary to indicate a modification of the prescription based on speed.

Example. The subject typed $28.00 \mathrm{gwpm}$ with the left hand and $23.00 \mathrm{gwpm}$ with the right hand. The difference of 5.0 gwpm yields a prescription based on speed of 3-1 (Step 2, Table II): three lines of right to one line of left since the right hand was slower.

If errors per minute were 8.00 with the left hand and 4.00 with the right hand, the $4.00 \mathrm{epm}$ difference would necessitate a one category change in favor of the right hand (decrease right-hand lines), making the accuracy modified prescription 2-1: two lines of right to one line of left. If errors per minute were 8.00 right hand and 4.00 left hand, the $4.00 \mathrm{epm}$ difference would necessitate a one category change in favor of the left hand (increase right-hand lines), 
making the accuracy modified prescription 4-1: four 1 ines of right to one line of left.

Constructing the packets. Following the formulation of prescriptions for each subject in Level 3, Left-hand/right-hand Prescribed practice, individualized practice packets were constructed.

In cases where there was a sufficient degree of difference to necessitate a proportional prescription, ihe right hand was the weaker hand in the majority of cases. There were four prescriptions made for right-hand improvement as follows: 2R-1L (two right-hand lines to one left-hand line), 3R-1L, 4R-1L, and 5R-1L. There was only one prescription for 1eft-hand improvement: 2L-1R. In some cases a sufficient degree of difference between hands was not found and a 1R-1L prescription was made. Table IV shows the number of students assigned to each type of prescription.

\section{TABLE IV}

FREQUENCY OF PRESCRIPTIONS IN THE PRESCRIBED GROUP

\begin{tabular}{cc}
\hline Prescription & Number of Subjects \\
\hline $1 R-1 L$ & 27 \\
$2 R-1 L$ & 26 \\
$3 R-1 L$ & 20 \\
$4 R-1 L$ & 7 \\
$5 R-1 L$ & 2 \\
$2 L-1 R$ & 3 \\
\hline
\end{tabular}

Lines of left-hand and right-hand words taken from the Level 2 packet were arranged proportionately to correspond to each of the 
prescriptions. Therefore, six prescribed packets were constructed. The six-page packets included five pages of practice lines and an instruction sheet (168 to 170 lines depending on the prescription). Each student in the prescribed group received an assigned packet labeled with his/her name. Material for the $3 \mathrm{R}-1 \mathrm{~L}$ packet is located in Appendix C.

\section{Duration of the Treatments}

The practice was conducted for five minutes per day, four/five days per week, for approximately three consecutive weeks during the middle of first semester, 1982-1983, providing a total of 75 minutes (15 sessions) of treatment time. The treatment time of five minutes per day included only time spent typing the practice materials and did not include giving directions, distributing packets, labeling pages, or any other such procedure.

Initial measures of the dependent variable criteria were obtained during the week preceding treatment in order to allow sufficient time to formulate prescriptions for the Level 3 group and to duplicate individualized packets.

Posttests were conducted on the first day following treatment. Table $V$ provides the timetable used in the study. 
TABLE V

TIMETABLE FOR THE STUDY

\begin{tabular}{ll}
\hline Activity & Date \\
\hline Pretesting & October 18 \\
Practice & October 27-November 18* \\
Posttesting & November 19 \\
\hline
\end{tabular}

*Two days were teacher workdays; fifteen tota 1 treatment days.

Eighty percent attendance at the practice sessions and participation in the pretest and posttest were required for a subject's performance to be included in the data analysis.

\section{Conducting the Practice}

On the first day of practice, students were given practice paper and a practice packet which contained the practice materials and instructions for the practice sessions. The following instructions were included in the packet and explained by the instructor:

1. DO NOT TYPE practice lines until your instructor tells you to do so.

2. In the upper right hand corner, label your color-coordinated practice paper as follows:

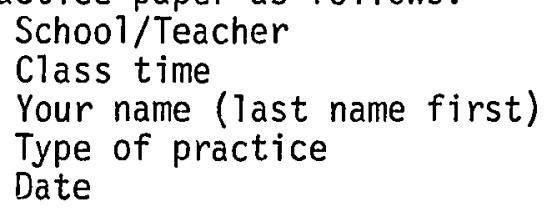

3. Set margins of 18 and 90 . Single spacing. 
4. Type lines as written. Do not type line numbers. Do not correct errors.

5. Type at a rate that is slightly faster than is comfortable. Use both sides of the practice paper if necessary.

6. When the five minutes of practice is completed:

1) Count the number of completed lines typed and write the number at the top of your practice paper next to the date.

2) Mark the practice line that you will start with the next day by circling the line number with a pencil.

7. Turn in your practice work and the practice materials to your instructor.

8. If you finish the materials provided before the study is concluded, start the packet over.

Students were made aware that the practice materials were different but were reassured that all types of practice were highly recommended. Practice packets were duplicated on paper of different colors for each treatment and subjects were provided practice paper of corresponding colors in order to facilitate recordkeeping.

Students were requested to count the number of 7 ines typed in order to encourage purposeful practice and to provide instructors with a monitoring device. Instructors were required to check typescripts periodically to ensure that students were typing at the desired rate--a little faster than comfortable.

Instructors collected practice typescripts and packets at the conclusion of each session. An examination of typescripts at the conclusion of the study showed that students either increased or retained the number of lines typed from day to day during the course of the study. 
Prior to the first day of practice, instructors received a set of practice guidelines and were trained in practice procedures by the researcher. Appendix $D$ contains the practice guidelines given to instructors.

\section{$\underline{\text { Testing }}$}

Pretesting and posttesting of the dependent variable criteria consisted of the same eight timed writings administered in the following order on each occasion:

1. Two three-minute straight-copy;

2. One one-minute left-hand copy;

3. One one-minute right-hand copy;

4. One one-minute left-hand copy;

5. One one-minute right-hand copy;

6. One one-minute left-hand copy; and

7. One one-minute right-hand copy.

Speed and accuracy measures were obtained for straight-copy, left-hand, and right-hand copy by averaging each set of timings of that type.

Copy for the two three-minute, straight-copy timings was selected from Modern College Typewriting--A Complete Course (West, 1977) with permission.

The six one-minute timings developed by the researcher each contained three 60-stroke 1 ines. Copy for all timings is located in Appendix E.

Prior to pretesting, a training seșsion was conducted for all 
teachers involved in the study. The importance of strict adherence to prescribed testing procedures was stressed. Instructors were advised of the critical nature of exact timing lengths and were required to utilize a stopwatch and exercise utmost care in the administration of al1 timed writings.

Detailed testing procedures were explained and discussed at the training session and written copies of the procedures provided for self-study. A review of testing procedures was conducted prior to the posttest. A copy of the testing procedures is located in Appendix $F$.

Teachers were asked to report any deviations from prescribed testing procedures. None were reported. An examination of all pretest and posttest timed writings revealed no discrepancies such as consistent gross differences in speeds by a class on three timings of one type which would suggest improper timing by the instructor.

\section{Treatment of the Data}

A11 timed writings were proofread twice and scored for speed and accuracy.

Typewriting words were counted for straight-copy timed writings using West's (1977) published word counts and for one-minute timed writings using word counts constructed by the researcher (5 strokes per word). Partial lines in both cases were counted using a typewriting ruler which measured each five strokes as a word with a remainder of 3 or 4 strokes being counted as a complete word. The following items were considered typographical errors in 
measuring errors per minute for this study.

7. Misstroke(s) within a word--one error per word.

2. Incorrect punctuation following a word--counted as part of the word and followed the one error per word rule.

3. Spacing errors such as more or fewer spaces between words than required or one space after a sentence or a colon--counted as a separate error and not as part of the word for purposes of the one error per word rule.

4. A line extending more than one-half inch into the margin; a line ending (except for the last paragraph) more than one-half inch inside the margin.

5. A strike-over.

6. Improper indention.

7. Line or portion of line omitted or added counted as one error, but words were added or substracted from the word count.

8. Hands on wrong keys--one error.

9. Incorrect vertical spacing--if directions were to double space the timing, single spacing of the timing counted as one error; otherwise, each separate instance of incorrect vertical spacing counted as one error.

The results of scoring and other information were transferred to computer coding sheets. Computer-generated frequency distributions for each dependent variable were compared with scores on the coding sheets to verify keypunching accuracy. 
Statistical analysis of the data was performed on the Winona State University Univac time-sharing computer, utilizing the analysis of covariance program in the Statistical Package for the Social Sciences (Nie et al., 1975). 
CHAPTER IV

FINDINGS

The findings of this study are presented in two sections: 1) description of the groups including pretest and posttest raw score data, and 2) tests of statistical significance.

Speed measures are reported in gross words per minute (gwpm) and error measures are reported in errors per minute (epm). Other abbreviations used in this chapter are explained as follows:

1. PROSE--groups practicing ordinary prose.

2. LHRH-E--groups practicing equal amounts of left-hand and right-hand 7 ines.

3. LHRH-P--group practicing a prescribed number of left-hand and right-hand 1 ines.

4. Pre--pretest; Post--posttest.

5. M--arithmetic mean.

6. SD--standard deviation.

\section{Description of the Groups}

The treatment variable, type of practice, consisted of three 1evels: 1) Prose practice, 2) Left-hand/right-hand Equal practice, and 3) Left-hand/right-hand Prescribed practice. The initial speed level variable consisted of two levels: 1) high, and 2) low. The highest retention rate (number of subjects included in the 
data analysis divided by the number of subjects pretested) was for the LHRH-E group, followed by the LHRH-P group, with the PROSE group having the lowest rate. Of the 284 subjects pretested, 260 (91.5\%) were included in the data analysis. Eighty percent attendance at practice sessions and participation in the pretest and posttest were required for a subject's performance to be included in the data analysis.

Table VI shows the retention rates by practice group for each high school and for the total sample.

TABLE VI

RETENTION PERCENTAGES BY PRACTICE GROUP AND HIGH SCHOOL

\begin{tabular}{ccccc}
\hline Practice Group & School A & School B & School C & Total \\
\hline PROSE & 89.1 & 100 & 84.2 & 89.5 \\
LHRH-E & 93.8 & 100 & 90.5 & 93.8 \\
LHRH-P & 88.7 & 100 & 95.0 & 91.4 \\
\hline Total Sample & 90.5 & 100 & 90.0 & 91.5 \\
\hline
\end{tabular}

Of the 260 subjects included in the data analysis, there were 85 subjects in the PROSE group, 90 subjects in the LHRH-E group, and 85 subjects in the LHRH-P group. Each initial speed level group consisted of 130 subjects. Table VII shows the distribution of subjects by practice and initial speed lever. 
TABLE VII

DISTRIBUTION OF SUBJECTS BY PRACTICE

GROUP AND SPEED LEVEL GROUP

\begin{tabular}{lcccc}
\hline Speed Leve & PROSE & LHRH-E & LHRH-P & Total \\
\hline High & 41 & 42 & 47 & 130 \\
Low & 44 & 48 & 38 & 130 \\
\hline Total & 85 & 90 & 85 & 260 \\
\hline
\end{tabular}

Straight-copy Pretest and Posttest Results

The straight-copy pretest and posttest speed and accuracy measures were obtained by the administration of the same pair of three-minute timed writings on each occasion.

Straight-copy Speed

Pretest straight-copy speed means ranged from $21.0 \mathrm{gwpm}$ for the LHRH-E group to $23.0 \mathrm{gwpm}$ for the LHRH-P group. A pretest difference in means of $9.3 \mathrm{gwpm}$ was found between the low and high initial speed Tevel groups.

Posttest straight-copy speed means ranged from $27.2 \mathrm{gwpm}$ for the LHRH-E group to 30.1 gwpm for the LHRH-P group, with the LHRH-E group showing the smallest gain in speed $(6.2 \mathrm{gwpm})$ from pretest to posttest, as compared to gains of $7.1 \mathrm{gwpm}$ for the LHRH-P group and 7.5 gwpm for the PROSE group. A posttest difference in means of 11.7 gwpm was found between the low and high initial speed level groups. 
Table VIII summarizes straight-copy speed pretest and posttest measures of central tendency (M) and dispersion (SD) for each treatment group, each initial speed level group, and the six classifications resulting from the combination of practice groups and initial speed level groups.

TABLE VIII

MEASURES OF CENTRAL TENDENCY AND DISPERSION

OF PRETEST AND POSTTEST STRAIGHT-COPY

SPEED RAW SCORES (GWPM)

\begin{tabular}{|c|c|c|c|c|c|c|c|c|c|}
\hline \multirow[b]{3}{*}{$\begin{array}{l}\text { Speed } \\
\text { Leve } 1\end{array}$} & \multirow[b]{3}{*}{ Stat. } & \multicolumn{8}{|c|}{ Practice Groups } \\
\hline & & \multicolumn{2}{|c|}{ PROSE } & \multicolumn{2}{|c|}{ LHRH-E } & \multicolumn{2}{|c|}{ LHRH-P } & \multicolumn{2}{|c|}{ TOTAL } \\
\hline & & Pre & Post & Pre & Post & Pre & Post & Pre & Post \\
\hline High & $\underline{S \bar{D}}$ & $\begin{array}{r}26.2 \\
4.0\end{array}$ & $\begin{array}{r}35.5 \\
5.9\end{array}$ & $\begin{array}{r}25.4 \\
3.7\end{array}$ & $\begin{array}{r}32.2 \\
5.5\end{array}$ & $\begin{array}{r}27.3 \\
4.8\end{array}$ & $\begin{array}{r}35.4 \\
5.1\end{array}$ & $\begin{array}{r}26.3 \\
4.3\end{array}$ & $\begin{array}{r}34.4 \\
5.7\end{array}$ \\
\hline Low & $\underline{S \underline{M}}$ & $\begin{array}{r}16.4 \\
3.1\end{array}$ & $\begin{array}{r}22.1 \\
4.6\end{array}$ & $\begin{array}{r}17.2 \\
3.5\end{array}$ & $\begin{array}{r}22.7 \\
5.1\end{array}$ & $\begin{array}{r}17.6 \\
3.0\end{array}$ & $\begin{array}{r}23.6 \\
4.8\end{array}$ & $\begin{array}{r}17.0 \\
3.2\end{array}$ & $\begin{array}{r}22.7 \\
4.8\end{array}$ \\
\hline Total & $\underline{S \underline{M}}$ & $\begin{array}{r}21.1 \\
6.0\end{array}$ & $\begin{array}{r}28.6 \\
8.6\end{array}$ & $\begin{array}{r}21.0 \\
5.5\end{array}$ & $\begin{array}{r}27.2 \\
7.1\end{array}$ & $\begin{array}{r}23.0 \\
6.3\end{array}$ & $\begin{array}{r}30.1 \\
7.7\end{array}$ & & \\
\hline
\end{tabular}

Straight-copy Accuracy

Pretest straight-copy accuracy means ranged from 1.7 epm for the LHRH-E group to $2.0 \mathrm{epm}$ for the LHRH-P group. A pretest difference in means of .6 epm was found between the low and high initial speed level groups with the low group exhibiting greater accuracy.

Posttest straight-copy accuracy means ranged from 2.8 epm for 
the LHRH-E group to 3.3 epm for the PROSE group. For a 11 three practice groups, the average number of errors per minute increased from the pretest to the posttest, with the greatest increase in errors per minute occuring in the PROSE group (1.4 epm), followed by the LHRH-E group (1.1 epm), with the smallest increase occurring in the LHRH-P group (.9 epm).

A posttest difference in means of $.8 \mathrm{epm}$ was found between the low and high initial speed level groups, with the low group retaining greater accuracy. For both initial speed level groups, the average number of errors per minute increased from the pretest to the posttest, with the greater increase occurring in the high group.

Table IX summarizes straight-copy accuracy pretest and posttest measures of central tendency and dispersion for each treatment group, each initial speed level group, and each of six classifications resulting from the combination of practice groups and speed level groups. 
TABLE IX

MEASURES OF CENTRAL TENDENCY AND DISPERSION

OF PRETEST AND POSTTEST STRAIGHT-COPY

ACCURACY RAW SCORES (EPM)

\begin{tabular}{|c|c|c|c|c|c|c|c|c|c|}
\hline \multirow{3}{*}{$\begin{array}{l}\text { Speed } \\
\text { Leve } 1\end{array}$} & \multirow[b]{3}{*}{ Stat. } & \multicolumn{8}{|c|}{ Practice Groups } \\
\hline & & \multicolumn{2}{|c|}{ PROSE } & \multicolumn{2}{|c|}{ LHRH-E } & \multicolumn{2}{|c|}{ LHRH-P } & \multicolumn{2}{|c|}{ TOTAL } \\
\hline & & Pre & Post & Pre & Post & Pre & Post & Pre & Post \\
\hline High & $\underline{S \bar{D}}$ & $\begin{array}{l}2.0 \\
1.1\end{array}$ & $\begin{array}{l}3.3 \\
1.9\end{array}$ & $\begin{array}{l}2.2 \\
1.2\end{array}$ & $\begin{array}{l}3.5 \\
1.8\end{array}$ & $\begin{array}{l}2.3 \\
1.5\end{array}$ & $\begin{array}{l}3.4 \\
1.9\end{array}$ & $\begin{array}{l}2.2 \\
1.3\end{array}$ & $\begin{array}{l}3.4 \\
1.8\end{array}$ \\
\hline Low & $\underline{\mathrm{S}}$ & $\begin{array}{l}1.8 \\
1.6\end{array}$ & $\begin{array}{l}3.3 \\
4.0\end{array}$ & $\begin{array}{r}1.3 \\
.9\end{array}$ & $\begin{array}{l}2.2 \\
1.4\end{array}$ & $\begin{array}{l}1.7 \\
1.1\end{array}$ & $\begin{array}{l}2.3 \\
1.4\end{array}$ & $\begin{array}{l}1.6 \\
1.2\end{array}$ & $\begin{array}{l}2.6 \\
2.6\end{array}$ \\
\hline Total & $s \bar{D}$ & $\begin{array}{l}1.9 \\
1.4\end{array}$ & $\begin{array}{l}3.3 \\
3.1\end{array}$ & $\begin{array}{l}1.7 \\
1.1\end{array}$ & $\begin{array}{l}2.8 \\
1.7\end{array}$ & $\begin{array}{l}2.0 \\
1.4\end{array}$ & $\begin{array}{l}2.9 \\
1.8\end{array}$ & & \\
\hline
\end{tabular}

Left-hand Pretest and Posttest Results

The left-hand pretest and posttest speed and accuracy measures were obtained by the administration of the same three, one-minute timed writings on each occasion.

Left-hand Speed

Pretest left-hand speed means ranged from $21.6 \mathrm{gwpm}$ for the LHRH-E group to $24.3 \mathrm{gwpm}$ for the LHRH-P group. A pretest difference in means of $9.1 \mathrm{gwpm}$ was found between the low and high initial speed level groups.

Posttest straight-copy speed means ranged from 28.1 gwpm for the 
PROSE group to 32.2 gwpm for the LHRH-P group. The PROSE group showed the smallest gain in speed (5.9 gwpm) from pretest to posttest, as compared to gains of $7.4 \mathrm{gwpm}$ for the LHRH-E group and $7.9 \mathrm{gwpm}$ for the LHRH-P group. A posttest difference in means of 11.6 gwpm was found between the low and high initial speed level groups.

Table $X$ gives the left-hand speed pretest and posttest measures of central tendency and dispersion for each treatment group, each initial speed level group, and each classification resulting from the combination of practice groups and speed level groups.

TABLE $X$

MEASURES OF CENTRAL TENDENCY AND DISPERSION

OF PRETEST AND POSTTEST LEFT-HAND

SPEED RAW SCORES (GWPM)

\begin{tabular}{|c|c|c|c|c|c|c|c|c|c|}
\hline \multirow{3}{*}{$\begin{array}{l}\text { Speed } \\
\text { Level }\end{array}$} & \multirow[b]{3}{*}{ Stat. } & \multicolumn{8}{|c|}{ Practice Groups } \\
\hline & & \multicolumn{2}{|c|}{ PROSE } & \multicolumn{2}{|c|}{ LHRH-E } & \multicolumn{2}{|c|}{ LHRH-P } & \multicolumn{2}{|c|}{ TOTAL } \\
\hline & & Pre & Post & Pre & Post & Pre & Post & Pre & Post \\
\hline High & $\underline{S \bar{D}}$ & $\begin{array}{r}27.2 \\
4.0\end{array}$ & $\begin{array}{r}34.7 \\
5.1\end{array}$ & $\begin{array}{r}25.8 \\
4.0\end{array}$ & $\begin{array}{r}34.3 \\
5.1\end{array}$ & $\begin{array}{r}28.3 \\
4.2\end{array}$ & $\begin{array}{r}37.5 \\
4.8\end{array}$ & $\begin{array}{r}27.2 \\
4.2\end{array}$ & $\begin{array}{r}35.6 \\
5.2\end{array}$ \\
\hline Low & $\underline{\mathrm{S}}$ & $\begin{array}{r}17.5 \\
3.7\end{array}$ & $\begin{array}{r}22.0 \\
4.5\end{array}$ & $\begin{array}{r}17.9 \\
3.7\end{array}$ & $\begin{array}{r}24.4 \\
5.1\end{array}$ & $\begin{array}{r}19.2 \\
3.7\end{array}$ & $\begin{array}{r}25.7 \\
5.7\end{array}$ & $\begin{array}{r}18.1 \\
3.7\end{array}$ & $\begin{array}{r}24.0 \\
5.3\end{array}$ \\
\hline Total & $\underline{\underline{M}}$ & $\begin{array}{r}22.2 \\
6.2\end{array}$ & $\begin{array}{r}28.1 \\
8.0\end{array}$ & $\begin{array}{r}21.6 \\
5.5\end{array}$ & $\begin{array}{r}29.0 \\
7.1\end{array}$ & $\begin{array}{r}24.3 \\
6.1\end{array}$ & $\begin{array}{r}32.2 \\
7.9\end{array}$ & & \\
\hline
\end{tabular}




\section{Left-hand Accuracy}

Pretest left-hand accuracy means ranged from $2.7 \mathrm{epm}$ for the LHRH-E group to $3.4 \mathrm{epm}$ for the PROSE group. A pretest difference in means of $1.3 \mathrm{epm}$ was found between the low and high initial speed level groups, with the low group exhibiting greater accuracy.

Posttest left-hand accuracy means ranged from $5.0 \mathrm{epm}$ for the LHRH-E group to $5.7 \mathrm{epm}$ for the LHRH-P group. For all three practice groups, the average number of errors increased from the pretest to thic posttest, with the greatest increase in errors per minute occurring in the LHRH-P group (2.4 epm), followed by the LHRH-E group (2.3 epm), with the smallest increase occurring in the PROSE group (1.7 epm). A posttest difference in means of 1.7 errors per minute was found between the high and low initial speed level groups, with the low group retaining greater accuracy. For both initial speed level groups, the average number of errors per minute increased from the pretest to posttest, with the greater increase occurring in the high group.

Table XI gives the left-hand accuracy pretest and posttest measures of central tendency ara dispersion for each treatment group, each initial speed level group, and each classification resulting from the combination of practice groups and speed level groups. 
TABLE XI

MEASURES OF CENTRAL TENDENCY AND DISPERSION

OF PRETEST AND POSTTEST LEFT-HAND

ACCURACY RAW SCORES (EPM)

\begin{tabular}{|c|c|c|c|c|c|c|c|c|c|}
\hline \multirow{3}{*}{$\begin{array}{l}\text { Speed } \\
\text { Level }\end{array}$} & \multirow[b]{3}{*}{ Stat. } & \multicolumn{8}{|c|}{ Practice Groups } \\
\hline & & \multicolumn{2}{|c|}{ PROSE } & \multicolumn{2}{|c|}{ LHRH-E } & \multicolumn{2}{|c|}{ LHRH-P } & \multicolumn{2}{|c|}{ TOTAL } \\
\hline & & Pre & Post & Pre & Post & Pre & Post & Pre & Post \\
\hline High & $\underline{S \bar{D}}$ & $\begin{array}{l}3.8 \\
2.0\end{array}$ & $\begin{array}{l}5.7 \\
3.2\end{array}$ & $\begin{array}{l}3.7 \\
2.4\end{array}$ & $\begin{array}{l}6.3 \\
4.0\end{array}$ & $\begin{array}{l}4.0 \\
2.7\end{array}$ & $\begin{array}{l}6.2 \\
3.5\end{array}$ & $\begin{array}{l}3.8 \\
2.4\end{array}$ & $\begin{array}{l}6.1 \\
3.4\end{array}$ \\
\hline Low & $\underline{S \underline{M}}$ & $\begin{array}{l}3.0 \\
3.1\end{array}$ & $\begin{array}{l}4.5 \\
4.2\end{array}$ & $\begin{array}{l}1.9 \\
1.2\end{array}$ & $\begin{array}{l}4.0 \\
2.6\end{array}$ & $\begin{array}{l}2.5 \\
1.8\end{array}$ & $\begin{array}{l}5.0 \\
4.7\end{array}$ & $\begin{array}{l}2.5 \\
2.2\end{array}$ & $\begin{array}{l}4.4 \\
3.9\end{array}$ \\
\hline Total & $\underline{\underline{M} \bar{D}}$ & $\begin{array}{l}3.4 \\
2.7\end{array}$ & $\begin{array}{l}5.1 \\
3.8\end{array}$ & $\begin{array}{l}2.7 \\
2.0\end{array}$ & $\begin{array}{l}5.0 \\
3.3\end{array}$ & $\begin{array}{l}3.3 \\
2.5\end{array}$ & $\begin{array}{l}5.7 \\
4.1\end{array}$ & & \\
\hline
\end{tabular}

Right-hand Pretest and Posttest Results

The right-hand pretest and posttest speed and accuracy measures were obtained by the administration of the same three, one-minute timed writings on each occasion.

Right-hand Speed

Pretest right-hand speed means ranged from $20.2 \mathrm{gwpm}$ for the LHRH-E group to 22.0 gwpm for the LHRH-P group. A pretest difference in means of $7.3 \mathrm{gwpm}$ was found between the high and low initial speed level groups.

Posttest right-hand speed means ranged from 25.9 gwpm for the 
PROSE group to 31.8 gwpm for the LHRH-P group. The PROSE group showed the smallest gain in speed ( $5.3 \mathrm{gwpm})$, as compared to gains of 7.8 gwpm for the LHRH-E group and $2.8 \mathrm{gwpm}$ for the LHRH-P group.

A posttest difference in means of $10.1 \mathrm{gwpm}$ was found between the low and high initial speed level groups.

Table XII gives the right-hand speed pretest and posttest measures of central tendency and dispersion for each treatment group, each initial speed level group, and each classification resulting from the combination of practice groups and speed level groups.

TABLE XII

MEASURES OF CENTRAL TENDENCY AND DISPERSION

OF PRETEST AND POSTTEST RIGHT-HAND

SPEED RAW SCORES (GWPM)

\begin{tabular}{|c|c|c|c|c|c|c|c|c|c|}
\hline \multirow{3}{*}{$\begin{array}{l}\text { Speed } \\
\text { Level }\end{array}$} & \multirow[b]{3}{*}{ Stat. } & \multicolumn{8}{|c|}{ Practice Groups } \\
\hline & & \multicolumn{2}{|c|}{ PROSE } & \multicolumn{2}{|c|}{ LHRH-E } & \multicolumn{2}{|c|}{ LHRH-P } & \multicolumn{2}{|c|}{ TOTAL } \\
\hline & & Pre & Post & Pre & Post & Pre & Post & Pre & Post \\
\hline High & $\underline{S D}$ & $\begin{array}{r}24.8 \\
3.0\end{array}$ & $\begin{array}{r}31.0 \\
4.5\end{array}$ & $\begin{array}{r}23.7 \\
3.4\end{array}$ & $\begin{array}{r}32.4 \\
4.6\end{array}$ & $\begin{array}{r}25.2 \\
3.4\end{array}$ & $\begin{array}{r}36.9 \\
5.3\end{array}$ & $\begin{array}{r}24.6 \\
3.3\end{array}$ & $\begin{array}{r}33.6 \\
5.4\end{array}$ \\
\hline Low & $\underline{\mathrm{M}}$ & $\begin{array}{r}16.7 \\
3.3\end{array}$ & $\begin{array}{r}22.1 \\
3.8\end{array}$ & $\begin{array}{r}17.1 \\
4.1\end{array}$ & $\begin{array}{r}24.2 \\
4.9\end{array}$ & $\begin{array}{r}18.1 \\
3.5\end{array}$ & $\begin{array}{r}25.4 \\
5.6\end{array}$ & $\begin{array}{r}17.3 \\
3.7\end{array}$ & $\begin{array}{r}23.5 \\
5.1\end{array}$ \\
\hline Total & $S \frac{M}{S D}$ & $\begin{array}{r}20.6 \\
5.1\end{array}$ & $\begin{array}{r}25.9 \\
6.5\end{array}$ & $\begin{array}{r}20.2 \\
5.0\end{array}$ & $\begin{array}{r}28.0 \\
6.3\end{array}$ & $\begin{array}{r}22.0 \\
4.9\end{array}$ & $\begin{array}{r}31.8 \\
7.9\end{array}$ & & \\
\hline
\end{tabular}


Right-hand Accuracy

Pretest right-hand accuracy means ranged from 3.1 epm for the LHRH-E group to 3.7 epm for the LHRH-P and PROSE groups. A pretest difference in means of 1.4 epm was found between the low and high initial speed level groups, with the low group exhibiting greater accuracy.

Posttest right-hand accuracy means ranged from 5.2 epm for the PROSE group to $6.9 \mathrm{epm}$ for the LHRH-P group. For all three practice groups, the average number of errors per minute increased from the pretest to posttest, with the greatest increase in errors per minute occurring in the LHRH-P group (3.2 epm), followed by the LHRH-E group (2.5 epm), with the smallest increase occurring in the PROSE group (1.5 epm).

A posttest difference in means of $1.7 \mathrm{epm}$ was found between the low and high initial speed level groups, with the low group retaining greater accuracy. For both initial speed level groups, the average number of errors per minute increased from the pretest to posttest, with the greater increase occurring in the high group.

Table XIII gives the right-hand accuracy pretest and posttest measures of central tendency and dispersion for each treatment group, each initial speed level group, and each classificaton resulting from the combination of practice groups and speed level groups. 
TABLE XIII

MEASURES OF CENTRAL TENDENCY AND DISPERSION

OF PRETEST AND POSTTEST RIGHT-HAND ACCURACY RAW SCORES (EPM)

\begin{tabular}{|c|c|c|c|c|c|c|c|c|c|}
\hline \multirow{3}{*}{$\begin{array}{l}\text { Speed } \\
\text { Level }\end{array}$} & \multirow[b]{3}{*}{ Stat. } & \multicolumn{8}{|c|}{ Practice Groups } \\
\hline & & \multicolumn{2}{|c|}{ Prose } & \multicolumn{2}{|c|}{ LHRH-E } & \multicolumn{2}{|c|}{ LHRH-P } & \multicolumn{2}{|c|}{ Total } \\
\hline & & Pre & Post & Pre & Post & Pre & Post & Pre & Post \\
\hline High & $\underline{S \underline{M}}$ & $\begin{array}{l}4.1 \\
2.2\end{array}$ & $\begin{array}{l}5.8 \\
2.6\end{array}$ & $\begin{array}{l}4.0 \\
1.9\end{array}$ & $\begin{array}{l}6.4 \\
3.9\end{array}$ & $\begin{array}{l}4.4 \\
2.6\end{array}$ & $\begin{array}{l}7.8 \\
4.4\end{array}$ & $\begin{array}{l}4.2 \\
2.3\end{array}$ & $\begin{array}{l}6.7 \\
3.8\end{array}$ \\
\hline Low & $\underline{\underline{M}}$ & $\begin{array}{l}3.3 \\
3.2\end{array}$ & $\begin{array}{l}4.6 \\
4.0\end{array}$ & $\begin{array}{l}2.4 \\
1.8\end{array}$ & $\begin{array}{l}4.8 \\
3.5\end{array}$ & $\begin{array}{l}2.7 \\
2.1\end{array}$ & $\begin{array}{l}5.7 \\
5.1\end{array}$ & $\begin{array}{l}2.8 \\
2.4\end{array}$ & $\begin{array}{l}5.0 \\
4.2\end{array}$ \\
\hline Tota 1 & $\frac{M}{S D}$ & $\begin{array}{l}3.7 \\
2.8\end{array}$ & $\begin{array}{l}5.2 \\
3.4\end{array}$ & $\begin{array}{l}3.1 \\
2.0\end{array}$ & $\begin{array}{l}5.6 \\
3.8\end{array}$ & $\begin{array}{l}3.7 \\
2.5\end{array}$ & $\begin{array}{l}6.9 \\
4.8\end{array}$ & & \\
\hline
\end{tabular}

\section{Tests of Statistical Significance}

The statistical model, hypothesis testing for the total sample, hypothesis testing for the high initial speed level classification, and hypothesis testing for the low initial speed level classification are presented in this section.

\section{Statistical Model}

The hypotheses were tested using analysis of covariance. Statistical significance at the .05 level of confidence was necessary to reject the statistical hypotheses.

Covariates. Respective initial measures of the dependent 
variable criteria were used as covariates. For example, in testing the hypothesis related to straight-copy speed, pretest straight-copy speed was used as the covariate; in testing the hypothesis related to straight-copy accuracy, pretest straight-copy accuracy was used as the covariate, and so on.

Degrees of freedom. The use of covariates resulted in the loss of one additional degree of freedom. Therefore, in each analysis, degrees of freedom are $\underline{N}$ (number of subjects) minus $\underline{K}$ (number of groups) minus one additional for the covariate.

Statistical tests. Eighteen hypotheses were tested. For each of the six dependent variables, three hypotheses were tested: 1) comparison of practice groups for the total sample, 2) comparison of the practice groups with the model replicated for the high initial speed level classification, and 3) comparison of practice groups with the model replicated for the low initial speed level classification.

Sums of squares, degrees of freedom (df), mean square, calculated $\underline{F}$ value $(\underline{F})$, the significance of $\underline{F}(\underline{p})$, and means adjusted for the effects of the covariate are provided in the tables summarizing the results of hypothesis testing.

\section{Hypothesis Testing--Total Sample}

There were 85 subjects in the Prose group (PROSE), 90 subjects in the Left-hand/right-hand Equal group (LHRH-E), and 85 subjects in the Left-hand/right-hand Prescribed group (LHRH-P).

Straight-copy speed. Table XIV provides the analysis of covariance results, including adjusted group means for the dependent 
variable, straight-copy speed. Pretest straight-copy speed was used as the covariate.

TABLE XIV

STRAIGHT-COPY SPEED: ANALYSIS OF COVARIANCE AND ADJUSTED GROUP MEANS FOR THE TOTAL SAMPLE

\begin{tabular}{|c|c|c|c|c|c|}
\hline $\begin{array}{l}\text { Source of } \\
\text { Variation }\end{array}$ & $\begin{array}{l}\text { Sum of } \\
\text { Squares }\end{array}$ & $\underline{d f}$ & $\begin{array}{l}\text { Mean } \\
\text { Square }\end{array}$ & $\underline{F}$ & $\mathrm{p}$ \\
\hline $\begin{array}{l}\text { Covariate } \\
\text { Practice } \\
\text { Residual }\end{array}$ & $\begin{array}{r}13634.939 \\
65.203 \\
2323.113\end{array}$ & $\begin{array}{r}1 \\
2 \\
256\end{array}$ & $\begin{array}{r}13634.939 \\
32.601 \\
9.075\end{array}$ & $\begin{array}{r}1502.529 \\
3.593\end{array}$ & $\begin{array}{l}.000 * \\
.029\end{array}$ \\
\hline Total & 16023.254 & 259 & 61.866 & & \\
\hline
\end{tabular}

Adjusted Practice Group Means (gwpm)

\begin{tabular}{|c|c|}
\hline Group & Adjusted Mean \\
\hline $\begin{array}{l}\text { Prose } \\
\text { Left-hand/right-hand Equal } \\
\text { Left-hand/right-hand Prescribed }\end{array}$ & $\begin{array}{l}29.22 \\
28.00 \\
28.55\end{array}$ \\
\hline
\end{tabular}

*Significant beyond the .001 level.

The probability of the calculated $\underline{F}$ value of 3.593 is .029 , with 2 and 256 degrees of freedom. Therefore, the statistical hypothesis that the straight-copy speed means of the populations for the various treatment levels are equal was rejected.

The statistical hypothesis for each pair-wise mean comparison was tested at the .05 level of confidence, using the Tukey test. With 2 and 256 degree of freedom, the estimated standard error of the mean is .3255 and the significant range is 1.08 . 
The adjusted means of the PROSE group (29.22) and the LHRH-E group (28.00) differed by 1.22 gwpm. The statistical hypothesis that the straight-copy speed means of the populations for the PROSE group and the LHRH-E group are equal was rejected. On straight-copy speed, the adjusted mean of the PROSE group was significantly greater than the adjusted mean of the LHRH-E group.

The adjusted means of the PROSE group (29.22) and the LHRH-P group (28.55) differed by $.67 \mathrm{gwpm}$. The statistical hypothesis that the straight-copy speed means of the populations for the PROSE group and the LHRH-P group are equal was not rejected.

The adjusted means of the LHRH-E group (28.00) and the LHRH-P group (28.55) differ by $.55 \mathrm{gwpm}$. The statistical hypothesis that the straight-copy speed means of the populations for the LHRH-E group and the LHRH-P group are equal was not rejected.

Straight-copy accuracy. Table XV provides the results of the analysis of covariance, including adjusted group means for the dependent variable, straight-copy accuracy. Pretest straight-copy accuracy was used as the covariate. 
TABLE XV

STRAIGHT-COPY ACCURACY: ANALYSIS OF COVARIANCE AND ADJUSTED GROUP MEANS FOR THE TOTAL SAMPLE

\begin{tabular}{|c|c|c|c|c|c|}
\hline $\begin{array}{l}\text { Source of } \\
\text { Variation }\end{array}$ & $\begin{array}{l}\text { Sum of } \\
\text { Squares }\end{array}$ & $\underline{\mathrm{df}}$ & $\begin{array}{l}\text { Mean } \\
\text { Square }\end{array}$ & $\underline{F}$ & $\underline{\mathrm{P}}$ \\
\hline $\begin{array}{l}\text { Covariate } \\
\text { Practice } \\
\text { Residual }\end{array}$ & $\begin{array}{r}342.321 \\
8.628 \\
998.032\end{array}$ & $\begin{array}{r}1 \\
2 \\
256\end{array}$ & $\begin{array}{r}342.321 \\
4.314 \\
3.899\end{array}$ & $\begin{array}{r}87.807 \\
1.107\end{array}$ & $\begin{array}{l}.000 * \\
.332\end{array}$ \\
\hline Total & 1348.981 & 259 & 5.208 & & \\
\hline
\end{tabular}

Adjusted Practice Group Means (epm)

\begin{tabular}{lr} 
Group & Adjusted \\
\cline { 1 - 2 } Prose & 3.26 \\
Left-hand/right-hand Equal & 2.96 \\
Left-hand/right-hand Prescribed & 2.82
\end{tabular}

*Significant beyond the .001 level.

The probability of the calculated $E$ value of 1.107 is .332 , with 2 and 256 degrees of freedom. Therefore, the statistical hypothesis that the straight-copy accuracy means of the populations for the various treatment levels are equal was not rejected.

Left-hand speed. Table XVI provides the results of the analys is of covariance, including adjusted group means for the dependent variable, left-hand speed. Pretest left-hand speed was used as the covariate. 
TABLE XVI

LEFT-HAND SPEED: ANALYSIS OF COVARIANCE AND ADJUSTED GROUP MEANS FOR THE TOTAL SAMPLE

\begin{tabular}{lrrrrr}
$\begin{array}{l}\text { Source of } \\
\text { Variation }\end{array}$ & $\begin{array}{l}\text { Sum of } \\
\text { Squares }\end{array}$ & $\underline{\mathrm{df}}$ & $\begin{array}{c}\text { Mean } \\
\text { Square }\end{array}$ & $\underline{\mathrm{F}}$ & $\mathrm{p}$ \\
\hline $\begin{array}{l}\text { Covariate } \\
\text { Practice } \\
\text { Residual }\end{array}$ & $\begin{array}{r}13553.749 \\
164.992\end{array}$ & $\begin{array}{r}1 \\
2\end{array}$ & $\begin{array}{r}13553.749 \\
82.096 \\
8.4288\end{array}$ & $\begin{array}{r}1647.220 \\
10.026\end{array}$ & $\begin{array}{r}.000^{*} \\
.000^{*}\end{array}$ \\
\hline Total & 15825.175 & 259 & 61.101 & & \\
\hline
\end{tabular}

Adjusted Practice Group Means (gwpm)

Group

Prose

Left-hand/right-hand Equal

Left-hand/right-hand Prescribed
Adjusted Mean

28.63

30.32

30.34

*Significant beyond the .001 level.

The probability of the calculated $F$ value of 10.026 is beyond .001 , with 2 and 256 degrees of freedom. Therefore, the statistical hypothesis that the left-hand speed means of the populations for the various treatment levels are equal was rejected.

The statistical hypothesis for each pair-wise mean comparison was tested at the .05 level of confidence, using the Tukey test. With 2 and 256 degrees of freedom, the estimated standard error of the mean is .3111 and the significant range is 1.03 .

The adjusted means of the PROSE group (28.63) and the LHRH-E group (30.32) differed by $1.69 \mathrm{gwpm}$. The statistical hypothes is that 
the left-hand speed means of the populations for the PROSE group and the LHRH-E group are equal was rejected. The adjusted mean of the LHRH-E group was significantly greater than the adjusted mean of the PROSE group.

The adjusted means of the PROSE group (28.63) and the LHRH-P group (30.34) differed by $1.71 \mathrm{gwpm}$. The statistical hypothesis that the left-hand speed means of the populations for the PROSE group and the LHRH-P group are equal was rejected. On left-hand speed, the adjusted mean of the LHRH-P group was significantly greater than the adjusted mean of the PROSE group.

The adjusted means of the LHRH-E group (30.32) and the LHRH-P group (30.34) differed by .02 gwpm. The statistical hypothesis that the left-hand speed means of the populations for the LHRH-E group and the LHRH-P group are equal was not rejected.

Left-hand accuracy. Table XVII provides the results of the analysis of covariance, including adjusted group means for the dependent variable, left-hand accuracy. Pretest left-hand accuracy was used as the covariate. 
TABLE XVII

LEFT-HAND ACCURACY: ANALYSIS OF COVARIANCE AND ADJUSTED GROUP MEANS FOR THE TOTAL SAMPLE

\begin{tabular}{|c|c|c|c|c|c|}
\hline $\begin{array}{l}\text { Source of } \\
\text { Variation }\end{array}$ & $\begin{array}{l}\text { Sum of } \\
\text { Squares }\end{array}$ & $\underline{d f}$ & $\begin{array}{l}\text { Mean } \\
\text { Square }\end{array}$ & $\underline{F}$ & $\mathrm{p}$ \\
\hline $\begin{array}{l}\text { Covariate } \\
\text { Practice } \\
\text { Residual }\end{array}$ & $\begin{array}{r}1436.264 \\
25.374 \\
2145.325\end{array}$ & $\begin{array}{r}1 \\
2 \\
256\end{array}$ & $\begin{array}{r}1436.264 \\
12.687 \\
8.380\end{array}$ & $\begin{array}{r}171.388 \\
1.514\end{array}$ & $\begin{array}{l}.000 * \\
.222\end{array}$ \\
\hline \multirow[t]{4}{*}{ Total } & 3606.963 & 259 & 13.926 & & \\
\hline & \multicolumn{5}{|c|}{ Adjusted Practice Group Means (epm) } \\
\hline & \multicolumn{3}{|c|}{ Group } & \multicolumn{2}{|l|}{ Adjusted Mean } \\
\hline & \multicolumn{3}{|c|}{$\begin{array}{l}\text { Prose } \\
\text { Left-hand/right-hand Equal } \\
\text { Left-hand/right-hand Prescribed }\end{array}$} & $\begin{array}{l}4.82 \\
5.47 \\
5.51\end{array}$ & \\
\hline
\end{tabular}

*Significant beyond the .001 level.

The probability of the calculated $\underline{F}$ value of 1.514 is .222 , with 2 and 256 degrees of freedom. Therefore, the statistical hypothesis that the left-hand accuracy means of the populations for the various treatment levels are equal was not rejected.

Right-hand speed. Table XVIII provides the results of the analysis of covariance, including adjusted group means for the dependent variable, right-hand speed. Pretest right-hand speed was used as the covariate. 
TABLE XVIII

RIGHT-HAND SPEED: ANALYSIS OF COVARIANCE AND ADJUSTED GROUP MEANS FOR THE TOTAL SAMPLE

\begin{tabular}{lrrrrr}
$\begin{array}{l}\text { Source of } \\
\text { Variation }\end{array}$ & $\begin{array}{l}\text { Sum of } \\
\text { Squares }\end{array}$ & df & $\begin{array}{c}\text { Mean } \\
\text { Square }\end{array}$ & $\underline{\mathrm{F}}$ & $\mathrm{p}$ \\
\hline $\begin{array}{l}\text { Covariate } \\
\text { Practice } \\
\text { Residual }\end{array}$ & $\begin{array}{r}10211.570 \\
773.441 \\
2742.578\end{array}$ & $\begin{array}{r}1 \\
2\end{array}$ & $\begin{array}{r}10211.570 \\
386.721 \\
10.713\end{array}$ & $\begin{array}{r}953.177 \\
36.098\end{array}$ & $\begin{array}{r}.000^{*} \\
.000^{*}\end{array}$ \\
\hline Total & 13727.589 & 259 & 53.002 & & \\
\hline
\end{tabular}

Adjusted Practice Group Means (epm)

\begin{tabular}{lc}
\multicolumn{1}{c}{ Group } & Adjusted Mean \\
\cline { 1 - 1 } Prose & 26.22 \\
Left-hand/right-hand Equal & 28.93 \\
Left-hand/right-hand Prescribed & 30.45
\end{tabular}

*Significant beyond the .001 level.

The probability of the calculated $\underline{F}$ value of 36.098 is beyond .001 , with 2 and 256 degrees of freedom. Therefore, the statistical hypothesis that the right-hand speed means of the populations for the various treatment levels are equal was rejected.

The statistical hypothesis for each pair-wise mean comparison was tested at the .05 level of confidence, using the Tukey test. With 2 and 256 degrees of freedom, the estimated standard error of the mean is .3539 and the significant range is 1.17 .

The adjusted means of the PROSE group (26.22) and the LHRH-E group (28.93) differed by $2.71 \mathrm{gwpm}$. The statistical hypothesis that 
the right-hand speed means of the populations for the PROSE group and the LHRH-E group are equal was rejected. On right-hand speed, the adjusted mean of the LHRH-E group was significantly greater than the adjusted mean of the PROSE group.

The adjusted means of the PROSE group (26.22) and the LHRH-P group (30.45) differed by $4.23 \mathrm{gwpm}$. The statistical hypothesis that the right-hand speed means of the populations for the PROSE group and the LHRH-P group are equal was rejected. On right-hand speed, the adjusted mean of the LHRH-P group was significantly greater than the adjusted mean of the PROSE group.

The adjusted means of the LHRH-E (28.93) group and the LHRH-P group (30.45) differed by $1.52 \mathrm{gwpm}$. The statistical hypothesis that the right-hand speed means of the populations for the LHRH-E group and the LHRH-P group are equal was rejected. On right-hand speed, the adjusted mean of the LHRH-P group was significantiy greater than the adjusted mean of the LHRH-E group.

Right-hand accuracy. Table XIX provides the results of the analys is of covariance, including adjusted group means for the dependent variable, right-hand accuracy. Pretest right-hand accuracy was used as the covariate. 
TABLE XIX

RIGHT-HAND ACCURACY: ANALYSIS OF COVARIANCE AND ADJUSTED GROUP MEANS FOR THE TOTAL SAMPLE

\begin{tabular}{|c|c|c|c|c|c|}
\hline $\begin{array}{l}\text { Source of } \\
\text { Variation }\end{array}$ & $\begin{array}{l}\text { Sum of } \\
\text { Squares }\end{array}$ & $\underline{d f}$ & $\begin{array}{l}\text { Mean } \\
\text { Square }\end{array}$ & $\underline{F}$ & $\mathrm{p}$ \\
\hline $\begin{array}{l}\text { Covariate } \\
\text { Practice } \\
\text { Residual }\end{array}$ & $\begin{array}{r}1815.407 \\
121.549 \\
2385.710\end{array}$ & $\begin{array}{r}1 \\
2 \\
256\end{array}$ & $\begin{array}{r}1815.407 \\
60.775 \\
9.319\end{array}$ & $\begin{array}{r}194.803 \\
6.521\end{array}$ & $\begin{array}{l}.000 * \\
.002\end{array}$ \\
\hline Total & 4322.666 & 259 & 16.590 & & \\
\hline
\end{tabular}

Adjusted Practice Group Means (epm)

\begin{tabular}{lr} 
Group & Adjusted \\
\hline Prose & 4.98 \\
Left-hand/right-hand Equal & 5.96 \\
Left-hand/right-hand Prescribed & 6.66
\end{tabular}

*Significant beyond the .001 level.

The probability of the calculated $\underline{F}$ value of 6.521 is .002 , with 2 and 256 degrees of freedom. Therefore, the itatistical hypothesis that the right-hand accuracy means of the populations for the various treatment levels are equal was rejected.

The statistical hypothesis for each pair-wise mean comparison was tested at the .05 level of confidence, using the Tukey test. With 2 and 256 degrees of freedom, the estimated standard error of the mean is .3290 and the significant range is 1.09 .

The adjusted means of the PROSE group (4.98) and the LHRH-E group (5.96) differed by $.98 \mathrm{epm}$. The statistical hypothesis that the 
right-hand accuracy means of the populations for the PROSE group and the LHRH-E group are equal was not rejected.

The adjusted means of the PROSE group (4.98) and the LHRH-P group (6.66) differed by $1.68 \mathrm{epm}$. The statistical hypothesis that the right-hand accuracy means of the populations for the PROSE group and the LHRH-P group are equal was rejected. On right-hand accuracy, the adjusted mean of the LHRH-P group was significantly greater than the adjusted mean of the PROSE Group.

The adjusted means of the LHRH-E group (5.96) and the LHRH-P group (6.66) differed by $.70 \mathrm{epm}$. The statistical hypothesis that the right-hand accuracy means of the populations for the LHRH-E group and the LHRH-P group are equal was not rejected.

Summary. In the analysis of covariance for the total sample, four of six statistical hypotheses were rejected for the main effects of practice: straight-copy speed, left-hand speed, right-hand speed, and right-hand accuracy.

On straight-copy speed, pair-wise mean comparisons showed a significant difference between the PROSE group and the LHRH-E group in favor of the PROSE group; no significant differences were found between the PROSE and LHRH-P groups or between the LHRH-E and the LHRH-P groups.

On left-hand speed, pair-wise mean comparisons showed a significant difference between the PROSE group and the LHRH-E group in favor of the LHRH-E group and a significant difference between the PROSE group and the LHRH-P group in favor of the LHRH-P group. No significant difference was found between the LHRH-E group and the 
LHRH -P group.

On right-hand speed, pair-wise mean comparisons showed a significant difference for each pair of means. The LHRH-P group was significantly higher than the LHRH-E group which was significantly higher than the PROSE group.

On right-hand accuracy, pair-wise mean comparisons showed a significant difference between the PROSE group and the LHRH-P group in favor of the PROSE group; no other significant differences between groups were found.

Table XX provides a summary of the results of hypothesis testing for the total sample. Adjusted speed means are reported in gwpm; adjusted error means are reported in epm. 
TABLE XX

SUMMARY OF HYPOTHESIS TESTING--TOTAL SAMPLE

\begin{tabular}{|c|c|c|c|c|}
\hline \multirow{2}{*}{$\frac{\text { Variable }}{\text { Straight-copy Speed }}$} & \multirow{2}{*}{ p } & \multicolumn{3}{|c|}{ Adjusted Means* } \\
\hline & & $\underline{L H R H-E}$ & LHRH-P & PROSE \\
\hline & & 28.00 & 28.55 & 29.22 \\
\hline \multirow[t]{2}{*}{ Straight-copy Accuracy } & .332 & PROSE & LHRH-E & LHRH-P \\
\hline & & 3.26 & 2.96 & 2.82 \\
\hline \multirow[t]{2}{*}{ Left-hand Speed } & $.000 * *$ & PROSE & LHRH-E & LHRH-P \\
\hline & & 28.63 & 30.32 & 30.34 \\
\hline \multirow[t]{2}{*}{ Left-hand Accuracy } & .222 & LHRH-P & LHRH-E & PROSE \\
\hline & & 5.51 & 5.47 & 4.82 \\
\hline \multirow[t]{2}{*}{ Right-hand Speed } & $.000 * \star$ & PROSE & LHRH-E & LHRH-P \\
\hline & & 26.22 & 28.93 & 30.45 \\
\hline \multirow[t]{2}{*}{ Right-hand Accuracy } & $.002 * *$ & LHRH-P & LHRH-E & PROSE \\
\hline & & 6.66 & 5.96 & 4.98 \\
\hline \multicolumn{5}{|c|}{$\begin{array}{l}\text { * Lines between Adjusted Means indicate significant differences. No } \\
\text { line indicates that the difference was not significant at the .05 } \\
\text { level. } \\
\text { **The statistical hypothesis for covariance was rejected. }\end{array}$} \\
\hline \multicolumn{5}{|c|}{ Hypothesis Testing--High Speed Level } \\
\hline
\end{tabular}


in the Left-hand/right-hand Equal (LHRH-E) group and 47 subjects in the Left-hand/right-hand Prescribed (LHRH-P) group for a total of 130 subjects in the model replicated for the high initia? speed level classification. Subjects in this classification obtained speeds of 21.0 gwpm or higher on the straight-copy pretest.

Straight-copy speed. Table XXI provides the results of the analysis of covariance, including adjusted group means for the high initial speed level classification on the dependent variable, straight-copy speed. Pretest straight-copy speed was used as the covariate.

TABLE XXI

STRAIGHT-COPY SPEED: ANALYSIS OF COVARIANCE AND ADJUSTED GROUP MEANS FOR THE HIGH INITIAL

SPEED LEVEL CLASSIFICATION

\begin{tabular}{lrrrrr}
\hline $\begin{array}{l}\text { Source of } \\
\text { Variation }\end{array}$ & $\begin{array}{c}\text { Sum of } \\
\text { Squares }\end{array}$ & df & $\begin{array}{r}\text { Mean } \\
\text { Square }\end{array}$ & $\underline{F}$ & $\mathrm{p}$ \\
\hline $\begin{array}{l}\text { Covariate } \\
\text { Practice } \\
\text { Residual }\end{array}$ & $\begin{array}{r}2839.256 \\
125.114\end{array}$ & $\begin{array}{r}1 \\
1194.351\end{array}$ & $\begin{array}{r}2839.256 \\
62.557 \\
9.479\end{array}$ & $\begin{array}{r}299.532 \\
6.600\end{array}$ & $\begin{array}{l}.000^{*} \\
.002\end{array}$ \\
\hline Total & 4158.722 & 129 & 32.238 & & \\
\hline
\end{tabular}

Adjusted Practice Group Means (gwpm)

Group

Prose

Left-hand/right-hand Equal Left-hand/right-hand Prescribed
Adjusted Mean

35.72

33.26

34.33

*Significant beyond the .001 1evel. 
The probability of the calculated $E$ value of 6.600 is .002 , with 2 and 126 degrees of freedom. Therefore, in the high initial speed level classification, the statistical hypothesis that the straight-copy speed means of the populations for the various treatment levels are equal was rejected.

The statistical hypothesis for each pair-wise mean comparison was tested at the .05 level of confidence, using the Tukey test. With 2 and 126 degrees of freedom, the estimated standard error of the mean is .4728 and the significant range is 1.59 .

The adjusted means of the PROSE group (35.72) and the LHRH-E group (33.26) differed by $2.46 \mathrm{gwpm}$. The statistical hypothesis that the straight-copy speed means of the populations for the PROSE group and the LHRH-E group are equal was rejected. On straight-copy speed, the adjusted mean of the PROSE group was significantly greater than the adjusted mean of the LHRH-E group.

The adjusted means of the PROSE group (35.72) and the LHRH-P group (34.33) differed by 1.39 gwpm. The statistical hypothesis that the straight-copy speed means of the populations for the PROSE group and the LHRH-P group are equa? was not rejected.

The adjusted means of the LHRH-E group (33.26) and the LHRH-P group (34.33) differed by $1.07 \mathrm{gwpm}$. The statistical hypothesis that the straight-copy speed means of the populations for the LHRH-E group and the LHRH-P group are equal was not rejected.

Straight-copy accuracy. Table XXII provides the results of the analysis of covariance, including adjusted group means for the high initial speed level classification on the dependent variable, 
straight-copy accuracy. Pretest straight-copy accuracy was used as the covariate.

TABLE XXII

STRAIGHT-COPY ACCURACY: ANALYSIS OF COVARIANCE AND ADJUSTED GROUP MEANS FOR THE HIGH

INITIAL SPEED LEVEL CLASSIFICATION

\begin{tabular}{|c|c|c|c|c|c|}
\hline $\begin{array}{l}\text { Source of } \\
\text { Variation }\end{array}$ & $\begin{array}{l}\text { Sum of } \\
\text { Squares }\end{array}$ & $\underline{\mathrm{df}}$ & $\begin{array}{l}\text { Mean } \\
\text { Square }\end{array}$ & $\underline{F}$ & $\mathrm{p}$ \\
\hline $\begin{array}{l}\text { Covariate } \\
\text { Practice } \\
\text { Residual }\end{array}$ & $\begin{array}{r}152.441 \\
.621 \\
284.391\end{array}$ & $\begin{array}{r}1 \\
2 \\
126\end{array}$ & $\begin{array}{r}152.441 \\
.310 \\
2.257\end{array}$ & $\begin{array}{r}67.539 \\
.138\end{array}$ & $\begin{array}{l}.000 * \\
.872\end{array}$ \\
\hline Total & 437.453 & 129 & 3.391 & & \\
\hline
\end{tabular}

Adjusted Practice Group Means (epm)

\begin{tabular}{lc}
\hline \multicolumn{1}{c}{ Group } & Adjusted Mean \\
\cline { 3 - 3 } & \\
Prose & 3.36 \\
Left-hand/right-hand Equal & 3.49 \\
Left-hand/right-hand Prescribed & 3.33 \\
\hline
\end{tabular}

*Significant beyond the .001 level.

The probability of the calculated $E$ value of .138 is .872 , with 2 and 126 degrees of freedom. Therefore, in the high initial speed level classification, the statistical hypothesis that the straight-copy accuracy means of the populations for the various treatment levels are equal was not rejected.

Left-hand speed. Table XXIII provides the results of the analysis of covariance, including adjusted group means for the high 
initial speed level classification on the dependent variable, left-hand speed. Pretest left-hand speed was used as the covariate.

TABLE XXIII

LEFT-HAND SPEED: ANALYSIS OF COVARIANCE AND ADJUSTED GROUP MEANS FOR THE HIGH INITIAL SPEED LEVEL CLASSIFICATION

\begin{tabular}{|c|c|c|c|c|c|}
\hline $\begin{array}{l}\text { Source of } \\
\text { Variation }\end{array}$ & $\begin{array}{l}\text { Sum of } \\
\text { Squares }\end{array}$ & $\underline{d f}$ & $\begin{array}{l}\text { Mean } \\
\text { Square }\end{array}$ & $\underline{F}$ & $\mathrm{p}$ \\
\hline $\begin{array}{l}\text { Covariate } \\
\text { Practice } \\
\text { Residual }\end{array}$ & $\begin{array}{r}2252.069 \\
67.298 \\
1135.532\end{array}$ & $\begin{array}{r}1 \\
2 \\
126\end{array}$ & $\begin{array}{r}2252.069 \\
33.649 \\
9.012\end{array}$ & $\begin{array}{r}249.892 \\
3.734\end{array}$ & $\begin{array}{l}.000^{*} \\
.027\end{array}$ \\
\hline \multirow[t]{4}{*}{ Total } & 3454.900 & 129 & 26.782 & & \\
\hline & \multicolumn{5}{|c|}{ Adjusted Practice Group Means (gwpm) } \\
\hline & \multicolumn{2}{|c|}{ Group } & & Adjusted Mean & \\
\hline & \multicolumn{3}{|c|}{$\begin{array}{l}\text { Prose } \\
\text { Left-hand/right-hand Equal } \\
\text { Left-hand/right-hand Prescribed }\end{array}$} & $\begin{array}{l}34.60 \\
35.66 \\
36.36\end{array}$ & \\
\hline
\end{tabular}

*Significant beyond the .001 level.

The probability of the calculated $\underline{F}$ value of 3.734 is .027 , with 2 and 126 degrees of freedom. Therefore, in the high initial speed level classification, the statistical hypothesis that the left-hand speed means of the populations for the various treatment levels are equal was rejected.

The statistical hypothesis for each pair-wise mean comparison was tested at the .05 level of confidence, using the Tukey test. With 
2 and 126 degrees of freedom, the estimated standard error of the mean is .4642 and the significant range is 1.56 .

The adjusted means of the PROSE group (34.60) and the LHRH-E group (35.66) differed by 1.06 gwpm. The statistical hypothes is that the left-hand speed means of the populations for the PROSE group and the LHRH-E group are equal was not rejected.

The adjusted means of the PROSE group (34.60) and the LHRH-P group (36.36) differed by $1.76 \mathrm{gwpm}$. The statistical hypothesis that the left-hand speed means of the populations for the PROSE group and the LHRH-P group are equal was rejected. On left-hand speed, the adjusted mean of the LHRH-P group was significantly greater than the adjusted mean of the PROSE group.

The adjusted means of the LHRH-E group (35.66) and the LHRH-P group (36.36) differed by $.70 \mathrm{gwpm}$. The statistical hypothesis that the left-hand speed means of the populations for the LHRH-E group and the LHRH-P group are equal was not rejected.

Left-hand accuracy. Table XXIV provides the results of the analysis of covariance, including adjusted group means for the high initial speed level classification on the dependent variable, left-hand accuracy. Pretest left-hand accuracy was used as the covariate. 
TABLE XXIV

LEFT-HAND ACCURACY: ANALYSIS OF COVARIANCE AND ADJUSTED GROUP MEANS FOR THE HIGH INITIAL SPEED LEVEL CLASSIFICATION

\begin{tabular}{|c|c|c|c|c|c|}
\hline $\begin{array}{l}\text { Source of } \\
\text { Variation }\end{array}$ & $\begin{array}{l}\text { Sum of } \\
\text { Squares }\end{array}$ & $\underline{d f}$ & $\begin{array}{l}\text { Mean } \\
\text { Square }\end{array}$ & $\underline{F}$ & $\mathrm{p}$ \\
\hline $\begin{array}{l}\text { Covariate } \\
\text { Practice } \\
\text { Residual }\end{array}$ & $\begin{array}{r}548.048 \\
10.818 \\
948.503\end{array}$ & $\begin{array}{r}1 \\
2 \\
126\end{array}$ & $\begin{array}{r}548.048 \\
5.409 \\
7.528\end{array}$ & $\begin{array}{r}72.803 \\
.719\end{array}$ & $\begin{array}{l}.000 * \\
.489\end{array}$ \\
\hline Total & 1507.369 & 129 & 11.685 & & \\
\hline \multicolumn{6}{|c|}{ Adjusted Practice Group Means (epm) } \\
\hline & \multicolumn{3}{|c|}{ Group } & \multicolumn{2}{|c|}{ Adjusted Mean } \\
\hline & \multicolumn{3}{|c|}{$\begin{array}{l}\text { Prose } \\
\text { Left-hand/right-hand Equal } \\
\text { Left-hand/right-hand Prescribed }\end{array}$} & $\begin{array}{l}5.73 \\
6.45 \\
6.08\end{array}$ & \\
\hline
\end{tabular}

*Significant beyond the .001 level.

The probability of the calculated $\underline{F}$ value of .719 is .489 , with 2 and 126 degrees of freedom. Therefore, in the high initial speed level classification, the statistical hypothesis that the left-hand accuracy means of the populations for the various treatment levels are equal was not rejected.

Right-hand speed. Table XXV provides the results of the analysis of covariance, including adjusted group means for the high initial speed classification on the dependent variable, right-hand speed. Pretest right-hand speed was used as the covariate. 
TABLE XXV

RIGHT-HAND SPEED: ANALYSIS OF COVARIANCE AND ADJUSTED GROUP MEANS FOR THE HIGH INITIAL SPEED LEVEL CLASSIFICATION

\begin{tabular}{lrrrrr}
\hline $\begin{array}{l}\text { Source of } \\
\text { Variation }\end{array}$ & $\begin{array}{l}\text { Sum of } \\
\text { Squares }\end{array}$ & df & $\begin{array}{c}\text { Mean } \\
\text { Square }\end{array}$ & $\underline{\mathrm{F}}$ & $\mathrm{p}$ \\
\hline $\begin{array}{l}\text { Covariate } \\
\text { Practice } \\
\text { Residual }\end{array}$ & $\begin{array}{r}2013.018 \\
650.641 \\
1152.188\end{array}$ & $\begin{array}{r}1 \\
2\end{array}$ & $\begin{array}{r}2013.018 \\
325.321 \\
9.144\end{array}$ & $\begin{array}{r}220.138 \\
35.576\end{array}$ & $\begin{array}{l}.000^{*} \\
.000^{*}\end{array}$ \\
\hline Total & 3815.848 & 129 & 29.580 & & \\
\hline
\end{tabular}

Adjusted Practice Group Means (gwpm)

\begin{tabular}{|c|c|}
\hline Group & Adjusted \\
\hline $\begin{array}{l}\text { Prose } \\
\text { Left-hand/right-hand Equal } \\
\text { Left-hand/right-hand Prescribed }\end{array}$ & $\begin{array}{l}30.72 \\
33.44 \\
36.17\end{array}$ \\
\hline
\end{tabular}

*Significant beyond the .001 level.

The probability of the calculated $\underline{F}$ value of 35.576 is beyond .001 , with 2 and 126 degrees of freedom. Therefore, in the high speed level classification, the statistical hypothesis that the right-hand speed means of the populations for the various treatment levels are equal was rejected.

The statistical hypothesis for each pair-wise mean comparison was tested at the .05 level of confidence, using the Tukey test. With 2 and 126 degrees of freedom, the estimated standard error of the mean is .4646 and the significant range is 1.56 .

The adjusted means of the PROSE group (30.72) and the LHRH-E 
group (33.44) differed by 2.72 gwpm. The statistical hypothes is that the right-hand speed means of the populations for the PROSE group and the LHRH-E group are equal was rejected. On right-hand speed, the adjusted mean of the LHRH-E group was significantly greater than the adjusted mean of the PROSE group.

The adjusted means of the PROSE group (30.72) and the LHRH-P group (36.17) differed by $5.45 \mathrm{gwpm}$. The statistical hypothesis that the right-hand speed means of the populations for the PROSE group and the LHRH-P group are equal was rejected. On right-hand speed, the adjusted mean of the LHRH-P group was significantly greater than the adjusted mean of the PROSE group.

The adjusted means of the LHRH-E group (33.44) and the LHRH-P group (36.17) differed by $2.73 \mathrm{gwpm}$. The statistical hypothes is that the right-hand speed means of the populations for the LHRH-E group are equal was rejected. On right-hand speed, the adjusted mean of the LHRH-P group was significantly greater than the adjusted mean of the LHRH-E group.

Right-hand accuracy. Table XXVI provides the results of the analysis of covariance, including adjusted group means for the high initial speed level classification on the dependent variable, right-hand accuracy. Pretest right-hand accuracy was used as the covariate. 
TABLE XXVI

RIGHT-HAND ACCURACY: ANALYSIS OF COVARIANCE AND ADJUSTED GROUP MEANS FOR THE HIGH INITIAL SPEED LEVEL CLASSIFICATION

\begin{tabular}{|c|c|c|c|c|c|}
\hline $\begin{array}{l}\text { Source of } \\
\text { Variation }\end{array}$ & $\begin{array}{l}\text { Sum of } \\
\text { Squares }\end{array}$ & $\underline{d f}$ & $\begin{array}{l}\text { Mean } \\
\text { Square }\end{array}$ & $\underline{\mathrm{F}}$. & $\mathrm{p}$ \\
\hline $\begin{array}{l}\text { Covariate } \\
\text { Practice } \\
\text { Residual }\end{array}$ & $\begin{array}{r}708.391 \\
64.768 \\
1111.043\end{array}$ & $\begin{array}{r}7 \\
2 \\
126\end{array}$ & $\begin{array}{r}708.391 \\
32.384 \\
8.818\end{array}$ & $\begin{array}{r}80.337 \\
3.673\end{array}$ & $\begin{array}{l}.000 * \\
.028\end{array}$ \\
\hline \multirow[t]{4}{*}{ Total } & 1884.202 & 129 & 14.606 & & \\
\hline & \multicolumn{5}{|c|}{ Adjusted Practice Group Means (gwpm) } \\
\hline & \multicolumn{3}{|c|}{ Group } & \multicolumn{2}{|l|}{ Adjusted Mean } \\
\hline & \multicolumn{3}{|c|}{$\begin{array}{l}\text { Prose } \\
\text { Left-hand/right-hand Equal } \\
\text { Left-hand/right-hand Prescribed }\end{array}$} & $\begin{array}{l}5.84 \\
6.61 \\
7.56\end{array}$ & \\
\hline
\end{tabular}

*Significant beyond the .001 level.

The probability of the calculated $\underline{F}$ value of 3.673 is .028 , with 2 and 126 degrees of freedom. Therefore, in the high initial speed level classification, the statistical hypothesis that the right-hand accuracy means of the populations for the various treatment levels are equal was rejected.

The statistical hypothesis for each pair-wise mean comparison was tested at the .05 level of confidence, using the Tukey test. With 2 and 126 degrees of freedom, the estimated standard error of the mean is .4526 and the significant range is 1.52 . 
The adjusted means of the PROSE group (5.84) and the LHRH-E group (6.61) differed by $.77 \mathrm{epm}$. The statistical hypothesis that the right-hand accuracy means of the populations for the PROSE group and the LHRH-E group are equal was not rejected.

The adjusted means of the PROSE group (5.84) and the LHRH-P group (7.56) differed by $1.72 \mathrm{epm}$. The statistical hypothes is that the right-hand accuracy means of the populations for the PROSE group and the LHRH-P group are equal was rejected. On right-hand accuracy, the adjusted mean on the LHRH-P group was significantly greater than the adjusted mean of the PROSE group:

The adjusted means of the LHRH-E group (6.61) and the LHRH-P group (7.56) differed by $.95 \mathrm{epm}$. The statistical hypothesis that the right-hand accuracy means of the populations for the LHRH-E group and the LHRH-P group are equal was not rejected.

Summary. In the analysis of covariance for the high initial speed level classification, four of six statistical hypotheses were rejected: straight-copy speed, left-hand speed, right-hand speed, and right-hand accuracy.

On straight copy speed, pair-wise mean comparisons showed a significant difference between the PROSE group and the LHRH-E group in favor of the PROSE group; no other significant differences between groups were found.

On left-hand speed, pair-wise mean comparisons showed a significant difference between the PROSE group and the LHRH-P group in favor of the LHRH-P group; no other significant differences between groups were found. 
On right-hand speed, pair-wise mean comparisons showed a significant difference between each pair of means. The LHRH-P group was significantly higher than the LHRH-E group which was significantly higher than the PROSE group.

On right-hand accuracy, pair-wise mean comparisons showed a significant difference between the PROSE group and the LHRH-P group in favor of the PROSE group. No other significant differences were found.

Table XXVII provides a summary of hypothesis testing for the high initial speed level classification. Adjusted speed means are reported in gwpm; adjusted error means are reported in epm. 
TABLE XXVII

SUMMARY OF HYPOTHESIS TESTING--HIGH SPEED LEVEL

\begin{tabular}{|c|c|c|c|c|}
\hline \multirow{2}{*}{$\frac{\text { Variable }}{\text { Straight-copy Speed }}$} & \multirow{2}{*}{$\frac{\mathrm{p}}{.002 \star \star}$} & \multicolumn{3}{|c|}{ Adjusted Means* } \\
\hline & & LHRH-E & LHRH-P & PROSE \\
\hline & & 33.26 & 34.33 & 35.72 \\
\hline \multirow[t]{2}{*}{ Straight-copy Accuracy } & .872 & LHRH-E & PROSE & LHRH-P \\
\hline & & 3.49 & 3.36 & 3.33 \\
\hline \multirow[t]{2}{*}{ Left-hand Speed } & $.027 * *$ & PROSE & LHRH-E & LHRH-P \\
\hline & & 34.60 & 35.66 & 36.36 \\
\hline \multirow[t]{2}{*}{ Left-hand Accuracy } & .489 & LHRH-E & LHRH-P & PROSE \\
\hline & & 6.45 & 6.08 & 5.73 \\
\hline \multirow[t]{2}{*}{ Right-hand Speed } & $.000 * *$ & PROSE & LHRH-E & LHRH-P \\
\hline & & 30.72 & 33.44 & 36.17 \\
\hline \multirow[t]{2}{*}{ Right-hand Accuracy } & $.028 * \star$ & LHRH-P & LHRH-E & PROSE \\
\hline & & 7.56 & 6.61 & 5.84 \\
\hline
\end{tabular}

* Lines between Adjusted Means indicate significant differences. No line indicates that the difference was not significant at the .05 Tevel.

**The statistical hypothesis for covariance was rejected.

Hypothes is Testing--Low Speed Level

There were 44 subjects in the Prose (PROSE) group, 48 subjects in the Left-hand/right-hand Equal (LHRH-E) group and 38 subjects in 
the Left-hand/right-hand Prescribed (LHRH-P) group for a total of 130

subjects in the model replicated for the low initial speed level

classification.

Straight-copy speed. Table XXVIII summarizes the results of the analysis of covariance including adjusted group means for the low initial speed level classification on the dependent variable, straight-copy speed. Pretest straight-copy speed was used as the covariate.

TABLE XXVIII

STRAIGHT-COPY SPEED: ANALYSIS OF COVARIANCE AND ADJUSTED GROUP MEANS FOR THE LOW INITIAL SPEED LEVEL CLASSIFICATION

\begin{tabular}{|c|c|c|c|c|c|}
\hline $\begin{array}{l}\text { Source of } \\
\text { Variation }\end{array}$ & $\begin{array}{l}\text { Sum of } \\
\text { Squares }\end{array}$ & $\underline{d f}$ & $\begin{array}{l}\text { Mean } \\
\text { Square }\end{array}$ & $\underline{F}$ & $\mathrm{p}$ \\
\hline $\begin{array}{l}\text { Covariate } \\
\text { Practice } \\
\text { Residual }\end{array}$ & $\begin{array}{r}1986.124 \\
1.996 \\
1024.142\end{array}$ & $\begin{array}{r}1 \\
2 \\
126\end{array}$ & $\begin{array}{r}1986.124 \\
.998 \\
8.128\end{array}$ & $\begin{array}{r}244.352 \\
.123\end{array}$ & $\begin{array}{l}.000 * \\
.885\end{array}$ \\
\hline \multirow[t]{4}{*}{ Total } & 3012.263 & 129 & 23.351 & & \\
\hline & \multicolumn{5}{|c|}{ Adjusted Practice Group Means (gwpm) } \\
\hline & \multicolumn{2}{|c|}{ Group } & & Adjusted Mean & \\
\hline & \multicolumn{3}{|c|}{$\begin{array}{l}\text { Prose } \\
\text { Left-hand/right-hand Equal } \\
\text { Left-hand/right-hanu Frescribed }\end{array}$} & $\begin{array}{l}22.79 \\
22.60 \\
22.90\end{array}$ & \\
\hline
\end{tabular}

*Significant beyond the .001 level.

The probability of the calculated $E$ value of .123 is .885 , with 
2 and 126 degrees of freedom. Therefore, in the low initial speed Tevel classification, the statistical hypothesis that the straightcopy speed means of the populations for the various treatment levels are equal was not rejected.

Straight-copy accuracy. Table XXIX summarizes the results of the analysis of covariance, including adjusted group means for the low initial speed level classification on the dependent variable, s.traight-copy accuracy. Pretest straight-copy accuracy was used as the covariate.

TABLE XXIX

STRAIGHT-COPY ACCURACY: ANALYSIS OF COVARIANCE AND ADJUSTED GROUP MEANS FOR THE LOW INITIAL SPEED LEVEL CLASSIFICATION

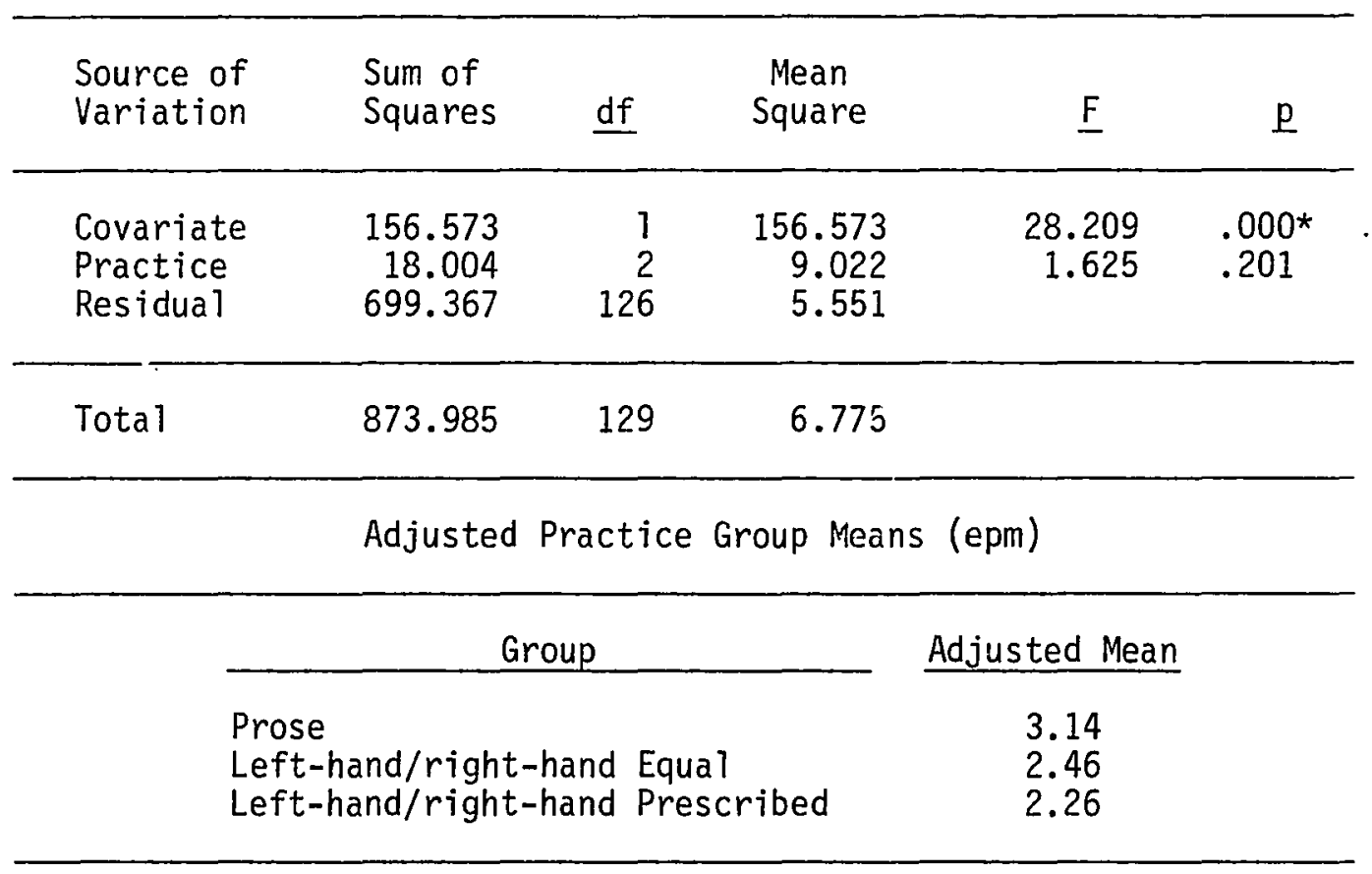

*Significant beyond the .001 level. 
The probability of the calculated $\underline{F}$ value of 1.625 is .201 , with 2 and 126 degrees of freedom. Therefore, in the low initial speed level classification, the statistical hypothesis that the straight-copy accuracy means of the populations for the various treatment levels are equal was not rejected.

Left-hand speed. Table XXX summarizes the results of the analysis of covariance, including adjusted group means for the low initial speed level classification on the dependent variable, left-hand speed. Pretest left-hand speed was used as the covariate.

TABLE XXX

LEFT-HAND SPEED: ANALYSIS OF COVARIANCE AND ADJUSTED GROUP MEANS FOR THE LOW INITIAL SPEED LEVEL CLASSIFICATION

\begin{tabular}{|c|c|c|c|c|c|}
\hline $\begin{array}{l}\text { Source of } \\
\text { Variation }\end{array}$ & $\begin{array}{l}\text { Sum of } \\
\text { Squares }\end{array}$ & $\underline{d f}$ & $\begin{array}{l}\text { Mean } \\
\text { Square }\end{array}$ & $\underline{F}$ & $\mathrm{p}$ \\
\hline $\begin{array}{l}\text { Covariate } \\
\text { Practice } \\
\text { Residual }\end{array}$ & $\begin{array}{r}2660.526 \\
107.118 \\
834.185\end{array}$ & $\begin{array}{r}7 \\
2 \\
126\end{array}$ & $\begin{array}{r}2660.526 \\
53.559 \\
6.621\end{array}$ & $\begin{array}{r}401.861 \\
8.090\end{array}$ & $\begin{array}{l}.000 * \\
.000 *\end{array}$ \\
\hline Tota 1 & 3601.829 & 129 & 27.921 & & \\
\hline
\end{tabular}

Adjusted Practice Group Means (gwpm) *-

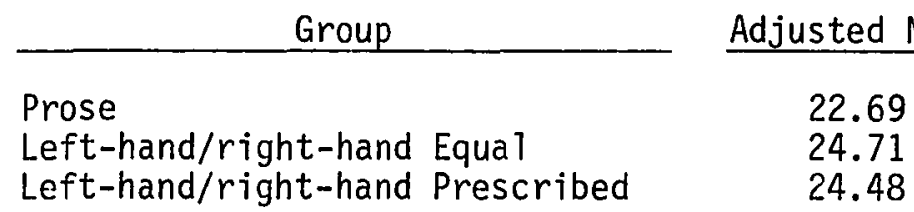

*Significant beyond the .001 level. 
The probability of the calculated $\underline{F}$ value of 8.090 is beyond .001 , with 2 and 126 degrees of freedom. Therefore, in the low initial speed level classification, the statistical hypothesis that the left-hand speed means of the populations for the various treatment levels are equal was rejected.

The statistical hypothesis for each pair-wise mean comparison was tested at the .05 level of confidence, using the Tukey test. With 2 and 126 degrees of freedom, the estimated standard error of the mean is .3962 and the significant range is 1.33 .

The adjusted means for the PROSE group (22.69) and the LHRH-E group (24.71) differed by 2.02 gwpm. The statistical hypothes is that the left-hand speed means of the populations for the PROSE and the LHRH-E group are equal was rejected. The adjusted mean of the LHRH-E group was significantly higher than the adjusted mean of the PROSE group.

The adjusted means for the PROSE group (22.69) and the LHRH-P group (24.48) differed by $1.79 \mathrm{gwpm}$. The statistical hypothes is that the left-hand speed means of the populations for the PROSE and the LHRH-P group are equal was rejected. The adjusted mean of the LHRH-P group was significantly higher than the adjusted mean of the PROSE group.

The adjusted means for the LHRH-E group (24.71) and the LHRH-P group (24.48) differed by $.23 \mathrm{gwpm}$. The statistical hypothesis that the left-hand speed means of the populations for the LHRH-E group and the LHRH-P group are equal was not rejected.

Left-hand accuracy. Table XXXI summarizes the results of the 
analysis of covariance, including adjusted group means for the low initial speed level classification on the dependent variable, left-hand accuracy. Pretest Teft-hand accuracy was used as the covariate.

TABLE XXXI

LEFT-HAND ACCURACY: ANALYSIS OF COVARIANCE AND ADJUSTED GROUP MEANS FOR THE LOW INITIAL SPEED LEVEL CLASSIFICATION

\begin{tabular}{lrrrrrr}
\hline $\begin{array}{l}\text { Source of } \\
\text { Variation }\end{array}$ & $\begin{array}{l}\text { Sum of } \\
\text { Squares }\end{array}$ & df & $\begin{array}{c}\text { Mean } \\
\text { Square }\end{array}$ & $\underline{F}$ & $\underline{p}$ \\
\hline $\begin{array}{l}\text { Covariate } \\
\text { Practice } \\
\text { Residual }\end{array}$ & $\begin{array}{r}732.217 \\
26.330\end{array}$ & $\begin{array}{r}1 \\
1165.075\end{array}$ & 126 & $\begin{array}{r}732.217 \\
13.165 \\
9.247\end{array}$ & $\begin{array}{r}79.188 \\
1.424\end{array}$ & $\begin{array}{l}.000^{*} \\
.245\end{array}$ \\
\hline Total & 1923.622 & 129 & 14.912 & & \\
\hline
\end{tabular}

Adjusted Practice Group Means (epm)

\begin{tabular}{lr} 
Group & Adjusted \\
\cline { 2 - 2 } Prose & 3.86 \\
Left-hand/right-hand Equal & 4.56 \\
Left-hand/right-hand Prescribed & 4.99
\end{tabular}

*Significant beyond the .001 level.

The probability of the calculated $\underline{F}$ value of 1.424 is .245 , with 2 and 126 degrees of freedom. Therefore, in the low initial speed level classification, the statistical hypothesis that the left-hand accuracy means of the populations for the various treatment levels are equal was not rejected. 
Right-hand speed. Table XXXII summarizes the results of the analysis of covariance, including adjusted group means for the low initial speed level classification on the dependent variable, right-hand speed. Pretest right-hand speed was used as the covariate.

TABLE XXXII

RIGHT-HAND SPEED: ANALYSIS OF COVARIANCE AND ADJUSTED GROUP MEANS FOR THE LOW INITIAL SPEED LEVEL CLASSIFICÁTION

\begin{tabular}{lrrrrrr}
\hline $\begin{array}{l}\text { Source of } \\
\text { Variation }\end{array}$ & $\begin{array}{c}\text { Sum of } \\
\text { Squares }\end{array}$ & df & $\begin{array}{c}\text { Mean } \\
\text { Square }\end{array}$ & $\underline{F}$ & $\mathrm{p}$ \\
\hline $\begin{array}{l}\text { Covariate } \\
\text { Practice } \\
\text { Residual }\end{array}$ & $\begin{array}{r}1778.604 \\
238.864 \\
1311.014\end{array}$ & $\begin{array}{r}1 \\
2\end{array}$ & $\begin{array}{r}1778.604 \\
119.432 \\
10.405\end{array}$ & $\begin{array}{r}170.940 \\
11.478\end{array}$ & $\begin{array}{l}.000^{*} \\
.000^{*}\end{array}$ \\
\hline Total & 3328.483 & 129 & 25.802 & & \\
\hline
\end{tabular}

Adjusted Practice Group Means (gwpm)

\begin{tabular}{|c|c|}
\hline Group & Adjusted Mean \\
\hline $\begin{array}{l}\text { Prose } \\
\text { Left-hand/right-hand Equal } \\
\text { Left-hand/right-hand Prescribed }\end{array}$ & $\begin{array}{l}21.61 \\
24.35 \\
24.65\end{array}$ \\
\hline
\end{tabular}

*Significant beyond the .001 level.

The probability of the calculated $\underline{F}$ value of 11.478 is beyond .001 , with 2 and 126 degrees of freedom. Therefore, in the low initial speed level classification, the statistical hypothesis that the right-hand speed means of the populations for the various treatment levels are equal was rejected. 
The statistical hypothesis for each pair-wise mean comparison was tested at the .05 level of confidence, using the Tukey test. With 2 and 126 degrees of freedom, the estimated standard error of the mean is .4951 and the significant range is 1.66 .

The adjusted means for the PROSE group (21.61) and the LHRH-E group (24.35) differed by $2.74 \mathrm{gwpm}$. The statistical hypothes is that the right-hand speed means of the populations for the PROSE group and the LHRH-E group are equal was rejected. On right-hand speed, the adjusted mean of the LHRH-E group was significantly greater than the adjusted mean of the PROSE group.

The adjusted means for the PROSE group (21.6i) and the LHRH-P group (24.65) differed by $3.04 \mathrm{gwpm}$. The statistical hypothesis that the right-hand speed means of the populations for the PROSE and the LHRH-P group are equal was rejected. On right-hand speed, the adjusted mean of the LHRH-P group was significantly greater than the adjusted mean of the PROSE group.

The adjusted means for the LHRH-E group (24.35) and the LHRH-P group (24.65) differed by .30 gwpm. The statistical hypothesis that the right-hand speed means of the populations for the LHRH-E group and the LHRH-P group are equal was not rejected.

Right-hand accuracy. Table XXXIII summarizes the results of the analysis of covariance, including adjusted group means for the low initial speed level classification on the dependent variable, right-hand accuracy. Pretest right-hand accuracy was used as the covariate. 
TABLE XXXIII

RIGHT-HAND ACCURACY: ANALYSIS OF COVARIANCE AND ADJUSTED GROUP MEANS FOR THE LOW INITIAL SPEED LEVEL CLASSIFICATION

\begin{tabular}{|c|c|c|c|c|c|}
\hline $\begin{array}{l}\text { Source of } \\
\text { Variation }\end{array}$ & $\begin{array}{l}\text { Sum of } \\
\text { Squares }\end{array}$ & $\underline{\mathrm{df}}$ & $\begin{array}{l}\text { Mean } \\
\text { Square }\end{array}$ & $\underline{F}$ & $\underline{P}$ \\
\hline $\begin{array}{l}\text { Covariate } \\
\text { Practice } \\
\text { Residual }\end{array}$ & $\begin{array}{r}924.582 \\
62.040 \\
1265.350\end{array}$ & $\begin{array}{r}7 \\
2 \\
126\end{array}$ & $\begin{array}{r}924.582 \\
31.020 \\
10.042\end{array}$ & $\begin{array}{r}92.067 \\
3.089\end{array}$ & $\begin{array}{l}.000 * \\
.049\end{array}$ \\
\hline \multirow[t]{4}{*}{ Total } & 2251.973 & 129 & 17.457 & & \\
\hline & \multicolumn{5}{|c|}{ Adjusted Practice Group Means (epmil) } \\
\hline & \multicolumn{3}{|c|}{ Group } & Adjusted Mean & \\
\hline & \multicolumn{3}{|c|}{$\begin{array}{l}\text { Prose } \\
\text { Left-hand/right-hand Equal } \\
\text { Left-hand/right-hand Prescribed }\end{array}$} & $\begin{array}{l}4.08 \\
5.30 \\
5.75\end{array}$ & \\
\hline
\end{tabular}

*Significant beyond the .001 level.

The probability of the calculated $E$ value of 3.089 is .049 , with 2 and 126 degrees of freedom. Therefore, in the low initial speed level classification, the statistical hypothesis that the right-hand accuracy means of the populations for the various treatment levels are equal was rejected.

The statistical hypothesis for each pair-wise mean comparison was tested at the .05 level of confidence, using the Tukey test. With 2 and 126 degrees of freedom, the estimated standard error of the mean is .4868 and the significant range is 1.64 . 
The adjusted means of the PROSE group (4.08) and the LHRH-E group (5.30) differed by $1.22 \mathrm{epm}$. The statistical hypothesis that the right-hand accuracy means of the populations for the PROSE group and the LHRH-E group are equal was not rejecteut.

The adjusted means of the PROSE group (4.08) and the LHRH-P group (5.75) differed by $1.67 \mathrm{epm}$. The statistical hypothesis that the right-hand accuracy means of the populations for the PROSE group and the LHRH-P group are equal was rejected. On right-hand accuracy, the adjusted mean of the LHRH-P group was significantly greater than the adjusted mean of the PROSE group.

The adjusted means of the LHRH-E group (5.30) and the LHRH-P group (5.75) differed by .45 . The statistical hypothesis that the right-hand accuracy means of the populations for the LHRH-E group and the LHRH-P group are equal was not rejected.

Summary. In the analysis of covariance for the low initial speed level classification, three of six statistica? hypotheses for the main effects of practice were rejected: left-hand speed, right-hand speed, and right-hand accuracy.

On left-hand speed, pair-wise mean comparisons showed significant differences between the PROSE group and the LHRH-E group in favor of the LHRH-E group and between the PROSE group and the LHRH-P group in favor of the LHRH-P group; no significant difference was found between the LHRH-E group and the LHRH-P group.

On right-hand speed, pair-wise mean comparisons showed significant differences between the PROSE group and the LHRH-E group in favor of the LHRH-E group and between the PROSE group and the 
LHRH-P group in favor of the LHRH-P group. No significant difference was found between the LHRH-E group and the LHRH-P group.

On right-hand accuracy, pair-wise mean comparisons showed a significant difference between the PROSE group and the LHRH-P group in favor of the PROSE group; no other significant differences were found. Table XXXIV provides a summary of hypothesis testing for the low initial speed level classification. Adjusted speed means are reported in gwpm; adjusted error means are reported in epm. 
TABLE XXXIV

SUMMARY OF HYPOTHESIS TESTING--LOW SPEED LEVEL

\begin{tabular}{|c|c|c|c|c|}
\hline \multirow{2}{*}{$\frac{\text { Variable }}{\text { Straight-copy Speed }}$} & \multirow{2}{*}{$\frac{\mathrm{p}}{.885}$} & \multicolumn{3}{|c|}{ Adjusted Means* } \\
\hline & & LHRH-E & PROSE & LHRH-P \\
\hline & & 22.60 & 22.79 & 22.90 \\
\hline \multirow[t]{2}{*}{ Straight-copy Accuracy } & .201 & PROSE & LHRH-E & LHRH-P \\
\hline & & 3.14 & 2.46 & 2.26 \\
\hline \multirow[t]{2}{*}{ Left-hand Speed } & $.000 \star \star$ & PROSE & LHRH -P & LHRH-E \\
\hline & & 22.69 & 24.48 & 24.71 \\
\hline \multirow[t]{2}{*}{ Left-hand Accuracy } & .245 & $\underline{\text { LHRH-P }}$ & LHRH-E & PROSE \\
\hline & & 4.99 & 4.56 & 3.86 \\
\hline \multirow[t]{2}{*}{ Right-hand Speed } & $.000 * \star$ & PROSE & LHRH-E & LHRH-P \\
\hline & & 21.61 & 24.35 & 24.65 \\
\hline \multirow[t]{2}{*}{ Right-hand Accuracy } & $.049 * *$ & LHRH-P & LHRH-E & PROSE \\
\hline & & 5.75 & 5.30 & 4.08 \\
\hline $\begin{array}{l}\text { * Lines between Adjuste } \\
\text { line indicates that } t \\
\text { leve } 1 . \\
\text { **The statistical hypot }\end{array}$ & $\begin{array}{l}\text { ans inc } \\
\text { ifferen }\end{array}$ & $\begin{array}{l}\text { signific } \\
\text { not sig }\end{array}$ & $\begin{array}{l}\text { differ } \\
\text { icant a }\end{array}$ & s. No \\
\hline
\end{tabular}




\title{
CHAPTER $V$
}

\author{
SUMMARY, CONCLUSIONS, IMPLICATIONS, AND \\ RECOMMENDATIONS FOR FURTHER STUDY
}

\begin{abstract}
This chapter presents an overview of the study, conclusions, implications for educational theory and methods, and recommendations for further study.
\end{abstract}

\section{Overview of the Study}

The major focus of this study was to compare the effects of prose practice and a specialized drill, left-hand/right-hand practice, on the development of straight-copy typewriting speed and accuracy. A secondary focus was to compare the effects of the practice on left-hand and right-hand speed and accuracy. In addition, the effects of the practices on stroking skills were examined for subjects with high and low initial straight-copy abilities.

\section{Methods and Procedures}

In the experimentai design, subjects from twelve classes at three selected southeastern Minnesota high schools were randomly assigned to three types of practice: 1) Prose, ordinary prose copy containing no special combinations of words, 2) Left-hand/right-hand Equal, copy containing an equal number of left-hand lines and right-hand Tines, and 3) Left-hand/right-hand Prescribed, copy 
containing a proportionate number of left-hand and right-hand lines depending on diagnosed pretest abilities. In the prescribed group, subjects with a weaker right hand practiced more lines with the right hand; subjects with a weaker left hand practiced more lines with the left hand.

There were six dependent variables included in the study: straight-copy speed, straight-copy accuracy, left-hand speed, left-hand accuracy, right-hand speed, and right-hand accuracy.

Pretest and posttest measures of the dependent variable criteria were obtained by the administration of two different three-minute straight-copy timed writings, three different one-minute left-hand timed writings, and three different one-minute right-hand timed writings on each occasion.

The five teachers involved in the study were carefully trained in testing procedures and in the procedures for conducting the practice sessions.

The practice sessions involved five minutes of practice per day, for fifteen days (75 minutes of treatment), for approximately three weeks during the middle of first semester; 1982-1983. Subjects received individualized packets of five pages of practice lines corresponding to their assigned treatments. During the timed five minutes of practice which included typing time only, subjects were advised to type at a slightiy faster than comfortable rate. Aii practice sessions were monitored by the instructors and student typescripts were collected in order to ensure adherence to the rules of practice. 
The statistical hypothesis that on the dependent variable of interest the means of the populations for the three treatment levels are equal was tested for the total sample and for the high and low initial speed level classifications separately. Subjects with pretest straight-copy speeds of $21.0 \mathrm{gwpm}$ and above were placed in the high initial speed level classification; subjects with speeds below 21.0 gwpm were placed in the low initial speed level classification.

Aralysis of covariance was used to test the eighteen statistical hypotheses, using respective pretest measures of the dependent variable criteria as covariates. Statistical significance at the .05 level of confidence was required to reject the statistical hypotheses.

\section{Findings}

An examination of the raw score pretest and posttest data and the types of prescriptions given to members of the prescribed group revealed a high number of students with right-hand weakness. Right-hand speed scores were consistently lower than left-hand speed scores.

Total sample. In testing the statistical hypothesis for the total sample $(\underline{n}=260)$, four hypotheses were rejected. There were significant differences among the practice groups on straight-copy speed, left-hand speed, right-hand speed, and right-hand accuracy. There were no significant differences among the groups on straight-copy accuracy or Teft-hand accuracy.

Following rejection for the main effects of the practice, pair-wise mean comparisons, using the Tukey test, were conducted to 
test the statistical hypothesis that on the dependent variable of interest the means of the populations for each pair of groups are equal. The Tukey tests showed: (1) a significant difference between the PROSE group and LHRH-E group, in favor of the PROSE group, on straight-copy speed; (2) significant differences between the PROSE group and LHRH-E group, in favor of the LHRH-E group, and between the PROSE and LHRH-P group, in favor of the LHRH-P group, on left-hand speed; (3) significant differences among all three pairs on right-hand speed with the LHRH-P group being significantly higher than LHRH-E group which was significantly higher than PROSE group; and (4) a significant difference between the PROSE group and the LHRH-P group, in favor of the PROSE group, on right-hand accuracy. Other pair-wise mean comparisons for the four dependent variables did not result in significant differences.

High speed level. In testing the statistical hypothesis for the high initial speed level classification $(\underline{n}=130)$, four hypotheses were rejected. There were significant differences among the practice groups on straight-copy speed, left-hand speed, right-hand speed, and right-hand accuracy. There were no significant differences among the groups on straight-copy accuracy or left-hand accuracy.

Subsequent pair-wise mean comparisons, using the Tukey test, revealed: (1) a significant difference between the PROSE group and the LHRH-E group, in favor of the PROSE group, on straight-copy speed; (2) a significant difference between the PROSE group and the LHRH-P group, in favor of the LHRH-P group, on left-hand speed; (3) significant differences among all three pairs on right-hand speed, 
with the LHRH-P group being significantly faster than the LHRH-E group which was significantiy faster than the PROSE group; and (4) a significant difference between the PROSE group and the LHRH-P group, in favor of the PROSE group, on right-hand accuracy. Other pair-wise mean comparisons for the four dependent variables did not result in significant differences.

Low speed level. In testing the statistical hypothesis for the low initial speed level classification $(\underline{n}=130)$, three hypotheses were rejected. There were significant differences among the practice groups on left-hand speed, right-hand speed, and right-hand accuracy. There were no significant differences among the groups on straight-copy speed, straight-copy accuracy, or left-hand accuracy. Subsequent pair-wise mean comparisons, using the Tukey test, showed: (1) a significant difference between the PROSE group and the LHRH-E group, in favor of the LHRH-E group, and between the PROSE group and the LHRH-P group, in favor of the LHRH-P group, on left-hand speed; (2) significant differences between the PROSE group and the LHRH-E group, in favor of the LHRH-E group, and between the PROSE group and the LHRH-P group, in favor of the LHRH-P group, on right-hand speed; and (3) a significant difference between the PROSE group and the LHRH-P group, in favor of the PROSE group, on right-hand accuracy. Other pair-wise mean comparisons for the three dependent variables did not result in significant differences.

\section{Conclusions}

The findings of this study support the following conclusions: 
1. Practice using prose copy is more effective than practice using equal amounts of left-hand/right-hand copy in the development of straight-copy speed for students with initial straight-copy ability of $21.0 \mathrm{gwpm}$ or higher.

2. Left-hand/right-hand practice in equal or prescribed amounts is more effective than prose practice in the development of left-hand speed.

3. Left-hand/right-hand practice in equal or prescribed amounts is more effective than prose practice in the development of right-hand speed.

4. Left-hand/right-hand practice in prescribed amounts results in more errors per minute on right-hand copy than does practice using prose copy.

5. Significartiy improving one-handed keystroking skill does not improve straight-copy stroking skill.

\section{Implications}

A comparison of pretest measures in this study shows right-hand speed scores were slower than left-hand and straight-copy speed scores and that right-hand accuracy scores tended to be higher than left-hand and straight-copy accuracy scores. This finding is consistent with the work of Beaumont (1968), Robinson (1972a), Winger (1965), and others who point to the characteristic weakness of the right hand in typewriting activities.

The findings of this study do not support Winger (1965; 1974), Robinson and Lessenberry (1977), Hal1 (1981; 1982), and others in the 
proposition that improving right-hand ability will improve straightcopy ability. The left-hand/right-hand groups achieved significantly higher left-hand and right-hand speeds than did the Prose group and showed decreases in the difference between left-hand and right-hand mean speeds from pretest to posttest (larger decrease in the Prescribed group) in comparison to an increase in difference for the Prose group. However, the left-hand/right-hand groups did not achieve significantly higher straight-copy speeds. In fact, in both the overall and the high initial speed level classification analyses, the Prose group was significantly faster than the Left-hand/Right-hand Equal group on straight-copy speed.

The findings of the study are similar to the results of a study by Shannon and Robertson (Note 2) of postsecondary typing students; they concluded that improving one-handed keystroking does not improve straight-copy skill. In addition, the left-hand/right-hand groups did not achieve significantly greater straight-copy, left-hand, or right-hand accuracy. The findings regarding accuracy support West's (1969, 1974, 1983) position that specialized drill materials, such as left-hand/right-hand, are of no value in the development of stroking skills. The findings and conclusions are consistent with those of Long (1977) and Prater (1976) who did not find contrived materials to be effective in the development of straight-copy speed and accuracy.

The findings and conclusions of this study, in conjunction with the findings of Shannon and Robertson (Note 2), Long (1977), and Prater (1976), provide strong evidence to support the elimination of left-hand/right-hand drills from typewriting skillbuilding programs. 
for high school and college students. These drills show no proven benefit to the development of straight-copy speed and accuracy which is the primary focus of straight-copy skillbuilding. Also, there is evidence to suggest that their use may impair straight-copy skill deveropment.

The findings and conclusions of the study may give rise to more far-reaching implications for typewriting instruction and methodology. If one such specialized drill shows no proven benefit and possible negative consequences to straight-copy skill development, are there benefits to using any other types of specialized drills in contrast to practice on ordinary prose copy?

\section{Recommendations for Further Study}

This study should be replicated involving subjects of higher straight-copy ability, i.e., intermediate and advanced high school and postsecondary typewriting classes, in order to compare the effects of the three types of practice on straight-copy speed. The results of this study indicate that there is support for using only prose practice, especially for students at higher straight-copy speeds.

Experimental evidence regarding the effectiveness of other specialized drills in contrast to prose would be beneficial in determining the proper components of skillbuilding programs. Experimental research similar to the left-hand/right-hand study should be conducted to validate the inclusion of other specialized drills, such as double-letter, reach stroke, concentration, and repetition, in the typewriting program. 


\section{REFERENCE NOTES}

1. Winger, F. Methods of teaching typewriting. Workshop presented at Portland State University, Portland, April 1982.

2. Shannon, B. \& Robertson, L. A comparison of the effects of practicing ordinary prose and left-hand/right-hand copy upon the development of keystroking skills (Faculty Working Paper, BUED, 81-2). Unpublished manuscript, Portland State University, 1981. 


\section{BIBLIOGRAPHY}

Beaumont, Lee R. H. The effect of balanced-hand and one-hand stroking upon the difficulty of typewriting copy (Doctoral dissertation, University of Pittsburgh, 1969). Dissertation Abstracts Internationa 1, $1969,30,2413 \mathrm{~A}$. (University Nicrofilms No. 69-27, 036)

Dvorak, A. = Merrick, N. L., Dca?cy, w. L., \& Fürù, G. C. Typewriting behavior. New York: American Book, 1936.

Erickson, L. W. An analysis of the control concept in typewriting, In J.W. Robinson (Ed.), Practices and preferences in teaching typewriting. Cincinnati: South-Western, 1967.

Hall, R. Pretest/practice/posttest--a teaching technique with student appeal. Business Education World, 1981, 62(2), 3-4.

Ha11, R. Opening activities for the typewriting class. Business Education Forum, 1982, 36(5), 9-11.

Holmes, A. \& Eide, C. Skillbuilding--a positive approach to improve keyboarding. Business Education Forum, 1981, 36(3), 13-14.

Javed, L. The effect of handedness on typewriting performance. BSU Journal for Business Educators, Fal1 1975, pp. 8-18.

Lloyd, A. C., Poland, R. P., Rowe, J. L., Winger, F. E., \& Griffith, W. D. Selective practice typing drills. New York: Gregg/McGraw-Hi11, 1974.

Long, $M$. The effects of ordinary prose copy and contrived copy upon the development of keystroking (copying) skill (Doctoral dissertation, University of Pennsylvania, 1977). Dissertation Abstracts Internationa $1,1977,38,5202 \mathrm{~A}-5203 \mathrm{~A}$. (University Microfilms No. 7801813)

Nie, N., Hu11, C., Jenkins, J., Steinbrenner, K. \& Bent, D. Statistical package for the social sciences. New York: McGraw-HiTh, 1975.

Prater, C. The effects of intelligence and types of drill materials on achievement in intermediate college typewriting (Doctoral dissertation, Michigan State University, 1976). Dissertation Abstracts International, 1976, 37, 1087A-1088A. TUniversity Microfilms No. 76-18, 665) 
Robinson, J. The relation of copy difficulty upon typewriting performance, Delta Pi Epsilon Journal, 1967, $\underline{9}(2), 9-24$.

Robinson, J. Typewriting accuracy: myth or mystery? Delta Pi Epsilon Journal, 1972, 14(2), 13-27. (a)

Robinson, J. (Ed.) Strategies of instruction in typewriting. Cincinnati. South-Western, 1972. (D)

Robinson, J., Erickson, L., Crawford, T. : Beaumont, L., \& Ownby, A. Typewriting--iearning and instruction, Cincinnati: South-Western, 1979.

Robinson J. \& Lessenberry, D. Relationship between keysiroking content of initial typewriting practice and "real world" communication. National Association of Business Teacher Education Review, 1977, No. 4, pp. 35-41.

Webster's new collegiate dictionary. Springfield, Mass.: Merriam, 1973.

West, L. Acquisition of typewriting ski1ls. New York: Pitman, 1969.

West, L. Implications of research for teaching typewriting (2nd ed.). Delta Pi Epsilon Research Butletin, No. 4, 1974.

West, L. Modern college typewriting--a complete course. New York: Harcourt Brace Jovanovich, 1977.

West, L. Acquisition of typewriting skills (2nd ed.). Indianapolis: Bobbs-Merri71, 1983.

Wildt, A. \& Ahtola, 0. Analysis of covariance. Series: Quantitative applications in the social sciences. Beverly Hills: Sage Publications, 1978.

Winger, F. Errors: their cause and cure. In J. L. Rowe (Ed.), Methods of teaching typewriting. 38th Yearbook, Eastern Business Teacher Association, 1965. pp. 77-89.

Winger, F. Pretest--practice--post-test: an action research project on two campuses. Business Education World, 1974, 54(3), 5-8. 
A P PENDICES 
APPENDIX A

PROSE PRACTICE

\section{DIRECTIOONS:}

1. DO NOT TYPE practice lines until your instructor tells you to do so.

2. In the upper right hand corner, label your color-coordinated practice paper as follows:

School/Teacher

Class time

Your name (1ast name first)

PROSE

Date

3. Set margins of 18 and 90 . Single spacing.

4. Type lines as written. Do not type line numbers. Do not correct errors.

5. Type at a rate that is slightly faster than is comfortable. Use both sides of the practice paper if necessary.

6. When the five minutes of practice is completed:

1) count the number of completed lines typed and write the number at the top of your practice paper next to the date.

2) mark the practice line that you will start with the next day by circling the line number with a pencil.

7. If you finish the materials provided before the study is concluded, start the packet over.

8. Turn in your practice work and the practice materials to your instructor. 
1. The war against inflation has been fought partially at the

2. expense of beginning farmers, says William Dobson, who just

3. finished a year-long stint on the Council of Economic Advis-

4. ors. Farmers will have to fight back as best they can, he

5. says, by becoming more efficient and specializing more, but

6. the next five years will be tough ones for American agricul-

7. ture, Dobson says. One way to improve efficiency might be

8. through the development of two-family farms in which one farm-

9. er specializes in grain and the other in the dairy side of the

10. operation, Dobson said. "There are benefits to specialization

11. in farming just as there are in other businesses, and it has

12. the important side benefit of allowing the farmer to take a

13. vacation once in awhile," he said in an interview. But the

14. effect of innovations like two-family farms is likely to be

15. dwarfed over the next several years by basic changes in the

16. economics of farming, symptoms of which have become evident

17. only in the last years or so, Dobson said. With commodity

18. prices low, farmland values dropping, and interest rates high

19. there is little farmers can do other than retrench, consoli-

20. date, regroup and improve their efficiency. It was an excit-

21. ing time to be in Washington even though the market-oriented

22. Council on Economic Advisors was often the losing side in the

23. administration's policy tussles. "The gains that have been

24. made against inflation, in my opinion, are really monumen-

25. tal," he said, describing himself as optimistic, but not eu-

26. phoric, at the recent improvements in the stock market and

27. interest rates. The Buffalo Courier-Express will cease publi-

28. cation in less than two weeks unless a buyer can be found for

29. the morning newspaper. The shutdown would leave the city with

30. one newspaper, the Buffalo Evening News. Parkinson announced

31. the shutdown at a news conference at the Buffalo Hilton after

32. employees were informed earlier in the day. "Today is a very

33. sad day for Buffalo and for all of us," Parkinson said. "The

34. paper wiil cease publication with the Sunday issue unless a

35. purchaser can be found." Parkinson said a shutdown on the

36. paper would mean the loss of jobs. Cowles said the company 
37. has had "conversations with the Evening News" going back al-

38. most to the time of our purchase of the Courier-Express." "As

39. is evident, they resulted in no resolution. We did not find

40. the conversations at 217 encouraging." Two months ago reports

41. circulated through the news industry here that the Courier and

42. the Evening News were talking about merging. Arab leaders

43. conferred in strict secrecy Tuesday at a summit meeting con-

44. vened to define a possible Arab peace strategy for the first

45. time since the creation of the state of Israel. The sources

46. gave no indication of the subjects discussed, but pointed out

47. that the Israeli invasion of Lebanon and its aftermath took

48. top place on the published summit agenda. Lebanon has asked

49. the summit to demand that a11 foreign forces should evacuate

50. all Lebanese territory without delay. It was clear, however,

51. that the most important discussions will center on two Arab

52. peace plans that envisage a general Arab recognition of Israel

53. and a third plan put forward by President Reagan proposing

54. creation of an autonomous Palestinian "domestic authority" in

55. association with Jordan. The United Auto Workers union hopes

56. to come up with a national program to curb absenteeism of the

57. hourly workers at Chrysier Corporation by the expiration of

58. its current contract, a UAW official says. The UA Workers

59. official declined to elaborate on what the national program

60. might entail, but said the union has talked about levying ec-

61. onomic penalties against Chrysler workers with chronic absen-

62. teeism rates. "There used to be a saying that you shouldn't

63. buy a car made on a Monday or Friday because absenteeism was

64. so bad then," Stepp said. "We want to kill that image. We

65. don't want people to think that absenteeism will affect the

66. quality of a Chrysler product." Chrysler negotiators have

67. said they hope to tie such fringe benefits as holiday and va-

68. cation pay and health insurance coverage to attendance. Stepp

69. said the union has yet to reach an agreement with the No. 3

70. U.S. automaker on absenteeism. The voice telling jokes and

71. reporting the weather last week on WDVE-FM sounded a little

72. like a disc jockey with a cold. It was actually a computer 
73. that generates speech from a text. The machine, dubbed "Hal" 74. after the thinking computer in the film "2001" made its first 75. public appearance with disc jockeys Jimmy Roach and Steve Han-

76. sen, promoting records for morning commuters. "This is the 77. world debut. This is a brand new product," said Ron Cole, a 78. research scientist at Carnegie-Mellon University who works

79. with speech recognition by computer and helped run Hal. Its

80. nasal voice was described as sounding like Lawrence Welk, a

81. man with a heavy cold, a French Canadian hockey player, or a

82. man with a Swedish accent. But Cole and station engineer Gary

83. Marince were pleased. "I don't think it taxed the listener.

84. There was enough of a buildup for them to pay close attention

85. When the computer talked," said Marince. One person called 86. the station to ask if he could get a similar computer to help

87. a paralyzed friend. He was put in touch with its developer.

88. To make it work, someone types a sequence of words on the key89. board and sends them to a computer board which converts the 90. string of characters into speech and produces a human-like

91. voice. The computer is programmed with phonemes, the basic 92. units of speech that distinguish one utterance from another 93. in a language. It strings these phonemes together to make

94. words and sentences. The fashions American men will be wear-

95. ing this fall reflect nostalgia for those old enough to remem-

96. ber "the good old days" and the strong basic appeal of hand-

97. somely styled apparel for a whole new generation. Stripes

98. are once again the leading patterns and here, too, in many

99. cases the stripes are more colorful than in the past. It is

100. not unusual to find stripes of two or three colors on a single 101. ground shade. The stylings of the stripes extend from hair-

102. lines to chalk stripes and include pin, pencil broken, and

103. beaded stripes. Double-breasted suits will show a marked in104. crease in popularity. The most popular style continues to be 105. the two-button, single-breasted, but there is a slight re-

106. vival of smooth finished sharkskins, cheviots, saxonies, and, 107. of course, flannels. With white collars on colored and pat108. terned shirts, a strong trend to new colors and revival of 
109. silk shirts that reflect the 1920 's, there is plenty of fash110. jon news in shirts. The white collar syndrome is just about 111. as strong in the conservative traditional shirts as it is in

112. the fashion area, providing a look of elegance without being 113. an overstatement. Patterns, including stripes and to a less114. er extent checks and plaids, will be exceptionally strong.

115. In keeping with the fall season, the solid colored shirtings 116. are a tone or two deeper than those worn in the spring sea117. son. When your old furnace clicks on for the first time this

118. fall, chances are someone in your home will soon complain a119. bout dry skin problems, your plants might wither and die; and 120. you'll notice plastered walls will crack, doors will stick,

121. paneling will buckle, furniture will become unglued, and stat122. ic electricity will crackle from rugs and upholstery. The

123. likely problem is low humidity. Humidification, the process

124. of adding moisture to the air, is extremely important in cold125. er climates. According to home economist, Janet K. Felmeth, 126. a non-humidified home in the north has a lower level of humid-

127. ity than the Sahara Desert. But apart from personal discom128. fort and other problems, she said, there's another reason for 129. considering a humidifier for your home. "The utilities and

130. our government agencies are asking us to lower the settings of 131. our thermostats during the heating season. Because the proper 132. level of humidity makes you feel more comfortable at a lower

133. temperature, you can set your thermostat about two degrees

134. lower." Ms. Felmeth explained. "Tests show that the rotat-

135. ing drum-type system is the most efficient and the least cost-

136. Ty to maintain," Ms. Felmeth continued. "The main parts of a 137. rotating, drum-shaped cylinder with a thick filter belt mount138. ed on the outer surface. The drum, mounted on two pulleys a-

139. way from the highly humid areas of the system, rotates through 140. the water, driven by a powerful motor. Since there are few 141. moving parts, this system is virtually trouble-free. Ameri-

142. cans like to complain about the complexity of figuring how 143. much federal income tax they owe. But are they willing to pay 144. more tax to get a simplified return that would fit on a post- 
145. card? The question will be raised this week as the Senate

146. Finance Committee opens hearings on proposals to radically

147. change the system by eliminating deductions and substituting

148. a "flat tax" in which most people would pay the same percent-

149. age of their income to the government. Despite a flurry of

150. Congressional interest, and polls showing taxpayers favor the

151. concept, there now seems 7 ittle chance such a system will be

152. enacted in the foreseeable future. The chief reason: it would

153. mean higher taxes for middle-and lower-income families. One

154. reason a "flat tax" is not universally popular is that the

155. greater simplicity offers almost nothing for the 69 percent

156. of individuals who do not itemize deductions. Most of the

157. complexity in the current system involves itemized deductions

158. and non-wage income. The flat tax that has drawri most atten-

159. tion was devised by Robert E. Hall and Alvin Rabushka of Stan-

160. ford University. The simplicity of the system would permit a

161. taxpayer to file a return on a form the size of a postcard.

162. Fresh asparagus is available for such a short time that we

163. need to enjoy it while we can. It's been in supermarkets for

164. awhile and just now is starting to appear in area gardens, so

165. it's an ideal time to try some new asparagus recipes. Many

166. people forget that asparagus, served cold, makes a delightful

167. salad. Tender tip ends of asparagus cook faster than stem

168. ends; so for more even cooking, cut tip ends slightly longer

169. than stem ends. Whether you use today's recipes or others

170. for microwaving asparagus, remember timings are only guides.

171. Timings vary according to sizes and initial temperatures of

172. the asparagus. Thin spears need a very short cooking time.

173. For example: a pound of thin asparagus, trimmed and sliced,

174. microwaves to a tender-crisp texture in as little as $2 \frac{1}{2}$ min-

175. utes. If the spring thaw all seems to be thawing into your

176. basement, you're not alone. Many homeowners are in the same

177. leaky boat. Since many homes sit on what was once marsh, wet

178. basements are common. Condensation occurs in basements dur-

179. ing hot summers. Humid air enters the house, then condenses.

180. It is time to prepare for the summer months--call us today! 


\section{APPENDIX B \\ LEFT-HAND/RIGHT-HAND PRACTICE--E \\ FOR ONE RIGHT TO ONE LEFT}

\section{DIRECTIONS:}

1. DO NOT TYPE practice lines until your instructor teilis you to do so.

2. In the upper right hand corner, label your color-coordinated practice paper as follows:

School/Teacher

Class time

Your name (last name first)

LHRH $--E$

Date

3. Set margins of 18 and 90 . Single spacing.

4. Type lines as written. Do not type line numbers. Do not correct errors.

5. Type at a rate that is slightly faster than is comfortable. Use both sides of the practice paper if necessary.

6. When the five minutes of practice is completed:

1) count the number of completed lines typed and write the number at the top of your practice paper next to the date.

2) mark the practice line that you will start with the next day by circling the line number with a pencil.

7. If you finish the materials provided before the study is concluded, start the packet over.

8. Turn in your practice work and the practice materials to your instructor. 
1. As at be we ace bad cab dad err fad err fad gad rag sac tab

2. Kink lily milk nook only pill upon yolk honk join limp mill

3. Aft bag car dew ear gag rat set tag vex wag age bar cat eve

4. Hip ill jojy kin lip mop nip oil pin you hop imp jop mum nun

5. Acre best case date ease fact gave rate save tact vase were

6. Ink mom non pop hun inn nil pun him pip pup Jon pin kin Jim

7. Far Eva sag gas tax web axe beg bat gat sea tea are wed bet

8. Noon pink oily hook kiln lion noun mink plum polk loop jump

9. Egg get fee was saw tee Eve ate awe ebb few see wee awe sat

10. My up on in him you $i 11$ hum oil ilk joy mop pop pin ink ply 11. Cafe babe draw east face gear race safe tare vast west area 12. Hop mum imp num kin yon pip ill lip kin pop yon ohm hip pin

13. Fade gage raft edge dare scab veer tart Arab wade barb card 14. Holy loom punk luny Lyon puny 7011 polo Lynn kill lily John 15. Fare garb rage scar tear verb wage bard cave data fast gate

16. Milky onion phony nylon Polly Holly imply kinky limpy pupil

17. Aware barge cadet extra farce great saber trade verse water

18. Union mummy plump unpin opium polio holly phony loopy milky

19. Affect Caesar facade secede target vacate defect garage add 20. Poplin unholy uphill limply phylon pipkin pompom Kokomo moan

21. Garter vertex tatter settee Warsaw accede batter Carter gab

22. Million minimum nonunion limpily monopoly polonium homonym

23. Deserve stagger address cascade abstract barrage traverse

24. Mini HonoluTu pumpkin unhilly lollipop polyphony Phillip hook

25. Watts baste dwarf facet screw waste eaves grade after carve

26. Lon pup him nil hun pop mom non ink kin lip mop nip imp $10 p$

27. Sear test ware base cart fate gaze rave ward text vest awed

28. Opium hilly plump junky nippy onion nylon phony lymph unpin

29. Sad far see tax bet bat get sea ace fee rat ate wet cat date

30. Lily milk only pill upon limp mill noon kiln noun Phio polk

31. Axe bet aft ere get rat sad tee vet web see fee war was sat

32. I1] joy kin lip mop pun pup Lon mom ink hum Jim non you joy

33. Age dew ear fed red set tar wed arc few war aft far cad vet

34. John only yolk jolk hulk mill junk hill loop look hook July

35. Stag afar bear beef deer beet fret grab deed best rest brag

36. Noon pull hymn upon hoop punk pony hilly loin lion link noon 
37. Add wad vat tab sac rag gad fad err fad err dad cab bad ace

38. Moon junk mill limp join honk yolk upon pill only nook milk

39. Gab aft eve fag cat bar age wag vex tag set rat gag dew ear

40. Hum ply ohm nun mum lop imp hop you pin oil nip mop lip kin

41. Aged zest were vase tact save rate gave fact ease date case

42. Mum oil Jim lip kin pin Jon pup pip him pun nil inn hum ohm

43. Brass taste carve after grade eaves waste screw facet dwarf

44. Johnny unhook Kokonon pompom pipkin phylon limpy uphill Kip

45. Seats deand awed vest text ward rave gaze fate cart base bed

46. Kinky poplin Phillip polyphony 101lipop urihilly pumpkin mini

47. Tax fax fed sat awe wee see few ebb awe ate Eve tee was fee

48. Milk kink John ijly kill Lynn polo 1011 puny Lyon luny punk

49. Extra aware traverse barrage abstract cascade address stagger

50. Hop lymph milky loopy phony holly polio opium unpin plump

51. Egress badger garage defeat vacate target secede facade fax

52. Puppy nippy oil minion hominy up mom Jill Holio minimum pop

53. Water agree refer great waste tease feast trade treat cadet

54. Nymph million oily Jim kuolou holly yippy monopoly lin join

55. Tweezers braggart stedfast deferred westward decrease federate 56. Mimi lily lumpy unholy opinion knoll pumpkin mom pop loopy

57. Addressee stewardess statecraft assessed beverage vegetate

58. Hip kink imply pippin million polyphony iil jump junky onion

59. Ate safe saber defeat address reassert fate rest water aware

60. Kiln Jon Jill Myni Yillip pupil uphill unkill pinion kimono

61. Are age axe bet bag bad cat car cab dew dad ere ear err fad

62. Joy Jim Jon kin Kuy poi pup pip pun poll pill pull pin 1 ip

63. Rat red rag sad set sac tab tar ree vet web wed wad bed arc

64. My up on in on in up joy poi limp junk jump lump mum nun imp 65. At Ed be we tree treat great vet set after dress feast geese

66. Only him pull my on no you upon million you look monk hulk

67. Sweater taffeta abreast Barbara cadaver Rebecca arrears wax 68. Lollipop mull opinion hominy ilk Polly nymph lily pulpy mink

69. Desecrate crevasse sassafras afterward effervesce retrace sew

70. Li11 Jyopin in on pinky hul1 moll punk you hooky pool non oi1

71. Bert Gredaw vet waxer dazed brace freed fewer evade taste art

72. Jillion polin loon polyphony minikin nonunion pompom plump 
73. Fastest seated areas seed asset crested acted rated fattest

74. Polyp imply plump upon ilium Ohio noon hoop pool kink hymn

75. Baggage regarded feeder barber degree estate garter rebate

76. My up Hopi ink Yukon inpull Miupy milky kip ill junk hilly

77. Greed state creed adage dregs eater aster serge tread waver

78. Loopy Lyon Phillip lily noon opium holly Kim unhook ion nil

79. Dead rat sever tatter Arab dart erst cast bred garage vertex

80. Unholy Kuu Holonui polo pool mom uphill kin pup lily only him

81. Career rage tear trade eaves baste award crate dress excess

82. Lymph honk puny loom John oil unpin pumpkin Jimmy Kopopolou

83. Exaggerate extravert staff barb garb raft fag tar bat greet

84. Molly poi jolly him lump nilly phono ilio Johnny Mik imp joy

85. Garb geezer facade effect dews razz bazaar street assert wage

86. Kink lily milk nook only pill upon yolk honk join limp mill

87. Weed breed create degree tweezers reef stab afar bear brew

88. Hip $i 11$ my up Lon lily Moonio limpily minimum kin mill noun

89. Aware crew brag rest best deed grab fret beet deer red set

90. Loopy jump polk Phiol kiln noon limp only Kimion kill unpin

91. Awe react cadet treat trade feast tease waste great refers

92. Holy loom punk luny Lyon loin monopoly yippy holly oily nymph

93. Affect after vet set tar sassafras desecrate dazed were aged

94. Lumpy 1ily mom-pop pumpkin lollipop pipkin unpin pin-up jumpy

95. Adverse arrears few ate Eve egg area zag saga razz wear cafe

96. Onion opinion kink junk monk lumpily Hilo Honolulu Kui mump

97. Erst crave wrest sever staff state brass sweet dare edge raft

98. Mop Kip ill hilly knoll hominy puppy loopy polio mini look

99. Beggar adverb watt free stag acre date ease few Ted bee card

100. Jon-Jon pomp nook poll hul1 ump nil mummy mommy poplin in on

101. Saber settee batter carter fact rate tact were deaf ward dead

102. Polloi plum imply nippy null pulpy pompom pool loop rook Kin

103. Detract fade scab tart Arab barb card fag wax saw tee web axe

104. Jimmy John Junopolo mill hippy ion joy join nook kink punk

105. Acre best ear dew cat edge gage scat veer rage tear card base

106. Juoio monopoly mop mip him hilly hunky junky pony in hominy

107. Exaggerate trade wager brass dregs craze adder east cease were

108. Poppy opium Lynn kill look hull monk junk kinkily nonunion 
109. Draft creed feat craw assessed vex dew rest ebb farce freed 110. Mump 01ly mini milky hill opinion unkill lo kiln Myni pipkin 111. East far sag gear draw vest grew seed tree wart abet tag var

112. Link kink noon link lion loin hilly pony punk hoop upon hymn 113. Aware crew brag rest best deed grab fret beet deer beef bear 114. Phony pink July hook look hoop hill junk mill hulk jolk yolk

115. Cat are awx vet cad far aft war few arc wed tar set red fed 116. Kip poi nil joy you non Jim hum ink mom Lon pup pun mop lip

117. Gad wad bed sat was war fee see web vet tee sad rat get ere

118. Yummy nymph mink pulpy lollipop Molly ilk hominy opinion mull

119. Facet scatter retrace effervesce afterward sassafras desecrate

120. Homonym yolk plump pompom nonunion minikin polyphony loon pill

121. Adverse waxweed arrears Rebecca cadaver Barbara abreast treat

122. In pony hook hulk monk look you million upon you no on my pull

123. Axes tweed geese feast dress after set vet great treat tree

124. Him limply imp nun mum lump jump junk limp poi joy up in on 125. Gad far fed fad err ear ere dad dew cab car cat bad bag bet 126. Lo ohm non kimono pirion unkill uphill pupil Yillip moon Jill

127. Affect Caesar facade secede target vacate defeat garage bad 128. Hunk join kin loin yippy monopoly holly Jim Huolou oily mom 129. Fat egg get fee was tee Eve awe ate ebb few see wee awe sat

130. Johnny unhook Kokomo pompom pipkin phylon limly uphill unholy

131. Add vat wad tab rag sac gad fad err fad dad err cab bad ace

132. Kip mum oil lip Jim Noun mink polk loop nook loom ump Koliopu

133. Aged zest were vase tact save rate gave fact ease date case 134. You kip hip kink pool hoop Ohio noon ilium plump upon imply 135. Bread aster rebate garter estate degree barber feeder regarded

136. Jil unkill mop lip Tumpkin mom-pop pop-up lymph polio opium

137. Decade detract free tread rater teeter bearer revert street

138. Milky Moonion pup John hill kill opium lily Lynn loll loom

139. Grease gadget wedded seesaw dread stress dews Best West bread

140. Million imply jumpy kinky holly ion Moihjoip ump you unpin nip

141. Tax saber farce extra fare rage tear verb wage wet was are war

142. Kink lily lion noun ion polo puny onion polyphony July pink

143. Abstract rat fave rate tact were aged cascade fate sear test

144. Kin Johnny Jim jump lumpily pill look pin-up hippy non mommy 
145. East zest tax few are fret deed aware cafe babe scar barter 146. Ink imp lump mummy Jon hominy Loopilio join pup Kopilio ill

147. Be exaggerate carve waste facet sweater watts best as ear east

148. Holly hippy jumpy pool poll Jill Jiku nook hook unpin pumpkin 149. Bass greed afar czar strata defer was excess bazaar garage 150. Phillip mink Honolulu yon ion unholy Phioliojoy him ill plump

151. Sweet seed swear egress faze bat ace rat afar best fret deer 152. Aft bag car ear dew ease fast traverse westward water farce 153. Hunk kin join nymph ohm ink jillion nun joy hippy kimono mum

154. Rat red Barbara baggage affect adverse beggar east reassert 155. Holy loom yippy Jim Jolopoloup poll oil you moll hull pinky 156. Eve trade reward beverage stewardess aft fag bar wag tag rat

157. Hun Kimmy holoyoki unkill limono pumpkin opinion unholy nook 158. Rebecca afterward retrace crevasse dazed red target facade 159. Junky junk polyp homonym luny link poppy pump inn nip yon hop

160. Garter tatter accede barrage dead seats few deed rest wag bag 161. Polonium jolly honky join mill moon ink hominy pony $i 11$ unpin 162. Stab afar deer cadet great verse water vase zest aged baste

163. Monopoly polyp join Kiliopolu noon jump Hopi kinkily opium 164. Tweed sad we afterward fewer brace waxer zebra desecrate tea 165. Jillion nonunion yolk homonym polio lily milky lollipop pop

166. Veer tart raft edge dare sweet state staff sever wrest crave 167. Polloi kin poplin Piku nippy only kill look monk mummy puppy 168. East far beggar best deed red stage serge aster dead rat rage 


\section{APPENDIX C \\ LEFT-HAND/RIGHT-HAND PRACTICE- P \\ FOR THREE RIGHT TO ONE LEFT}

\section{DIRECTIONS:}

1. DO NOT TYPE practice lines until your instructor tells you to do so.

2. In the upper right hand corner, label your color-coordinated practice paper as follows:

School/Teacher

Class time

Your name (last name first)

LHRH--P (3 RIGHT - 1 LEFT)

Date

3. Set margins of 18 and 90 . Single spacing.

4. Type lines as written. Do not type line numbers. Do not correct errors.

5. Type at a rate that is slightly faster than is comfortable. Use both sides of the practice paper if necessary.

6. When the five minutes of practice is completed:

1) count the number of completed lines typed and write the number at the top of your practice paper next to the date.

2) mark the practice line that you will start with the next day by circling the line number with a pencil.

7. If you finish the materials provided before the study is concluded, start the packet over.

8. Turn in your practice work and the practice materials to your instructor. 
1. Kink lily milk nook only pill upon yolk honk join 1 imp mill

2. Hip $i 11$ joy kin lip mop nip oil pin you hop imp lop mum nun

3. Ink mom non pop hun inn nil pun him pip pup Jon pin kin Jim

4. Far Eva sag gas tax web axe beg bat get sea tea are wed bet

5. Noon pink oily hook kiln lion noun mink plum polk loop jump

6. My up on in him you $i l l$ hum oil ilk joy mop pop pin ink ply

7. Hop mum imp num kin yon pip 111 lip kin pop yon ohm hip pin

8. Fade gage raft edge dare scab veer tart Arab wade barb card

9. Holy loom punk luny Lyon puny 1011 polo Lynn kill lily John

10. Milky onion phony nylon Polly Holly imply kinky limpy pupil

11. Union mummy plump unpin opium polio holly phony loopy milky

12. Affect Ceasar facade secede target vacate defect garage add

13. Popl in unholy uphill limply phylon pipkin pompom Kokomo mom

14. Million minimum nonunion limpily monopoly polonium homonym

15. Mini Honolulu pumpk in unhilly lollipop polyphony Phillip hook

16. Watts baste dwarf facet screw waste eaves grade after carve

17. Lon pup him nil hun pop mom non ink kin lip mop nip imp lop

18. Opium hilly plump junky nippy onion nylon phony lymph unpin

19. Lily milk only pill upon 7 imp mill noon kiln noun Phio polk

20. Axe bet aft ere get rat sad tee vet web see fee war was sat

21. Ill joy kin lip mop pun pup Lon mom ink hum Jim non you joy

22. John only yolk jolk hulk mill junk hill loop look hook July

23. Noon pull hymn upon hoop punk pony hilly lo in lion link noon

24. Add wad vat tab sac rag gad fad err fad err dad cab bad ace

25. Moon junk mill limp join honk yolk upon pill only nook milk

26. Hum ply ohm nun mum lop imp hop you pin oil nip mop lip kin

27. Mum oil Jim lip kin pin Jon pup pip him pun nil inn hum ohm

28. Brass taste carve after grade eaves waste screw facet dwarf

29. Johnny unhook Kokonon pompom pipkin phylon 1 impy uphill Kip

30. Kinky poplin Phillip polyphoris lollipop unhilly pumpkin mini

31. Milk kink John lily kill Lynn polo 1011 puny Lyon luny punk

32. Extra aware traverse barrage abstract cascade address stagger

33. Hop lymph milky loopy phony holly polio opium unpin plump

34. Puppy nippy oil minion hominy up mom Jill Holio minimum pop

35. Nymph million oily Jim Kuolou holly yippy monopoly lin join

36. Tweezers braggart stedfast deferred westward decrease federate 
37. Mimi lily lumpy unholy opinion knoll pumpkin mom pop loopy 38. Hip kink imply pippin million polyphony $i 11$ jump junky onion

39. Kiln Jon Jill Myni Yillip pupil uphill unkill pinion kimono

40. Are age axe bet bag bad cat car cab dew dad ere ear err fad 41. Joy Jim Jon kin Kuy poi pup pip pun poll pill pull pin 1 ip

42. My up on in on in up joy poi Timp junk jump lump mum nun imp

43. Only him pull my on no you upon million you look monk hulk 44. Sweater taffeta abreast Barbara cadaver Rebecca arrears wax 45. Lollipop mull opinion hominy ilk Polly nymph lily pulpy mink

46. Lill Jyopin in on pinky hull moll punk you hooky pool non oil

47. Jillion pol in loon polyphony minikin nonunion pompom plump

48. Fastest seated areas seed asset crested acted rated fattest

49. Polyp imply plump upon ilium Ohio noon hoop pool kink hymn

50. My up Hopi ink Yukon inpul1 Miupy milky kip ill junk hilly

51. Loopy Lyon Phillip lily noon opium holly Kim unhook ion nil

52. Dead rat sever tatter Arab dart erst cast bred garage vertex

53. Unholy Kuu Holonui polo pool mom uphill kin pup lily only him

54. Lumph honk puny loom John oil unpin pumpkin Jimmy Kopopolou

55. Molly poi jolly him lump nilly phono ilio Johnny Mik imp joy

56. Garb geezer facade effect dews razz bazaar street assert wage

57. Kink lily milk nook only pill upon yolk honk join 7 imp mill

58. Hip ill my up Lon lily Moonio limpily minimum kin mill noun 59. Loopy jump polk Phiol kiln noon limp only Kimion kill unpin

60. Awe react cadet treat trade feast tease waste great refers

61. Holy loom punk luny Lyon loin monopoly yippy holly oily nymph

62. Lumpy lily mon-pop pumpkin 1011ipop pipkin unpin pin-up jumpy

63. Onion opinion kink junk monk lumpily Hilo Honolulu Kui mump

64. Erst crave wrest sever staff state brass sweet dare edge raft

65. Mop Kip ill hilly knoll hominy puppy loopy polio mini look

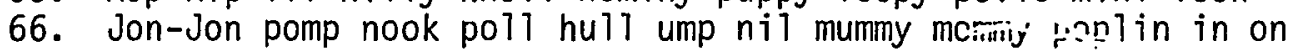

67. Polloi plum imply nippy null pulpy pompom pool loop nook Kim

68. Detract fade scab tart Arab barb card fag wax saw tee web axe

69. Jimmy John Junopolo mill hippy jon joy join nook kink punk

70. Juoio monopoly mop mip him hilly hunky junky pony in hominy

71. Poppy opium Lynn kill look hull monk junk kinkily nonunion

72. Draft creed feat craw assessed vex dew rest ebb farce freed 
73. Mump 017y mini milky hill opinion unkill lo kiln Myni pipkin

74. Link kink noon link lion loin hilly pony punk hoop upon hymn

75. Phony pink July hook look hoop hill junk mill hulk jolk yolk

76. Cat are awe vet cad far aft war few arc sed tar set red fed

77. Kip poi nil joy you non Jim hum ink mom Lon pup pun mop lip

78. Yummy nymph mink pulpy lollipop Molly ilk hominy opinion mull

79. Homonym yolk plump pompom nonunion minikin polyphony loon pill

80. Adverse waxweed arrears Rebecca cadaver Barbara abreast treat

81. In pony hook hulk monk look you million upon you no on my pull

82. Him limply imp nun mum lump jump junk limp poi joy up in on

83. Lo ohm non kimono pinion unkill uphill pupil Yillip moon jill

84. Affect Ceasar facade secede target vacate defeat garage bad

85. Hunk join kin loin yippy monopoly holly Jim Huolou oily mom

86. Johnny unhook Kokomo pompom pipkin phylon limly uphill unholy

87. Kip mum oil lip Jim Noun mink polk loop nook loom ump Koliopu

88. Aged zest were vase tact save rate gave fact ease date case

89. You kip hip kink pool hoop Ohio noon ilium plump upon imply

90. Jil unkill mop Tip Tumpkin mom-pop pop-up lymph polio opium

91. Milky Moonion pup John hill kill opium 1ily Lynn loll loom

92. Grease gadget wedded seesaw dread stress dews Best West bread

93. Million imply jumpy kinky holly ion Moihjoip ump you unpin nip

94. Kink lily lion noun ion polo puny onion polyphony July pink

95. Kin Johnny Jim jump lumpily pill look pin-up hippy non mommy

96. East zest tax few are fret deed aware cafe babe scar barter

97. Ink imp Tump mummy Jon hominy Loopilio join pup Kopilio ill

98. Holly hippy jumpy pool poll jill Jiku nook hook unpin pumpkin

99. Phillip mink Honolulu yon ion unholy Phiolio joy him ill plump

100. Sweet seed swear egress faze bat ace rat afar best fret deer

101. Hunk kin join nymph ohm ink jillion nun joy hippy kimono mum

102. Holy loom yippy Jim Jolopoloup poll oil you moll hu1l pinky

103. Hun Kimmy holoyoki unkill limono pumpkin opinion unholy nook

104. Rebecca afterward retrace crevasse dazed red target facade

105. Junky junk polyp homonym luny link poppy pump inn nip yon hop

106. Polonium jolly honky join mill moon ink hominy pony $i 11$ unpin

107. Monopoly polyp join Kiliopolu noon jump Hopi kinkily opium

108. Tweed sad we afterward fewer brace waxer zebra desecrate tea 
109. Jillion nonunion yolk homonym polio lily milky lollipop pop

110. Polloi Kin poplin Piku nippy only kill look monk mummy puppy

111. Mill limp join honk yolk upon pill only nook milk lily kink

112. Aft bag car dew ear gag rat set tag vex wag age bar cat eve

113. Nun mum lop imp hop you pin oil nip mop kip kin joy ill hip

114. Jim kin pin Jon pup pip him pun nil inn hun pop non mom ink

115. Jump loop polk plum mink noun lion kiln hook oily pink noon

116. Egg get fee was saw tee Eve ate awe ebb few see wee awe sat

117. Ply ink pin pop mop joy ilk oil hum ill you him in on up my

118. Pin hip ohm yon pop kin lip ill pip non kin num imp mum hop

119. John lily kill Lynn polo 1011 puny Lyon Tuny punk loom holy

120. Fare garb rage scar tear verb wage bard cave data fast gate

121. Pupil limpy kinky imply Holly Polly nylon phony onion milky

122. Milky loopy phony holly polio opium unpin plump mummy union

123. Mom Kikomo pompom pipkin phylon limply uphill unholy poplin

124. Garter vertex tatter settee Warsaw accede batter Carter gab

125. Homonym polonium monopoly limpily nonunion minimum million

126. Hook Phillip polyphony lollipop unhilly pumpkin Honolulu mini

127. Lop imp nip mop lip kin ink non mom pop hun nit him pup lon

128. Sear test ware base cart fate gaze rave ward text vest awed

129. Unpin lumph phony nylon onion nippy junky plump hilly opium

130. Polk Phio noun kitn noon mill limp upon pill only milk lily

131. Joy you non Jim hum ink mom Lon pup pun mop lip kin joy $i 11$

132. Age dew ear fed red set tar wed arc few war aft far cad vet

133. July hook look loop hill junk mill hulk jolk yolk only John

134. Noon link lion loin hilly pony punk hoop upon hymn pull noon

135. Milk nook only pill pun yolk honk join limp mill junk moon

136. Gab aft eve fag cat bar age wag vex tag set rat gag dew ear

137. Kin lip mop nip oil pin you hop imp lop mum nun ohm ply hum

138. Ohm hun inn nil pun him pip pup Jon pin kin lip Jim oil mum

139. Kip uphi11 limpy phylon pipk in pompom Kokonon unhook Johnny

140. Seats dead awed vest text ward rave gaze fate cart base bed

141. Mini pumpkin unhilly lollipop polyphony Phillip poplin kinky

142. Punk Tuny Lyon puny 1011 polo Lynn kil1 lily John kink milk

143. Junk plump unpin opium polio holly phony loopy milky lump hop

144. Egress badger garage defeat vacate target secede facade fax 
145. Pop minimum Holio Jill mom up hominy minion oil nippy puppy 146. Join lin monopoly yippy holly Kuolou Jim oily million nymph 147. Loopy mom-pop pumpkin knoll opinion unholy lumpy lily mimi

148. Addressee stewardess statecraft assessed bevarage vegetate 149. Onion junky jump $i 11$ polyphony million pippin imply kink hip 150. Kimono pinion unkill uphill pupil Yillip Myni Jill Jon kiln

151. Lip pin pul1 pill poll pun pip pup poi Kuy kin Jon Jim Joy 152. Rat red rag sad set sac tab tar tree vet web wed wad bed arc 153. Imp nun mum lump jump junk $1 \mathrm{imp}$ poi joy up in on in on up my

154. Hulk monk look you million upon you no on my pull him only 155. Mink pulpy lily nymph Polly ilk hominy opinion mull lollipop

156. Sew retrace effervesce afterward sassafras crevasse desecrate

157. 0il non pool hooky you punk moll hull pinky on in Jyopin Lill

158. Plump pompom nonunion minikin polyphony loon polin jillion

159. Hymn kink pool hoop noon Ohio ilium upon plump imply polyp

160. Baggage regarded feeder barber degree estate garter rebate 161. Hiliy junk ill kip milky Miupy inpull Yukon ink Hopi up my

162. Nil ion unhook Kim holly opium noon Tity Phillip Lyon loopy

163. Him only lily pup kin uphill mom pool polio Holonui Kuu unholy 164. Excess dress crate award baste eaves trade tear rage career 165. Kopopolou Jimmy pumpkin unpin oil John loom puny honk lymph

166. Joy imp Mik Johnny ilio phono nilly lump him jolly poi molly 167. Mill limp join honk yolk upon pill only nook milk lily kink 168. Weed breed create degree tweezers reef stab afar bear brew 
APPENDIX D

PRACTICE GUIDELINES

Students within each classroom have been randomly assigned to three practice groups: PROSE, LHRH-E, LHRH-P.

PROSE (Ordinary Prose). Students will practice for five minutes per day on a packet of twelve-word prose lines. The copy contains no special features or combinations of words.

LHRH-E (left-hand/Right-hand Equal). Students will practice for five minutes per day on a packet of twelve-word left-hand/right-hand lines. The copy on each page of the packet is arranged with alternating liens of left-hand and right-hand words.

LHRH-P (Left-hand/Right-hand Prescribed). Students wil1 practice for five minutes per day on a packet of twelve-word left-hand/ right-hand lines. The students in this group will practice different amounts of left-hand and right-hand lines depending on individual hand weaknesses diagnosed on the pretest.

Packets have been duplicated using three different colors: PROSE--bTue; LHRH-E--buff; LHRH-P--canary. Each student will receive an individualized packet. Students will be provided colored practice paper corresponding to packet colors. Packets contain practice directions.

\section{Conducting the Practice}

1. On the first day of practice, 0ctober 27 , give students the individualized packets and a sheet of matching colored practice paper. Make them aware that the types of practice are different, but that all three are customarily used in classes.

2. Explain the practice instructions included on the first page of the packet--in detail. Answer any questions.

3. Explain to students that you will start the 5 minutes of practice with a 3,2, 1 countdown and that they are to start typing on

"1". They are to continue until you say STOP.

4. Time for exactly five minutes using a stopwatch; call STOP.

5. After you have called STOP:

1. Ask students to count completed lines typed and write that 
number at the top of their practice paper next to the date.

2. Have students check the heading at the top of their practice papers to make sure aî information is included.

3. Have students circle the line on the packet that they will start with at the next practice session.

6. Collect ali student typescripts and packets. It is important that students use the packets during the five minutes of practice only.

Instruct students to pick up packets and appropriate paper at the beginning of the next class period and to label the practice paper according to packet directions. However, remind them they are not to begin typing until you start the countdown.

7. Place student typescripts in the appropriate folder (paper-clip each day's work). Separate folders have been provided for each week's practice. 
APPENDIX E

TEST TIMINGS

Straight-copy

(SC $3^{\prime} \# 1$ )

Another important research finding about learning to type is that there is no tendency for speed and accuracy to go together. Typists at all levels of accuracy may be found at all levels of speed. This means that the two aspects of performance are based on different underlying factors. Therefore, it is not possible to practice toward both objectives at the same time.

The skill building program in this book is based on the research findings. You practice for speed until you have attained a substantial gain--with little regard for errors. Then you change to accuracy practice at a slower speed. If you have practiced with understanding and with high motivation toward gaining skill, your test performance at an unhurried rate will have an acceptable level of accuracy and be faster than it was before. 
Straight-copy

(SC $\left.3^{\prime} \# 2\right)$

It is clear that the ease of making the motions required to type a letter combination mostly determines the sequences that can be easily chained, to wit: those motions that can be brought sufficiently close together in time. When a series of motions is made rapidly, the muscular sensations that arise from one motion trigger off the next one. An instance is walking: The sensations in one leg as you complete a step trigger off the movement of the other leg. This and thousands of other skilled movements are done as chained responses, without awareness of the separate motions that make up the series. Indeed, a response chain is defined as one based on muscular sensations--on the kinesthetic cues. Because the chained responses that characterize high skill result from reduced time intervals between motions, mucin practice ought to be done at fast rates. Accuracy practice should be done separately, at a slower rate. 
Handed timings

(one-minute)

\section{Timing 1}

waste dew vase aged ceded aft zest card dwarf facet bag were was save vexes eb' tact rate carve ease after taste feed tax best edge added babe dread draw aster gab few case brass fed

Timing 2

kink hip union look joy mummy milk nook unpin molly mink kin hoop pulp junky mop polio pill nip holly hoop oil yolk phony yukon join milky you limp mill pump pupil lymph pin honk hop

Timing 3

wear trade scar set verb defer rat great gag farce save rate vex aware acre bade raft wag cadet beet age extra barge stag bare saver fate cat test watts eve gaze tease tag water deed

\section{Timing 4}

ink hilly junk moon nippy loin onion lip nylon polk mom hulk imp poppy pul1 lump loom plump polo pup yummy non lolly kill puny hum polly kip limp lymph nil jolly pull mink honk phony

\section{Timing 5}

ware greed cafe arc serge cage stab waver sax awe afar dress get bear egg deer tweed gas fret react zebra wade brag adage crew staff bed area brace wad garb web dazed tree axed freed 
Handed timings, continued

\section{Timing 6}

ohm lion imply kip noun pylon poi knoll noun mill jumpy plum kiln pun loony pool yum jolly lou link pony lumph join puppy opium him punk molly yip john hymn lumpy poll pink ilk polyp 
APPENDIX $F$

TESTING PROCEDURES

The findings and conclusions of this research study will be drawn from the data collected in your classrooms. Data gathering procedures are therefore the critical element in the study. The uniform testing procedures will help to gather consistent and reliable pretest and posttest scores.

PRIOR TO CLASS MEETING

1. Check typewriters to make sure they are in good working order.

2. Write the following three items on the biackboard:

Item 1: Paper Heading Write example for your school and class on the board:

Your school

Teacher name

Class time

Student name

PRETEST (or POSTTEST)
Anytown High

Mrs. Jones

8: 35

Jackson, Marjorie PRETEST

Item 2: Testing Order

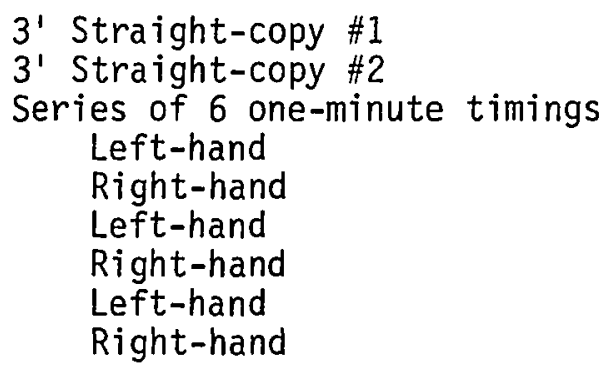

Item 3: Machine Settings

$$
\begin{aligned}
& \text { 3' timings = Double space } \quad 1^{\prime} \text { Timings = Single space } \\
& 12 \text { and } 90 \text { margins } 20 \text { and } 85 \\
& \text { (70 space line) } \\
& \text { margins }(60 \\
& \text { 5-space tab } \\
& \text { space line) }
\end{aligned}
$$


WHEN CLASS BEGINS

1. Give each student three sheets of blank white paper.

2. Instruct them to type the following information in the upper right-hand corner of each sheet following the example on the blackboard:

\author{
High School \\ Teacher \\ Class (time class starts) \\ Student name (last name first) \\ PRETEST (or posttest)
}

3. Explain to students that they will be doing a total of 12 minutes of timed writings of the following type and in the following order using the three sheets of paper indicated. Concentration and attention to test directions is important in order to complete the testing in the allocated time.

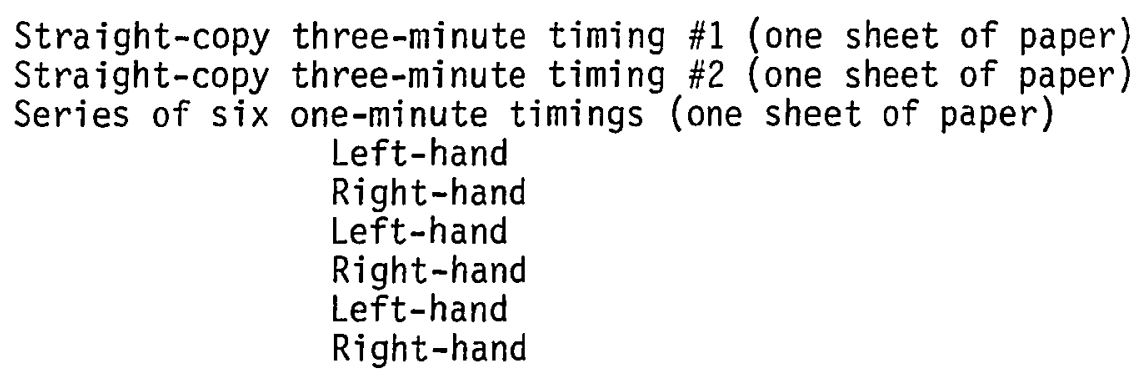

4. Explain to students that they should type at a comfortable rate, say "type all timings at a comfortable rate, don't try to set a speed record nor slow down to a crawl in order to avoid errors--just type at a comfortable rate."

Also explain how you will be starting and ending the timings. My suggestion is to use a $3,2,1$, countdown and instruct students to begin typing on " 1 ". They are to stop immediately when they hear you say STOP. 
CONDUCTING THE THREE-MINUTE STRAIGHT-COPY TIMINGS

1. Explain to students that they will first do the two 3-minute timings and will need to use a separate piece of paper for each one and that they will have separate copy for each timing.

2. Give each student a copy of SC $3^{\prime}$ \#1 (straight copy), and SC $3^{\prime}$ \#2 (straight copy). (Folders 1 \& 2)

3. Have them look over SC 3' \#1 (straight-copy). Ask them to avoid writing on the test copy.

4. Tell them to insert a piece of prepared paper in the machine.

5. Have them type SC $3^{\prime} \# 1$ following the word PRETEST at the top of the page and then triple space.

6. Instruct them to prepare the typewriter as follows:

Set margins of 12 left and 90 right (70-space 1 ines).

Set machine on double spacing.

Set tab for a 5-space paragraph indention.

7. Instruct them to type the timing as it appears--not adjusting margins to reach the right margin, etc. Omit the headings at top of page and the scale numbers. If they finish the timing, they are to start it again. No erasing of errors.

8. Ask if everyone is ready to type $S C 3^{\prime} \# 1$. Is paper labeled and copy ready? Have them check to see if they have the copy for \#1. Te11 them you are ready to begin the countdown, and they should type on "I" and continue until they hear the STOP signal.

9. Countdown and begin.

10. Time them by stopwatch for exactly three minutes. Do not move around the room while the timing is in progress.

11. Call STOP--ask them to remove the typescript from the typewriter and keep it until all testing is completed.

12. Collect copy for Timing \#1, but have them retain what they typed.

13. Have them Took over SC 3' \#2.

14. Tell them to insert a piece of prepared paper in the machine. 
15. Have them type SC 3' \#2 following the word PRETEST at the top of the page and then triple space.

16. Tell them that the machine settings are the same for this timing as for \#1. (12, 90; DS; tab).

17. Remind them to type the timing as it appears, (repeat 7).

18. Ask if everyone is ready to type SC $3^{\prime}$ \#2. Paper 7 abeled and copy ready? Tel1 them you are ready to begin the countdown, and they should begin on "1" and stop when they hear STOP.

19. Countdown and begin. Time for exactly 3 minutes.

20. Cal1 STOP--ask them to remove the typescript from the typewriter and keep it until all testing is completed.

21. Collect copy for Timing \#2, but have them retain what they typed.

INSTRUCTIONS FOR SERIES OF ONE-MINUTE TIMINGS

1. Give students copies of test materials for the series. Ask them to look them over. Point out the order: we will alternate six one-minute timings between the left-hand and right-hand (timings $1-6)$.

2. Instruct them to insert the third piece of prepared paper in the machine and type 1' Timings next to the word PRETEST at the top of the page and then triple space.

3. Tel1 them that the one-minute timings are to be typed in single spacing with a double space between each timing.

Set the machine on single spacing.

Set margins of 20 and 85 .

4. Tell them that for the first one-minute timing they will type Timing 1--type each line only once. If they should finish the lines in Timing 1 before one-minute is completed, do not go to Timing 2; repeat Timing 1. Do not type the headings, scale numbers at the right and do not correct errors.

5. Remind them that each timing will begin with a countdown and they are to start on " 1 " and stop when they hear STOP. Immediately following the STOP call they should "double down" in preparation for the next timing. Timings will progress rapidly. We will type Timing 1 , double down and immediately type Timing 2, etc., through the 6 timings. 
6. Say--"Ready for Timing 1, type Timing $1 ; 3,2,1 . "$

7. Time for one-minute exactiy and call "STOP", "double down."

8. Say--"ready for Timing 2, type Timing 2; 3, 2, 1." Go through a 116 timings. Students can use the back of the paper if they find it necessary.

9. Collect copy for one-minute timings, but have students retain what they typed.

10. Ask them to check each of the three pieces of paper to make sure the headings are complete and accurate. Have them arrange them

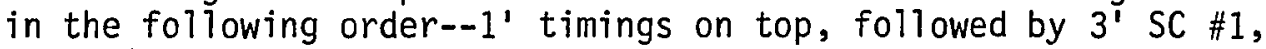
then $3^{\prime}$ SC \#2. Have them bring them to you at the front of the room or walk around and collect them. Staple them as they are handed in.

11. Place all timing copy (three folders) and students typescripts (folder for each class) in the folders provided. 